Reversão anaglífica em vídeos estereoscópicos Felipe Maciel Rodrigues 

Assinatura:

\title{
Felipe Maciel Rodrigues
}

\section{Reversão anaglífica em vídeos estereoscópicos}

\author{
Dissertação apresentada ao Instituto de Ciências \\ Matemáticas e de Computação - ICMC-USP, \\ como parte dos requisitos para obtenção do título \\ de Mestre em Ciências - Ciências de Computação e \\ Matemática Computacional. VERSÃO REVISADA \\ Área de Concentração: Ciências de Computação e \\ Matemática Computacional \\ Orientador: Prof. Dr. Rudinei Goularte
}


Ficha catalográfica elaborada pela Biblioteca Prof. Achille Bassi e Seção Técnica de Informática, ICMC/USP, com os dados fornecidos pelo(a) autor(a)

Rodrigues, Felipe Maciel
Reversão anaglifica em vídeos estereoscópicos /
Felipe Maciel Rodrigues; orientador Rudinei Goularte.
- São Carlos - SP, 2016.
110 p.
Dissertação (Mestrado - Programa de Pós-Graduação
em Ciências de Computação e Matemática Computacional)
- Instituto de Ciências Matemáticas e de Computação,
Universidade de São Paulo, 2016.
1. Vídeo Anaglifico. 2. Visualização
Estereoscópica. 3. Codificação estereoscópica. I.
Goularte, Rudinei, orient. II. Título.




\section{Felipe Maciel Rodrigues}

\section{Anaglyphic reversion in stereoscopic videos}

Master dissertation submitted to the Instituto de Ciências Matemáticas e de Computação - ICMCUSP, in partial fulfillment of the requirements for the degree of the Master Program in Computer Science and Computational Mathematics. FINAL VERSION

Concentration Area: Computer Science and Computational Mathematics

Advisor: Prof. Dr. Rudinei Goularte

USP - São Carlos

July 2016 

Este trabalho é dedicado à minha família,

suportes fundamentais para a finalização de mais uma etapa de minha vida. 

Muitas pessoas foram importantes durante o período deste mestrado, e merecem ser lembradas nestes agradecimentos.

Aos meus pais Laércio Batista Rodrigues e Sonia Maria Diniz Maciel, e minha irmã Camila Maciel Rodrigues, pela criação que me deram e pelos valores que me ensinaram ao longo da vida. Muito obrigado pelo apoio dado ao longo de toda a minha formação acadêmica, e que não foi diferente durante este mestrado.

À minha namorada e companheira Letícia Annes Mackert Marreira, pelo apoio e compreensão nos momentos de dificuldades.

À Cindy, pelo companheirimo. Sempre deitada no sofá de frente ao computador cochilando, aguardando meus estudos terminarem, para então eu dizer "vamos dormir".

Ao grande professor Rudinei Goularte, meu orientador. Muito obrigado por todas as oportunidades e pelos conhecimentos compartilhados durante estes anos, pela confiança depositada em mim, pela paciência, pelas correções e pelo tempo dedicado até a conclusão deste trabalho.

Aos professores da Fatec Lins, em especial, aos professores, Mario Henrique de Souza Pardo, Anderson Pazin, Alexandre Ponce de Oliveira e José Eduardo Santarém Segundo, nos quais inspiraram-me a escolher e seguir a carreira acadêmica.

Aos professores do Programa de Pós-Graduação em Computação, pelo aprendizado, oportunidade de crescimento, realização profissional e pessoal.

Aos meus colegas do grupo de pesquisa, Intermídia, com quem convivi durante este período. Agradecimentos especiais aos colegas Arthur, Rafael, Tiago, Matheus, Johana, Juliano, Edson e Rodrigo. Muito obrigado a todos pelo apoio, discuções técnicas, revisões de artigos e conversas na hora do café. Foi um prazer ter participado e contribuído com o grupo durante este período.

Por fim, agradeço à todas as pessoas que, diretamente ou indiretamente contribuíram para a realização dessa dissertação. 

"Não siga aonde leva a trilha.

Em vez disso vá aonde não há trilhas e deixe seu rastro."

(Anônimo) 



\section{RESUMO}

RODRIGUES, F. M.. Reversão anaglífica em vídeos estereoscópicos. 2016. 110 f. Dissertação (Mestrado em Ciências - Ciências de Computação e Matemática Computacional) - Instituto de Ciências Matemáticas e de Computação (ICMC/USP), São Carlos - SP.

A atenção voltada à produção de conteúdos 3D atualmente tem sido alta, grande parte devido à aceitação e à manifestação de interesse do público para esta tecnologia. Novas técnicas de captação e codificação e modos de reprodução de vídeos 3D, particularmente vídeos estereoscópicos, vêm surgindo ou sendo melhorados, visando aperfeiçoar e integrar esta nova tecnologia com a infraestrutura disponível. No entanto, em relação a avanços na área de codificação, nota-se a ausência de uma técnica compatível com mais de um método de visualização de vídeos estereoscópicos - para cada método de visualização há uma técnica de codificação diferente, o que inviabiliza ao usuário escolher o método que deseja visualizar o conteúdo. Uma abordagem para resolver este problema é desenvolver uma técnica genérica, isto é, uma técnica que seja independentemente do método de visualização, que através de parâmetros adequados, produza um vídeo estereoscópico sem perda significativa de qualidade ou a percepção de profundidade, que é a característica marcante desse tipo de conteúdo. O método proposto neste trabalho, chamado HaaRGlyph, transforma um vídeo esterescópico em um único fluxo contendo um anáglifo, codificado de modo especial. Esse fluxo além de ser compatível com o método de visualização anaglífica é também reversível à uma aproximação do par estéreo original, possibilitando a independência de visualização. Além disso, a HaaRGlyph atinge maiores taxas de compressão do que o trabalho relacionado.

Palavras-chave: Vídeo Anaglífico, Visualização Estereoscópica, Codificação estereoscópica. 



\section{ABSTRACT}

RODRIGUES, F. M.. Reversão anaglífica em vídeos estereoscópicos. 2016. 110 f. Dissertação (Mestrado em Ciências - Ciências de Computação e Matemática Computacional) Instituto de Ciências Matemáticas e de Computação (ICMC/USP), São Carlos - SP.

Attention towards 3D content production has been currently high, mostly because of public acceptance and interest in this kind of technology. Therefore, new capturing techniques, coding and playback modes for 3D video, particularly stereoscopic video, have been emerging or being enhanced, focusing on improving and integrating this new kind of technology with the available infrastructure. However, regarding advances in the coding area, there are conflicts because each stereoscopic visualization method uses a different coding technique. That leads to incompatibility between those methods. An approach to tackle this problem is to develop a generic technique, that is, a technique that is appropriate regardless the visualization method. Such technique, with suitable parameters, outputs a stereoscopic video with no significant loss of quality or depth perception, which is the remarkable feature of this kind of content. The method proposed in this work, named HaaRGlyph, transforms a stereo pair of videos into a single anaglyph stream, coded in a special manner. Such stream is not only compliant with the anaglyph visualization method but also reversible to something close to the original stereo pair, allowing visualization independence. Moreover, HaarGlyph achieves higher compression rates than related work.

Key-words: Anaglyph Video, Stereoscopic Visualization, Stereoscopic Video Coding. 



\section{LISTA DE ILUSTRAÇÕES}

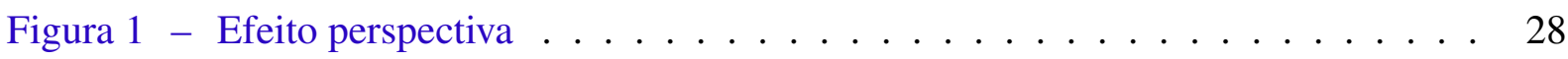

Figura 2 - Interposição . . . . . . . . . . . . . . . . . 28

Figura 3 - Variação de luz . . . . . . . . . . . . . . . . . . 29

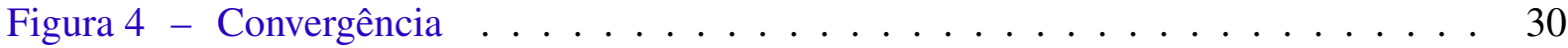

Figura 5 - Exemplo de observância da informação de disparidade. . . . . . . . . . . . 31

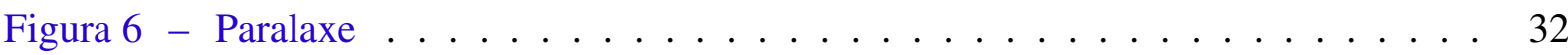

Figura 7 - Processo de conversão de um par estéreo para vídeo anaglífico. Note que os dados de $\mathrm{R}_{1}, \mathrm{G}_{2}$ e $\mathrm{B}_{1}$ são perdidos . . . . . . . . . . . . . . . . . 33

Figura 8 - A lente verde bloqueia a cor verde e a lente magenta bloqueia as cores vermelha e azul . . . . . . . . . . . . . . . . 33

Figura 9 - (A) Luz - (B) Propagação do feixe de luz em todas as direções (luz não polarizada) - (C) Filtro polarizador vertical - (D) Propagação da luz em apenas uma direção (luz polarizada) . . . . . . . . . . . . . . . . 34

Figura 10 - Cada uma das lentes interpreta uma das imagens de acordo com o filtro utilizado 35

Figura 11 - Óculos e monitor sincronizados, exibindo a imagem apenas em uma das lentes 36

Figura 12 - HMD . . . . . . . . . . . . . . . . . 36

Figura 13 - Google Cardboard . . . . . . . . . . . . . . . . . . . . . 37

Figura 14 - Duas imagens iguais em angulação distintas entrelaçadas projetadas no monitor 38

Figura 15 - Monitores autoestereoscópicos . . . . . . . . . . . . . . . . . 38

Figura 16 - Modelo RGB . . . . . . . . . . . . . . . . . . . . . 43

Figura 17 - Tipos de subamostragem de crominância . . . . . . . . . . . . . . . . . 45

Figura 18 - Efeito blockiness . . . . . . . . . . . . . . . . . . . . . . 47

Figura 19 - DWT aplicada a uma imagem bidimensional . . . . . . . . . . . . . . 48

Figura 20 - Iterações DWT - sinal de entrada (s); banco de filtros passa-alta (h); banco de filtros passa-baixa (1); coeficientes de detalhes (d); coeficientes de aproximações $(\mathrm{a}) . \ldots \ldots \ldots$. . . . . . . . . . . . . . . . . . . . 48

Figura 21 - DWT Haar em 3 níveis de decomposição . . . . . . . . . . . . . . . . . 50

Figura 22 - Matriz de quantização proposta por Nayan et al . . . . . . . . . . . . . . 51

Figura 23 - Subáreas da matriz de quantização . . . . . . . . . . . . . . . 52

Figura 24 - Ordem de construção de um vetor, sendo a leitura realizada em uma imagem processada por três níveis de uma DWT . . . . . . . . . . . . . 52

Figura 25 - Par estéreo armazenado lado-a-lado e sobreposto . . . . . . . . . . . . . 55

Figura 26 - Par estéreo armazenado entrelaçado . . . . . . . . . . . . . . 55 
Figura 27 - Codificação mapa de profundidades . . . . . . . . . . . . . . . 56

Figura 28 - Compressão IPB . . . . . . . . . . . . . . . . . . . . . . 59

Figura 29 - Predição entrevisões. Uma das visões se torna a base e é utilizada para predizer a outra visão do par estéreo . . . . . . . . . . . . . . 60

Figura 30 - Esquematização da codificação do HDB2 . . . . . . . . . . . . . . . . 61

Figura 31 - (A) Valores da diagonal correspondente às subáreas de 1 a 4 da matriz de quantização do HDB2; (B) Valores das subáreas de 1 a 4 da nova matriz de quantização, com dimensões de 8 x 8 pixels . . . . . . . . . . . .

Figura 32 - Exemplo de redundância existente entre as componentes de luminância dos anáglifos formados a partir de um par estereoscópico . . . . . . . . . . .

Figura 33 - Exemplo da aplicação do agrupamento por limiar de aceitação nos valores da Diferença de Luminâncias . . . . . . . . . . . . . . . . . . . . . 66

Figura 34 - Esquematização da codificação e decodificação da técnica RevGlyph . . . . 67

Figura 35 - Resultado da replicação dos canais de cores de um anáglifo verde-magenta na tentativa de recriar o par estéreo . . . . . . . . . . . . . . . . . . . . . . . . . . 68

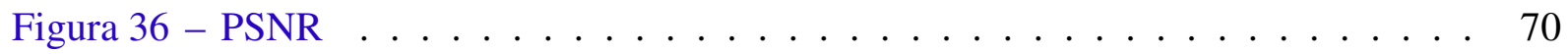

Figura 37 - Estrutura de vídeo utilizada para medida subjetiva . . . . . . . . . . . 70

Figura 38 - Tabela de classificação de vídeo . . . . . . . . . . . . . . . . 71

Figura 39 - Esquematização da codificação da técnica HaaRGlyph . . . . . . . . . . . . 74

Figura 40 - Estrutura do arquivo codificado com a HaaRGlyph . . . . . . . . . . . 77

Figura 41 - Representação de cada bit da região Dados de Controle. . . . . . . . . . . . 78

Figura 42 - Análise da conversão e reversão do espaço de cores . . . . . . . . . . . . 81

Figura 43 - Análise da subamostragem de crominância . . . . . . . . . . . . . . . . . . 83

Figura 44 - (A) Imagem Original; (B) Imagem Subamostrada . . . . . . . . . . . . . 84

Figura 45 - Análise da DWT e quantização . . . . . . . . . . . . . . . 85

Figura 46 - (A) Par estéreo original; (B) Par estéreo recuperado. . . . . . . . . . . . . 86

Figura 47 - Par estéreo recuperado utilizando limiar $0 \ldots \ldots$. . . . . . . . . . . . 89

Figura 48 - Par estéreo recuperado utilizando limiar $1 \ldots \ldots$. . . . . . . . . 9 90

Figura 49 - Par estéreo recuperado utilizando limiar $2 \ldots \ldots$. . . . . . . . 91

Figura 50 - Par estéreo recuperado utilizando limiar $3 \ldots \ldots$. . . . . . . . . . 92

Figura 51 - Par estéreo recuperado utilizando limiar $4 \ldots \ldots$. . . . . . . . . 93

Figura 52 - Par estéreo recuperado utilizando limiar $5 \ldots \ldots$. . . . . . . . . 94

Figura 53 - (A) Imagem original; (B) Imagem recuperada com limiar 5; (C) Imagem recuperada com limiar $30 \ldots \ldots$. . . . . . . . . . . . . . 95

Figura 54 - Codificação HaaRGlyph eliminando a codificação diferencial . . . . . . . . 95

Figura 55 - Resultados MOS. . . . . . . . . . . . . . . . . . . . 99 
Tabela 1 - Comparações entre métodos de visualização estereoscópica . . . . . . . . . 40

Tabela 2 - Análise PSNR da conversão RGB $\Rightarrow \mathrm{YCbCr} \Rightarrow \mathrm{RGB} \ldots$. . . . . . . . 82

Tabela 3 - Análise PSNR da conversão $\mathrm{RGB} \Rightarrow \mathrm{YCbCr} \Rightarrow \mathrm{RGB}$ juntamente com subamostragem de crominância . . . . . . . . . . . . . . . . . 83

Tabela 4 - Análise PSNR da conversão $\mathrm{RGB} \Rightarrow \mathrm{YCbCr} \Rightarrow \mathrm{RGB}$ juntamente com subamostragem de crominância, transformada wavelet e quantização . . . . . 85

Tabela 5 - Melhores resultados de compressão da HaaRGlyph para os diferentes limiares 88

Tabela 6 - Melhores resultados de PSNR da HaaRGlyph para os diferentes limiares . 88

Tabela 7 - Melhores resultados de compressão da HaaRGlyph utilizando o componente Y 96

Tabela 8 - Melhores resultados de PSNR da HaaRGlyph utilizando o componente $\mathrm{Y}_{1}$. 96

Tabela 9 - Comparação da HaaRGlyph utilizando a componente $\mathrm{Y}_{2}$ e a estrutura Diferença de Luminância $\left(\mathrm{Y}_{\mathrm{d}}\right) \ldots \ldots$. . . . . . . . . . . . . . 97

Tabela 10 - Comparação entre HaaRGlyph e a RevGlyph . . . . . . . . . . . . . . . . 97

Tabela 11 - Análise MOS . . . . . . . . . . . . . . . . . . . 100 



\section{LISTA DE ABREVIATURAS E SIGLAS}

ATTEST .. Advanced Three-Dimensional Television System Technologies

CSV ..... Conventional Stereo Video

$\mathrm{dB} \ldots . .$. decibéis

DCT ..... Discret Cossine Transform

DSCQS .. Double-Stimulus Continuos Quality-Scale

DWT .... Discrete Wavelet Transform

EZW ..... Embedded Zerotree Wavelet Coder

FVV ..... Free Viewpoint Video

HD ....... High Definition

IDCT ..... Inverse discrete cosine transform

IDWT .... Inverse Discrete Wavelet Transform

JPEG .... Joint Photographic Experts Group

LCD ..... Liquid Crystal Display

LDV .... Layered Depth Video

LZSS .... Lempel-Ziv-Storer-Szymanski

MOS ..... Mean Opinion Score

MRWD ... Morphological Representation of Wavelet Data

MVC ..... Multiview Video Coding

MVD ..... MultiView Plus Depth

OSVR .... Open-Source Virtual Reality

PPM .... Prediction by Partial Matching

PSNR .... Peak Signal-to-Noise Ratio

RLE ..... Run-Lenght Encoding

SLCCA .. Significance-Linked Connected Component Analysis

SPIHT ... Set Partitioning in Hierarchical Trees

V+D .... Video Plus Depth

ZPS ...... Zero Parallax Setting 



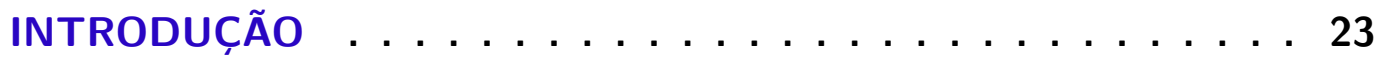

$2.1 \quad$ Aspectos da visão humana . . . . . . . . . . . . . . 27

2.1.1 Informações monoculares . . . . . . . . . . . . . . . 28

2.1.2 Informações óculo-motoras . . . . . . . . . . . . . . . 30

2.1.3 Informações estereoscópicas . . . . . . . . . . . . . . . . . 30

2.2 Tipos de visualização estereoscópica . . . . . . . . . . . . . . 32

2.2.1 Estereoscopia anaglífica . . . . . . . . . . . . 32

2.2.2 Estereoscopia por luz polarizada . . . . . . . . . . . . . . . 34

2.2.3 Óculos obturadores (ou multiplexação temporal) . . . . . . . . . . . 35

2.2.4 Head Mounted Display . . . . . . . . . . . . . . . . . . . . 36

2.2.5 Monitores autoestereoscópicos . . . . . . . . . . . . . 37

$2.3 \quad$ Aplicações de conteúdo estereoscópico . . . . . . . . . . . . . 39

$2.4 \quad$ Considerações finais . . . . . . . . . . . . . . . 40

3 COMPRESSÃO E CODIFICAÇÃO DE VÍDEO DIGITAL . . . . . . 41

$3.1 \quad$ Compressão de vídeos digitais . . . . . . . . . . . . . 41

3.1.1 Espaços de cor . . . . . . . . . . . . . . . . . 42

3.1.2 Subamostragem de crominância . . . . . . . . . . . . . . . . 44

3.1.3 Transformadas matemáticas . . . . . . . . . . . . . . . . . . 45

3.1.4 Quantização ...................... 50

3.1.5 Codificação por entropia . . . . . . . . . . . . . . . 52

$3.2 \quad$ Organização dos dados estereoscópicos . . . . . . . . . . . . 54

3.2.1 Codificação convencional . . . . . . . . . . . . . . . . . . 54

3.2.2 Codificações em múltiplas visões . . . . . . . . . . . . . . . . . 54

3.2.3 Codificação baseada em vídeo e profundidade . . . . . . . . . . . 56

$3.3 \quad$ Compressão . . . . . . . . . . . . . . . . . 57

3.3.1 Compressão $2 D \ldots \ldots \ldots \ldots \ldots \ldots \ldots$

3.3.2 Compressão estereoscópica . . . . . . . . . . . . . . . 59

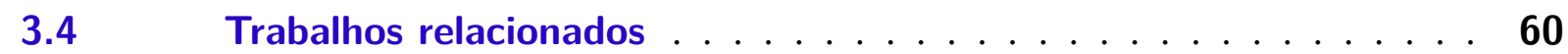

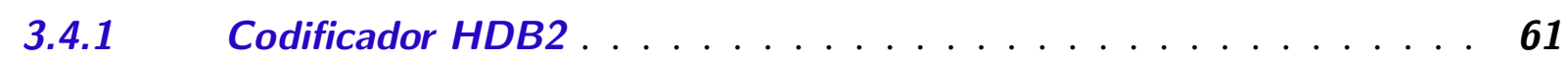

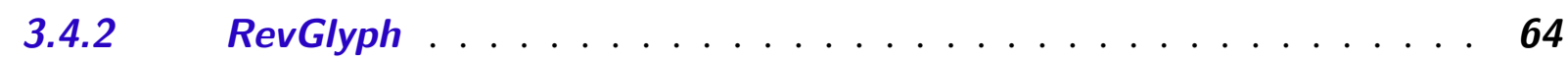




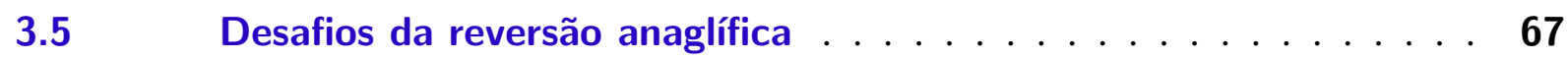

3.6 Métricas de avaliação de qualidade e de compressão . . . . . . . . 69

3.6.1 Métricas Objetivas . . . . . . . . . . . . . . . . 69

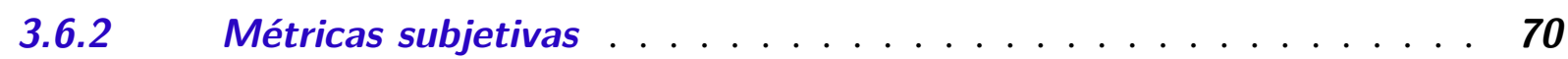

3.6.3 Desenvolvimento dos testes objetivos e subjetivos . . . . . . . . 71

$3.7 \quad$ Considerações finais . . . . . . . . . . . . . . . . 72

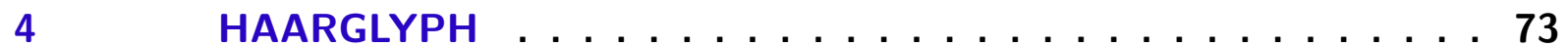

$4.1 \quad$ A técnica HaaRGlyph . . . . . . . . . . . . . . . 73

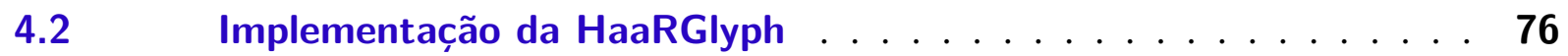

$4.3 \quad$ Considerações finais . . . . . . . . . . . . . . . . . 79

5 ANÁLISE DA HAARGLYPH $\ldots \ldots \ldots \ldots \ldots$

5.1 Análise da conversão e reversão do espaço de cores . . . . . . . 81

5.2 Análise da subamostragem de crominância . . . . . . . . . . . 82

5.3 Análise da DWT e quantização . . . . . . . . . . . . . . 84

5.4 Análise da Diferença de Luminâncias . . . . . . . . . . . . . 86

5.5 Comparação entre HaaRGlyph e RevGlyph . . . . . . . . . 97

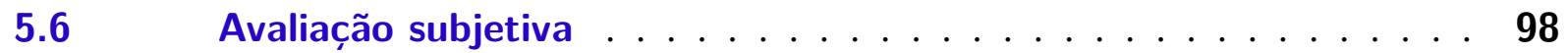

5.7 Considerações finais . . . . . . . . . . . . . . . . . . . . 99

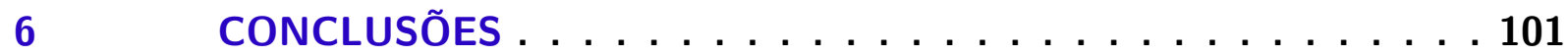

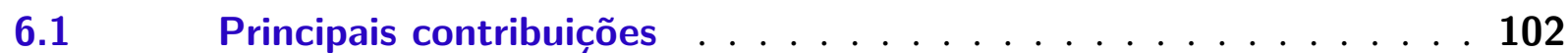

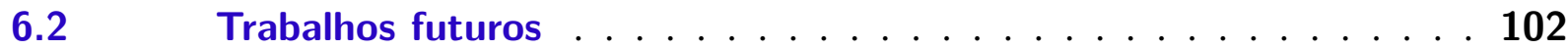

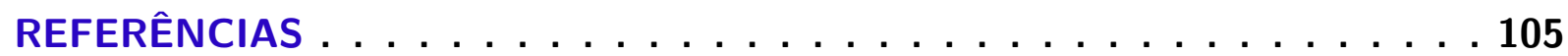




\section{1}

\section{INTRODUÇÃO}

Grande parte da população hoje em dia faz uso de variados tipos de mídia como modo de obter informações e interagir socialmente. Com a evolução da Web e o avanço da banda larga nota-se o surgimento de novos serviços como Youtube ${ }^{1}$, Facebook $^{2}$, Netflix ${ }^{3}$ e Twitter ${ }^{4}$, os quais alcançaram grande repercussão, mostrando a demanda dos usuários por novos modos de interação e visualização de informações. Dentre esses serviços encontra-se o retorno do vídeo 3D aos cinemas - com novidades tecnológicas - e os novos televisores 3D. Esse fato tem incentivado indústria e os meios acadêmicos a pesquisar e desenvolver métodos e técnicas que promovam a produção e distribuição desse tipo de conteúdo.

Vídeos 3D são aqueles que propiciam ao expectador a sensação de profundidade, sendo os vídeos estereoscópicos um tipo de vídeo 3D. Os métodos estereoscópicos para vídeo consistem em apresentar duas sequências de imagens bidimensionais especiais - um par estéreo - para serem interpretadas pelo cérebro humano na criação de uma sequência única de imagens tridimensionais, provocando a sensação de profundidade e distanciamento entre os componentes. Tais métodos visam simular o efeito obtido pela visão humana pelo fato de nossos olhos estarem distantes horizontalmente um do outro, o que faz com que cada olho tenha um ponto de vista diferente da cena - disparidade binocular (GOLDSTEIN, 2010).

A tecnologia 3D não é novidade, sendo que a produção de vídeos estereoscópicos já sofreu vários avanços tanto no modo de captação quanto no modo de reprodução. Câmeras especiais foram desenvolvidas visando capturar dois pontos de vista diferentes de uma mesma imagem (gerando o par estéreo), ou então gerando um mapa de profundidade das cenas juntamente com o vídeo (FEHN et al., 2002). Também foram desenvolvidas técnicas para conversão e apresentação de vídeos 3D a partir de vídeos originalmente em 2D (TAM; ZHANG, 2006).

\footnotetext{
http://www.youtube.com.br

http://www.facebook.com.br

http://www.netflix.com

http://www.twitter.com.br
} 
No que diz respeito à visualização de vídeos 3D, existem tecnologias que fazem uso de óculos especiais para separar o par estéreo, direcionando a imagem correta para cada olho (STEREOGRAPHICS, 1997)(GOLDSTEIN, 2010), bem como monitores denominados autoestereoscópicos, os quais permitem assistir ao conteúdo 3D sem o auxílio de óculos (FEHN; BARRE; PASTOOR, 2006).

Apesar do recente impulso que a tecnologia 3D vem recebendo da indústria do cinema (MENDIBURU, 2009)(SUPPIA, 2007) e da televisão, ainda existe a necessidade de pesquisa nesta área. Um reflexo disso é a atual falta de padronização no modo de organizar dados estereoscópicos para fins de armazenamento ou transmissão, sendo que tais métodos podem ser divididos em dois grandes grupos: o método de Lipton (LIPTON, 1997) e os métodos aqui chamados de vinculados (SMOLIC et al., 2009). No método de Lipton o par estéreo é armazenado em contêineres genéricos (AVI, por exemplo), com compressão ou sem compressão. Apesar de ser flexível, resulta em um volume de dados duas vezes maior devido à necessidade de se armazenar dois fluxos de vídeo (o par estéreo).

Os métodos vinculados, por sua vez, utilizam técnicas consagradas de compressão de vídeo (como MPEG-2 e H.264) para diminuir o volume de dados e armazená-los em contêineres próprios, visando atender às demandas de armazenamento/transmissão. Contudo, tais técnicas: ainda armazenam dois fluxos de vídeo como no método de Lipton; são adaptadas do vídeo 2D para tratar vídeo 3D e funcionam somente para casos particulares (SMOLIC et al., 2009); utilizam compressão com perdas, o que pode impossibilitar a correta percepção de profundidade em alguns casos, notadamente em vídeo anaglíficos (ANDRADE; GOULARTE, 2009).

Uma consequência importante da utilização dos métodos vinculados é a dificuldade dos reprodutores em reutilizar conteúdo sem a necessidade de complexas recodificações. Cada técnica possui um decodificador/reprodutor próprio e, assim, o conteúdo codificado por uma técnica específica fica vinculado a um modo de visualização. Por exemplo, um vídeo codificado pela técnica anaglífica (SIEGEL et al., 1994) possui o par estéreo fundido em um único fluxo de dados, o que impossibilita a exibição desse conteúdo em sistemas que utilizam óculos obturadores ou polarizadores, pois estes necessitam do par estéreo para realizar a correta reprodução do conteúdo. Vídeos codificados com a técnica de mapa de profundidade (MULLER; MERKLE; WIEGAND, 2011) não possuem o par estéreo e necessitam de métodos complexos de renderização para gerar o par estéreo e possibilitar a visualização da profundidade por quaisquer dos modos de visualização/reprodução.

Nesse contexto, a literatura relacionada apresenta uma lacuna: até o momento, não foram encontradas técnicas para codificação de vídeo 3D que forneçam altas taxas de compressão sem perda significativa de qualidade na percepção de profundidade e que, ao mesmo tempo, possibilitem que o conteúdo seja facilmente visualizado independentemente do modo de visualização escolhido.

Conforme discutido subseção 3.2.3, padrões (como o MPEG2) e técnicas (como Layered 
video e Video plus Depth) recentes voltados para a codificação de vídeos estereoscópicos utilizam, entre outros, os métodos usuais para compressão espacial de vídeo - podem causar perdas na sensação de profundidade (ANDRADE; GOULARTE, 2010). Além disso, geram como saída dois fluxos de informação codificada: dois fluxos de vídeo ou um fluxo de vídeo e um mapa de profundidade. Nesse ponto a utilização de vídeo anaglífico, apesar de vantajosa, não vem sendo largamente explorada.

Em um trabalho relacionado Andrade (2012) apresenta uma técnica de codificação espacial, denominada HDB2, que explora vídeos anaglíficos e transformadas wavelet. Vídeos anaglíficos, por sua natureza, eliminam $50 \%$ de dados durante a codificação, favorecendo a compressão. Analisando as etapas onde perdas ocorrem, Andrade (2012) aplica transformadas wavelets de modo a aumentar a taxa de compressão sem, contudo, perder qualidade de percepção de profundidade quando comparado a técnicas relacionadas. Porém, a HDB2 utiliza Lipton para armazenar os dados e é específica para o método anaglífico de visualização. Para outros métodos de visualização são necessárias recodificações.

Em outro trabalho relacionado, Zingarelli (2013) desenvolveu uma técnica de codificação espacial (RevGlyph) capaz de reverter um vídeo anaglífico a uma aproximação de seu par estéreo original, sendo, portanto, independente do modo de visualização. Por outro lado, a RevGlyph utiliza apenas métodos usuais para compressão espacial de dados, sugerindo que a taxa de compressão obtida pode ainda ser melhorada.

Uma questão de pesquisa que surge nesse contexto é a seguinte: é possível aplicar à RevGlyph métodos mais aprimorados de codificação de vídeo, como os utilizados na técnica HDB2, obtendo maior compressão sem, contudo, gerar perdas significativas na qualidade da percepção de profundidade?

Assim, o objetivo deste trabalho é responder à questão de pesquisa e, por consequência, reduzir a lacuna identificada. Para tanto, nesta dissertação é proposta a técnica HaaRGlyph, uma nova técnica de codificação de vídeo estéreo baseada no método anaglífico que combina as qualidades das técnicas RevGlyph e HDB2.

A técnica proposta foi avaliada utilizando medidas objetivas e subjetivas bem conhecidas da área - Peak Signal-to-Noise Ratio (PSNR) e Double-Stimulus Continuos Quality-Scale (DSCQS) - aplicadas em uma base de vídeos e imagens comum (ITU-R, 2002b). Os resultados obtidos comprovam que houve um aumento de $13,99 \%$ na taxa de compressão e que a qualidade das imagens não foi significativamente afetada.

Este texto está organizado do seguinte modo: o Capítulo 2 trata da revisão bibliográfica acerca de vídeos estereoscópicos e os aspectos biológicos da visão humana relacionados. $\mathrm{O}$ Capítulo 3 apresenta os conceitos básicos sobre compressão, codificação e organização dos dados de vídeos digitais, bem como os trabalhos relacionados. A técnica HaaRGlyph é apresentada no Capítulo 4, enquanto no Capítulo 5 são apresentadas análises individuais de cada um dos 
processos que constituem a HaaRGlyph, tal como a comparação entre o método proposto e uma técnica de reversão anaglífica estado da arte. As conclusões do trabalho, bem como, oportunidades de novas pesquisas são encontradas, no Capítulo 6. 


\section{FUNDAMENTOS DA VISUALIZAÇÃO ESTEREOSCÓPICA}

\subsection{Aspectos da visão humana}

Os olhos humanos estão distantes aproximadamente $6,5 \mathrm{~cm}$ um do outro, movimentam-se em conjunto para uma mesma direção e cada um possui um ângulo de visão limitado. Por apresentarem-se em posições diferentes, cada olho observa uma imagem ligeiramente diferente um do outro, característica classificada como disparidade binocular (GOLDSTEIN, 2010). Por essas razões era de se esperar que, ao olhar para um objeto, os olhos captassem duas imagens e não apenas uma. Além disso, dentre os vários objetos presentes no campo da visão humana, há a capacidade de interpretar diferentes profundidades e texturas entre eles, e tal capacidade permanece mesmo movimentando-se para um lado ou para outro. Essa utilização de ambos os olhos para formar uma única imagem, com diferentes níveis de profundidade entre os objetos nela presentes, é definida como estereopsia (LIPTON, 1982)(GOLDSTEIN, 2010)

O principal personagem envolvido nesses fenômenos é o cérebro. Entretanto, ainda não é totalmente conhecido o processo que este realiza, para fundir as duas imagens captadas pelos olhos em apenas uma. Mesmo assim, alguns conceitos físicos e biológicos da visão humana ajudam a compreender melhor as tarefas envolvidas.

Assim, a subseção 2.1.1 discute como informações monoculares contribuem para a percepção de profundidade, mesmo não utilizando o par estéreo. A subseção 2.1.1 trata das informações óculo-motoras, enquanto a subseção 2.1.3 aborda as informações estereoscópicas que para reproduzir a sensação de profundidade e distanciamento utilizam dois fluxos de informações, um referente ao olho direito e outro ao esquerdo. 


\subsubsection{Informações monoculares}

As informações monoculares, do inglês static depth cues, são as obtidas por meio de imagens formadas na retina do olho. A maioria delas são amplamente exploradas pelos artistas em técnicas de pintura e podem ser divididas em: perspectiva linear, interposição, luz e sombra, perspectiva aérea, variação da densidade de textura, conhecimento prévio do objeto e paralaxe de movimento (STEREOGRAPHICS, 1997)(GOLDSTEIN, 2010).

A informação da perspectiva linear está ligada à sensação de que o tamanho dos objetos diminui à medida que estes se distanciam, valendo o mesmo para o processo inverso. Um exemplo clássico é a sensação que a distância entre as linhas paralelas de uma estrada diminui até convergir no horizonte. A perspectiva é uma das principais técnicas utilizadas para expressar a noção de profundidade no papel, e foi uma das grandes descobertas no campo das Artes, sendo amplamente utilizada pelos pintores renascentistas (GOLDSTEIN, 2010).

Na Figura 1, ambos paralelepípedos possuem o mesmo tamanho, porém devido ao efeito de perspectiva gerado pelas linhas existentes (definindo um ponto de fuga), concluí-se que o paralelepípedo que encontra-se mais ao centro da imagem possui tamanho maior.

Figura 1 - Efeito perspectiva

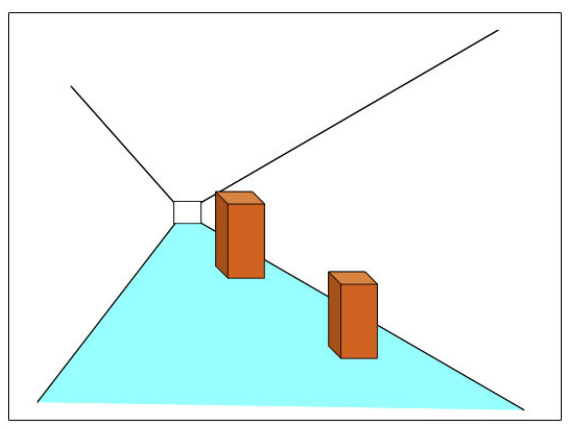

Fonte: Siscoutto et al. (2004).

A interposição é um conceito simples que remete a informação da posição relativa entre objetos. Dado que um objeto A oculta parte ou o todo de B, entende-se que A está à frente de B e mais próximo de nós.

Figura 2 - Interposição

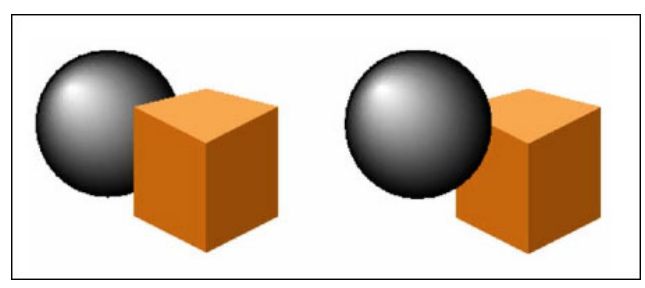

Fonte: Siscoutto et al. (2004).

Junto com a interposição, a variação de luz incidente sobre um objeto, bem como a 
utilização de sombras, concede informações importantes sobre as características deste, tais como, o volume de espaço que ele preenche, sua curvatura, sua posição em relação a outros objetos, sua solidez, transparência e textura. Note que na Figura 3 (A) obtem-se a impressão de existir um círculo e um hexágono preenchido com cores sólidas de forma uniforme. Já na Figura 3 (B), pode-se observar as verdadeiras formas dos objetos tridimensionais, uma esfera e um cubo.

Figura 3 - Variação de luz

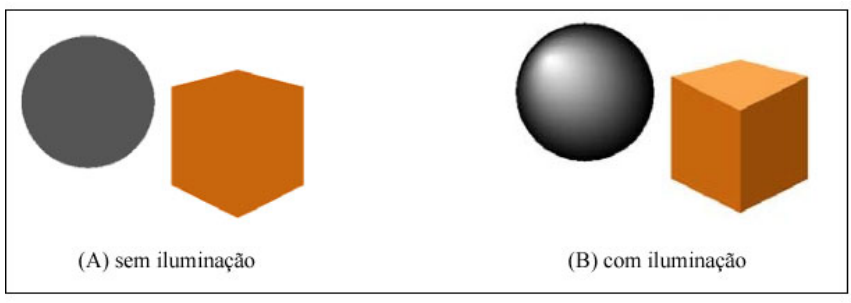

Fonte: Siscoutto et al. (2004).

A perspectiva aérea, é a percepção de que objetos, cuja visibilidade é atrapalhada por algum fenômeno atmosférico (neblina, chuva, incidência solar), encontram-se mais distantes. Por exemplo, ao olhar para uma cadeia de montanhas, nota-se que as que encontram-se mais distantes, aparecem menos nítidas, como se estivessem desaparecendo. Tais fenômenos atmosféricos podem enganar o cérebro e fazer com que uma imagem pareça estar mais distante do que realmente está.

A variação na densidade de uma textura também fornece informações sobre a distância que um objeto se encontra, dada pelo nível de detalhamento que é obtido. Quanto mais distante encontra-se um objeto, menos detalhes de sua textura são percebidos. Por exemplo, ao olhar para uma árvore, à medida que nos distanciamos dela, perdemos os pequenos detalhes de suas folhas e seu tronco.

Por meio do conhecimento prévio, o cérebro armazena informações dos objetos ao passo que é tido contato com eles no mundo real, criando padrões de tamanho e profundidade destes em comparação a outros e ao ambiente em que se encontram. Com isso, ao ver tais objetos em uma mesma imagem, de acordo com as experiências e conhecimento prévio, consegue-se inferir qual está mais próximo ou mais afastado, qual é maior ou menor.

A paralaxe de movimento, como o próprio nome sugere, é uma informação que por meio da movimentação fornece a distância entre objetos. Neste fenônemo, os objetos mais próximos dos nossos olhos parecem mover-se mais rapidamente do que os distantes. Assim, ao olhar par fora da janela de um carro em movimento, os objetos que se encontram mais próximos (uma cerca, por exemplo) parecem se mover rapidamente, enquanto os objetos que se encontram mais distantes (árvores no horizonte) parecem se mover mais lentamente (GOLDSTEIN, 2010). Da mesma forma, tem-se a impressão de que a velocidade de um avião no céu é inferior a velocidade de um carro próximo, mesmo a sua velocidade sendo muito superior. 


\subsubsection{Informações óculo-motoras}

Diferente das informações monoculares que podem ser reproduzidas em imagens no papel, as informações óculo-motoras são baseadas em aspectos fisiológicos. Elas são produzidas de acordo com o relaxamento e contração dos músculos envolvidos no movimento do globo ocular e são interpretadas pelo cérebro para relacionar a distância e profundidade entre objetos. Temos dois tipos: a acomodação e a convergência (STEREOGRAPHICS, 1997)(GOLDSTEIN, 2010).

A acomodação é relacionada às contrações musculares envolvidas para mudar o formato do cristalino, com o objetivo de alterar o foco nas imagens. Assim, consegue-se obter informação sobre a distância entre objetos de acordo com o esforço muscular envolvido para alterar o foco.

Cada olho produz uma imagem diferente do que está sendo visto, porém, consegue-se fazer com que um objeto seja visto na mesma posição em ambos os olhos. Para que isto ocorra, o objeto deve encontrar-se em um mesmo ponto para os dois olhos, chamado de ponto de convergência. De acordo com a distância em que se encontra o objeto, deve-se alterar o ponto de convergência. $O$ ângulo formado na movimentação dos olhos em torno do seu eixo vertical para esse ponto de convergência indica a informação da distância do objeto. Na Figura 4 (A) a convergência dos olhos ocorre quando uma pessoa olha um objeto que está muito próximo, enquanto em (B), os olhos encontram-se olhando para a frente quando a pessoa observa algo que está distante.

A Figura 4 (A) Foco em um objeto que encontra-se próximo; (B) Foco em um objeto que encontra-se distante e.

Figura 4 - Convergência

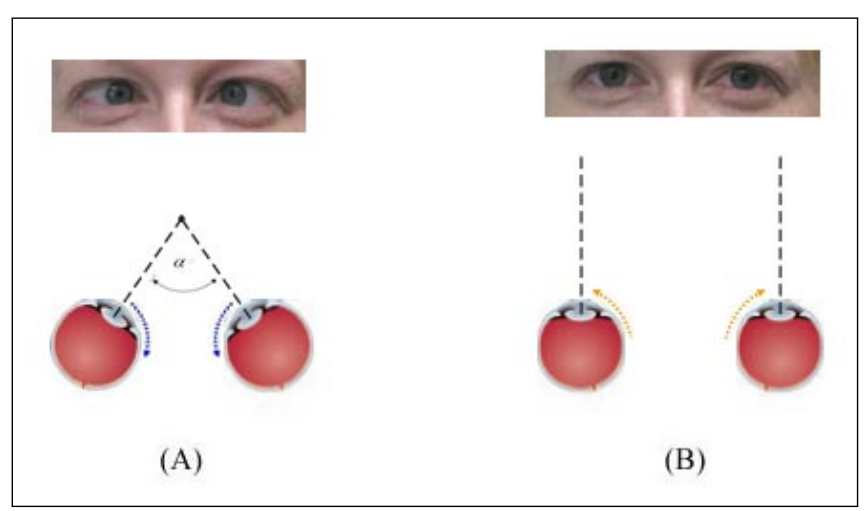

Fonte: Adaptada de Goldstein (2010, p.231).

\subsubsection{Informações estereoscópicas}

Como anteriormente exposto, cada olho produz uma imagem diferente, devido ao fato de estarem a uma distância e ângulos diferentes (disparidade binocular). Cabe ao cérebro se encarregar de retirar as informações das distâncias relativas dos objetos e de interpretar essas 
duas imagens resultando na produção de uma única. As principais informações estereoscópicas são: a estereopsia, disparidade e paralaxe (STEREOGRAPHICS, 1997).

Já citada anteriormente, a estereopsia é responsável pela sensação de profundidade entre os objetos, e é obtida em virtude da disparidade binocular. Sendo assim, o requisito obrigatório para obter a estereopsia é possuir visão em ambos olhos. É com esta informação, em cooperação com as outras informações aqui descritas, que é possível sentir objetos mais próximos ou mais distantes. Esta sensação é explorada em filmes 3D para passar a impressão de que os objetos estão saindo da tela, ficando bem próximos ao observador.

A diferença na distância entre as posições da imagem formada em cada retina em relação ao centro desta é chamada de disparidade. Isso é melhor entendido com o seguinte exemplo: observe um objeto a sua frente e posicione o seu polegar entre seus olhos e o objeto. Ao focar oo polegar, ou seja, ele se encontra no ponto de convergência das duas retinas, o objeto fica após o ponto de convergência (mais distante), aparecendo como que duplicado (Figura 5 A). Isso se dá pelo fato das imagens fora do ponto de convergência serem formadas em posições diferentes em cada retina. A disparidade é a distância entre essas duas imagens duplicadas. O mesmo acontece caso o foco seja dado ao objeto (Figura 5 B).

Figura 5 - Exemplo de observância da informação de disparidade.

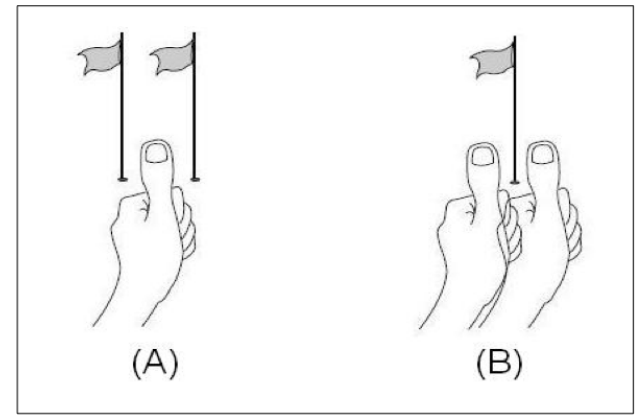

Fonte: Stereographics (1997).

Diretamente ligado ao conceito de disparidade (obtida na imagem formada na retina) temos a paralaxe, caracterizado pela distância entre os pontos correspondentes nas imagens formadas em um monitor. Com os valores de paralaxe, é possível dar um ponto de vista diferente de uma mesma imagem para cada olho, tendo como consequência a formação da disparidade, e esta, por conseguinte, produz o efeito de estereopsia. Uma maneira fácil de calcular a paralaxe entre dois pontos é sobrepondo uma imagem à outra e medindo a distância entre os mesmos pontos em cada imagem.

Pode-se classificar a paralaxe em quatro tipos (STEREOGRAPHICS, 1997), os quais afetam a noção de profundidade acerca dos objetos que compõem a imagem: a paralaxe zero - Zero Parallax Setting (ZPS), a positiva, a negativa e a divergente. A paralaxe zero é obtida quando os pontos correspondentes em cada imagem estão na mesma posição, ou seja, a diferença entre eles é zero; neste caso, os pontos convergem na retina. A paralaxe positiva ocorre quando a 
distância entre pontos correspondentes está entre zero e uma constante $t$, e submetem a sensação de que os objetos estão distantes; isto ocorre porque o ponto de convergência das imagens no eixo de projeção de cada olho é obtido após o plano de projeção. Já a paralaxe negativa propicia a sensação de que os objetos estão próximos de nós, como que saindo do monitor; tal efeito é consequência do cruzamento dos eixos de projeção de cada olho ocorrer antes de chegar ao plano de projeção. Por fim, a paralaxe divergente é um caso especial da paralaxe positiva, quando a distância entre os pontos correspondentes ultrapassa a constante $t$, causando um certo desconforto ao usuário, já que esse tipo de fenômeno não encontra similaridade na visão humana.

Figura 6 - Paralaxe

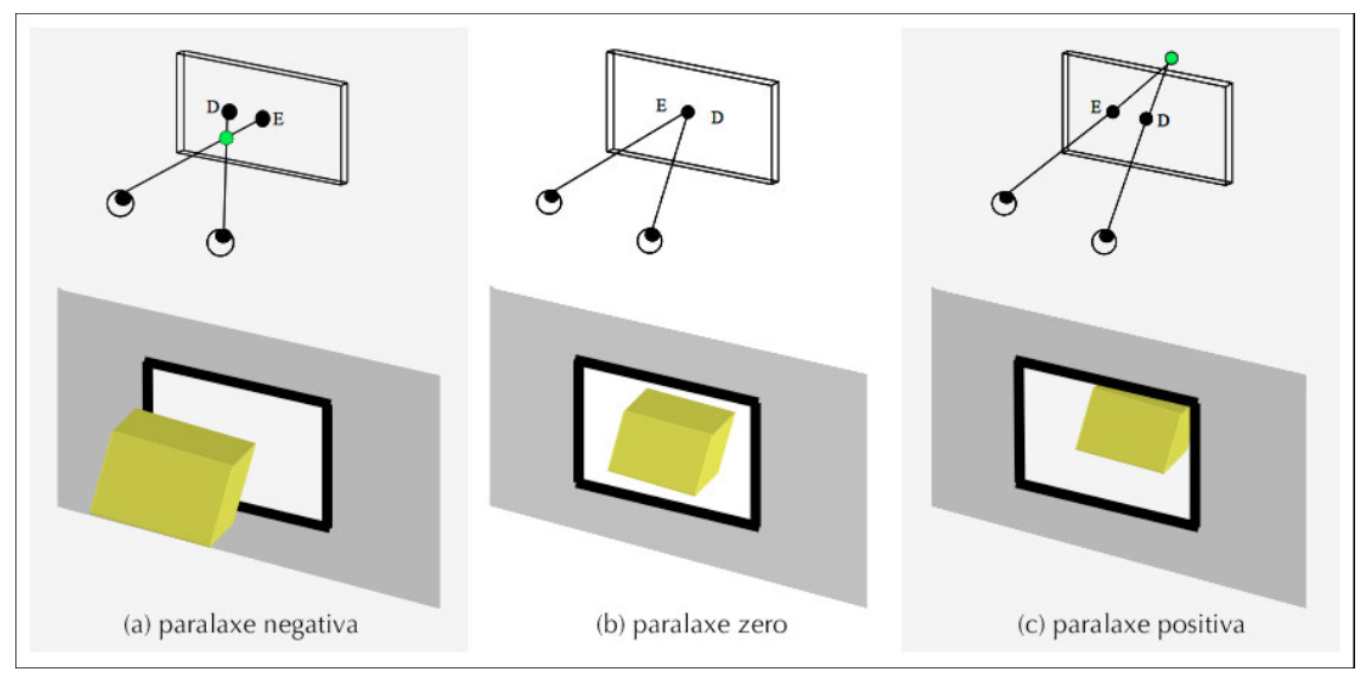

Fonte: Siscoutto et al. (2004).

\subsection{Tipos de visualização estereoscópica}

A estereoscopia baseia-se em métodos que utilizam um par de imagens planas para visualização de uma imagem tridimensional, oferecendo a cada olho do observador uma perspectiva diferente. Dessa forma, um requisito para obtermos o efeito estereoscópico é a utilização de ambos os olhos. Com imagens estereoscópicas, é resgatada uma informação muito importante que se perde em imagens bidimensionais: a sensação de profundidade entre os diferentes objetos que compõem a cena.

Nas Seções de subseção 2.2.1 à subseção 2.2.5, os principais métodos de visualização de vídeos estereoscópicos são detalhados, sendo eles: estereoscopia anaglífica, estereoscopia por luz polarizada, óculos obturadores, Head Mounted Display e monitores autoestereoscópicos.

\subsubsection{Estereoscopia anaglífica}

É o modo mais simples, o qual consiste em converter o par estéreo em um único fluxo de vídeo. Para isso, os canais RGB de cada vídeo são combinados de modo a se ter informações 
de ambos os vídeos (do olho esquerdo e do olho direito) (MENDIBURU, 2009). A Figura 7 ilustra um exemplo dessa conversão. Seja o par estéreo formado por $\mathrm{R}_{1} \mathrm{G}_{1} \mathrm{~B}_{1}$ (o vídeo do olho esquerdo) e $\mathrm{R}_{2} \mathrm{G}_{2} \mathrm{~B}_{2}$ (o vídeo do olho direito). A conversão é realizada aproveitando-se, por exemplo, o canal vermelho $\left(\mathrm{G}_{1}\right)$ do vídeo do olho esquerdo e os canais $\mathrm{R}_{2}$ e $\mathrm{B}_{2}$ do olho direito, formando um terceiro vídeo (o vídeo anaglífico) com informações de ambos os vídeos do par estéreo: $R_{2} G_{1} B_{2}$. Como a combinação de cores vermelho $\left(R_{2}\right)$ e azul $\left(B_{2}\right)$ resulta na cor magenta, o modo anaglífico exemplificado na Figura 7 é conhecido como Verde/Magenta. Outros modos anaglíficos possíveis são: Vermelho/Ciano $\left(\mathrm{R}_{1} \mathrm{G}_{2} \mathrm{~B}_{2}\right)$ e Azul/Amarelo $\left(\mathrm{R}_{1} \mathrm{G}_{1} \mathrm{~B}_{2}\right)$.

Figura 7 - Processo de conversão de um par estéreo para vídeo anaglífico. Note que os dados de $R_{1}, G_{2}$ e $B_{1}$ são perdidos

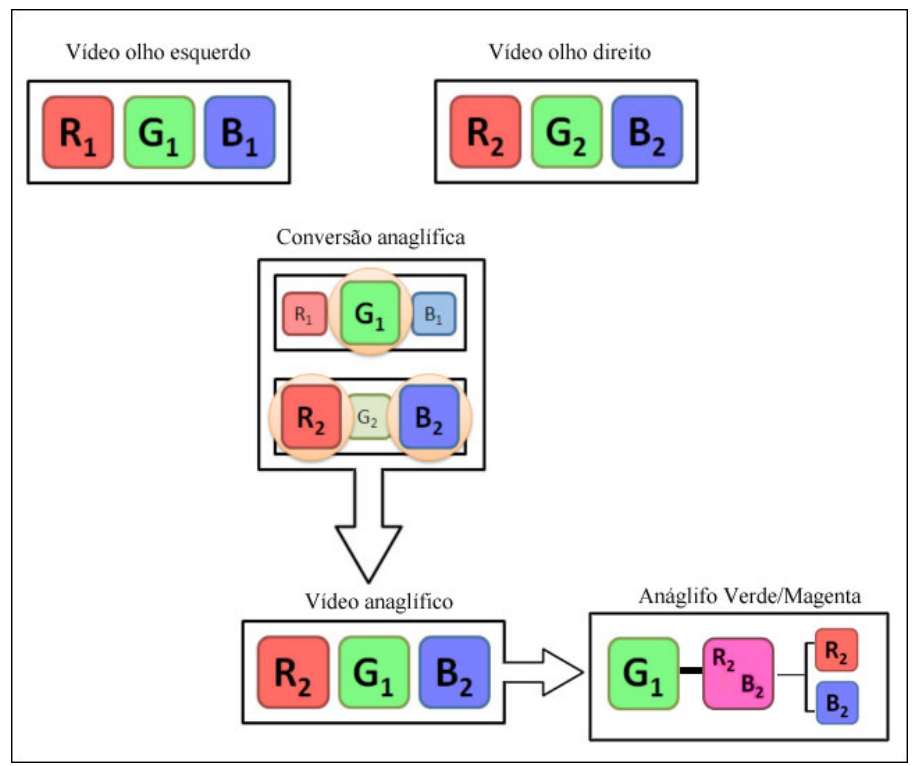

Fonte: Adaptada de Zingarelli (2013).

Durante a reprodução do vídeo anaglífico, o espectador utiliza óculos com lentes coloridas atuando como filtros. No caso do exemplo da Figura 7, seriam filtros verde e magenta. Com isso, consegue-se separar as imagens, recriando uma aproximação do par estéreo, direcionando cada imagem para o olho correto. Assim, cada olho recebe uma imagem diferente, gerando disparidade binocular e estereopsia (MENDIBURU, 2009).

Figura 8 - A lente verde bloqueia a cor verde e a lente magenta bloqueia as cores vermelha e azul

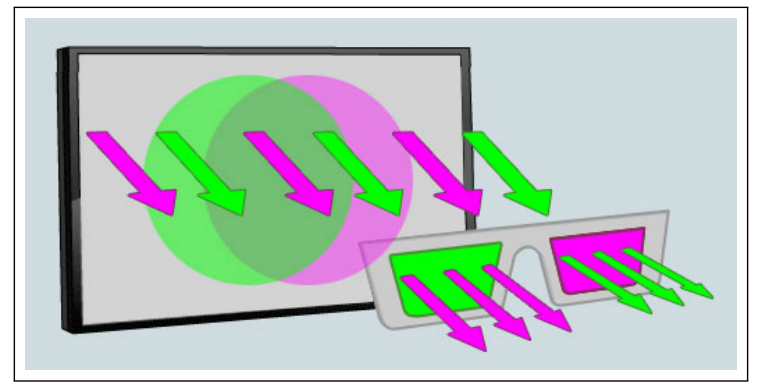

Fonte: Adaptada de Barbosa (2014). 
As duas principais vantagens desta técnica são o custo para a produção/reprodução do vídeo anaglífico e o tamanho do arquivo final. O custo para a produção/reprodução é baixo, pois não requer equipamentos com alta tecnologia. $O$ tamanho do arquivo final é menor em relação aos outros modos, já que se tem somente um sinal de vídeo resultante da junção dos dois originais, garantindo compressão tornando-se vantajoso para situações de armazenamento e transmissão dos dados. Além disso, em termos de tecnologia, trata-se de uma técnica simples de ser implementada.

Já a principal desvantagem é que a técnica anaglífica é sensível à perda de cores, prejudicando a percepção de profundidade dependendo do grau da perda. Além disso, se por um acaso for necessária a reversão do processo, isto é, realizar a reversão do anaglífico para o par estéreo, não há uma solução trivial, pois a conversão anaglífica envolve perdas de informações de cores de ambos vídeos do par estéreo. A reversão anaglífica utilizando apenas as informações intracodificadas no anáglifo resultante não tem sido reportada na literatura (para o melhor de nosso conhecimento, não há registro de tais estudos) exigindo uma maior investigação.

\subsubsection{Estereoscopia por luz polarizada}

Este modo de visualização baseia-se no fato de que a luz, como energia, irradia-se de forma ondulatória. Pode-se então considerar, que tais ondas vibram em todas direções perpendiculares à direção do deslocamento. Toda via, com a utilização de filtros é possível direcionar a luz, a fim de que a mesma, vibre apenas em um sentido, filtrando assim todos os raios cuja vibração não ocorra em uma direção pré-determinada.

Figura 9 - (A) Luz - (B) Propagação do feixe de luz em todas as direções (luz não polarizada) - (C) Filtro polarizador vertical - (D) Propagação da luz em apenas uma direção (luz polarizada)

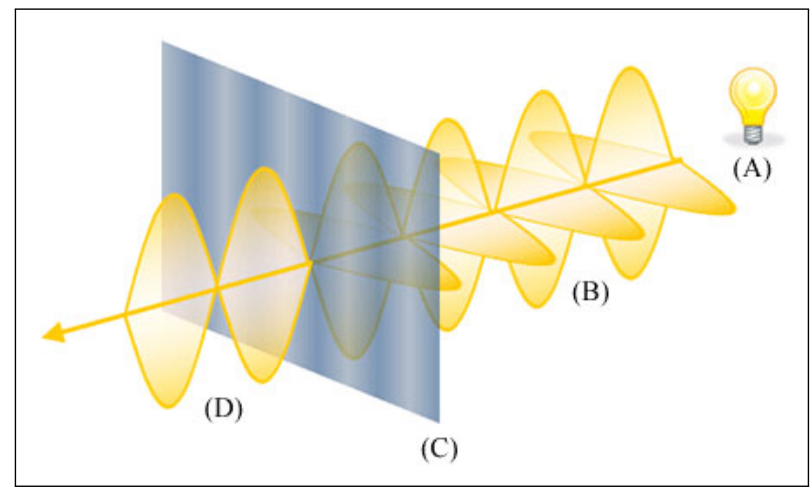

Fonte: Adaptada de Gåsvik (2002).

A polarização do sinal pode ser realizada de forma linear (horizontal e vertical) ou de forma circular (sentido horário e anti-horário), sendo que no primeiro caso, a movimentação da cabeça do usuário pode interferir na percepção estereoscópica.

Este modo de visualização utiliza dois vídeos e dois projetores, cada qual destinado a um dos nossos olhos, para que seja mantida a polarização da luz (realizada pelos filtros), devem 
ser projetadas em uma tela metalizada (ou anti-despolarizadora). Cada projetor possui um filtro polarizador, responsável por projetar a imagem em um ângulo diferente na tela e com o auxílio de óculos (possuindo esses mesmos filtros), consegue-se que cada olho, veja apenas a projeção destinada a ele (MENDIBURU, 2009).

Figura 10 - Cada uma das lentes interpreta uma das imagens de acordo com o filtro utilizado

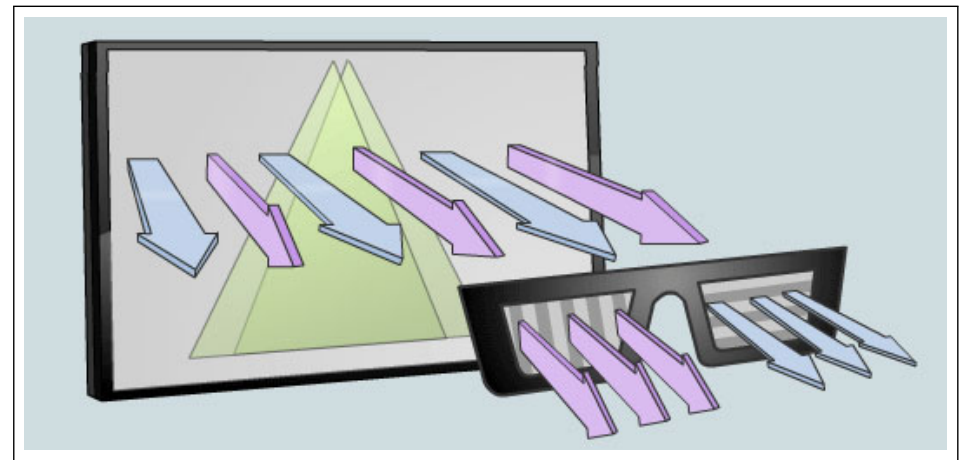

Fonte: Barbosa (2014).

Como os dois vídeos são reproduzidos separadamente e de forma íntegra, não há desvantagem da perda real das cores da cena. Por essa razão, dispositivos com estereoscopia por luz polarizada são os que vêm sendo utilizados pela indústria cinematográfica e é a tecnologia utilizada nos cinemas 3D atuais. Entretanto, uma complexidade a mais é introduzida por esta técnica: ambos os vídeos devem estar em perfeita sincronia, para que sejam reproduzidos na mesma linha de tempo. Isso é válido tanto para a gravação, quanto para a edição e a reprodução, fazendo-se necessário a utilização de equipamentos mais robustos e por consequência, mais caros. Adicionalmente, a utilização de dois fluxos de vídeo ao mesmo tempo também pode ser considerado uma desvantagem.

\subsection{3 Óculos obturadores (ou multiplexação temporal)}

Diferente dos óculos utilizados em vídeos anaglíficos e por luz polarizada, que filtram as imagens corretas para cada olho, os óculos obturadores separam as imagens mecanicamente. Esta é uma tecnologia muito utilizada pelos televisores 3D e funciona da seguinte forma: o monitor exibe alternadamente em uma alta frequência as imagens para cada olho; os óculos, compostos por lentes de Liquid Crystal Display (LCD), são sincronizados com o monitor a fim de alternarem entre si na mesma frequência o nível de opacidade de cada lente. Com isso, por uma fração mínima de tempo, uma lente estará opaca e a outra não, e consequentemente, um olho enxergará a imagem e o outro não. Como essa troca ocorre muitas vezes a cada segundo (mais de 60 quadros por segundo), nossos olhos não notam a opacidade das lentes e o efeito adquirido é a estereopsia sem perda de qualidade de imagem.

Os principais problemas desta técnica são: o alto custo para a produção dos óculos, inviabilizando seu uso em cinemas, por exemplo; a falta de um padrão para estes, não sendo 
Figura 11 - Óculos e monitor sincronizados, exibindo a imagem apenas em uma das lentes

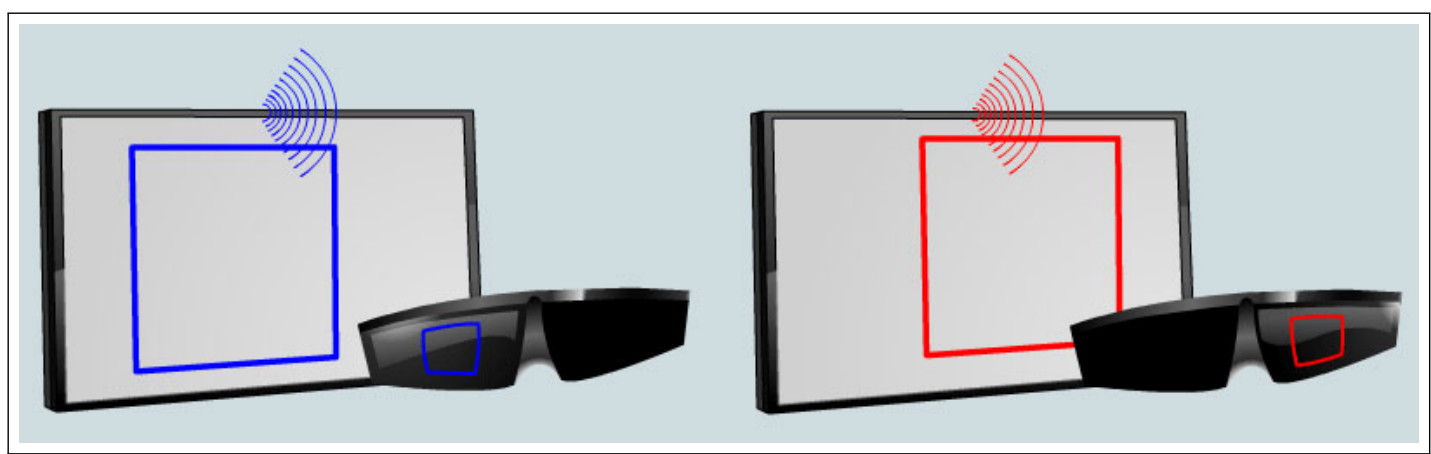

Fonte: Barbosa (2014).

possível utilizar o mesmo óculos para televisores 3D de marcas diferentes; e a perda da resolução ou brilho das imagens, dependendo do padrão de reprodução.

Apesar de seu custo elevado, estes dispositivos são os que possuem melhor qualidade de imagem, podendo exibir 240 imagens em Full High Definition (HD) por segundo para cada olho $(480 \mathrm{~Hz})$. Assim, como no método que utiliza filtros polarizados, esta técnica também utiliza dois fluxos simultâneos de vídeo.

\subsubsection{Head Mounted Display}

Os dispositivos HMD são compostos por duas mini-telas (uma para cada olho), e durante a sua utilização o dispositivo exibe em cada tela uma imagem específica para cada um dos olhos (cada uma sendo visível apenas por um dos olhos), propiciando assim, a visualização estereoscópica.

Figura $12-\mathrm{HMD}$

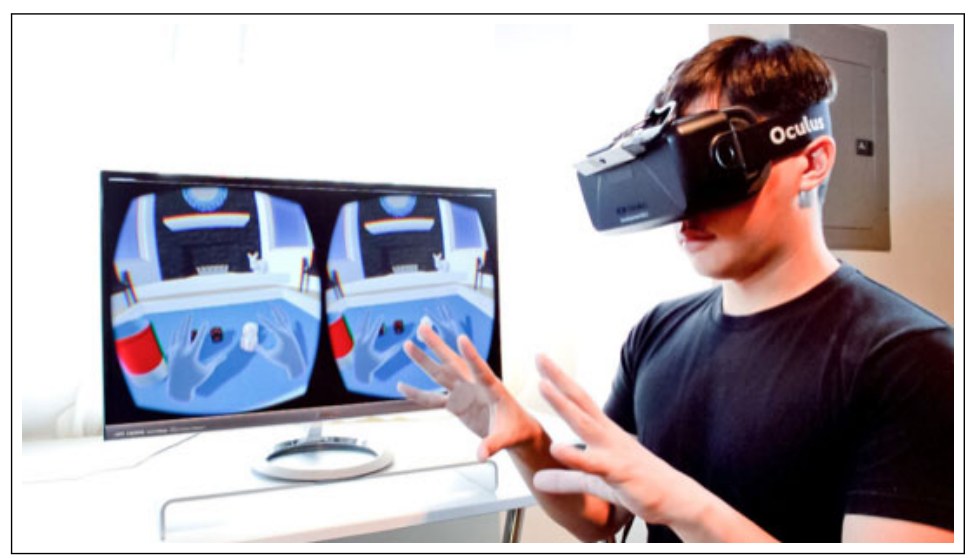

Fonte: NimbleVR (2012).

Além disto, tal dispositivo possuí sensores de rastreamento que captam a movimentação da cabeça do usuário, sendo possível utilizá-los para aplicações de realidade virtual, renderizando em tempo real informações gráficas de acordo com a perspectiva e movimento do usuário, 
causando um efeito de imersão 3D e propiciando uma maior interação do usuário com o ambiente virtual.

Por possibilitar a criação de ambientes virtuais, os HMD's têm sido utilizados nas áreas militares, no qual junto com a cena real, podem ser exibidas informações táticas, mapas, distâncias e nas áreas médicas e industriais, podendo ser utilizado em simulações e treinamentos.

No entretenimento, os HMD's vêm se popularizando, prometendo revolucionar a forma de se jogar um game. Após o desenvolvimento do Oculus Rift ${ }^{1}$, outras empresas apostam nesta tecnologia e têm desenvolvido produtos similares, tal como o Open-Source Virtual Reality (OSVR) da Razer ${ }^{2}$. Como uma alternativa aos altos custos destes dispositivos e a fim de estimular o interesse e desenvolvimento de aplicações de realidade virtual, a Google anunciou durante o Google I/O 2014, o projeto Cardboard $^{3}$, um óculos de realidade virtual feito de papelão juntamente com velcro, imã e duas lentes. Neste caso, o celular é utilizado como tela, e um aplicativo é responsável por dividir a tela do celular em duas imagens, separando assim as imagens corretas para cada olho.

Figura 13 - Google Cardboard

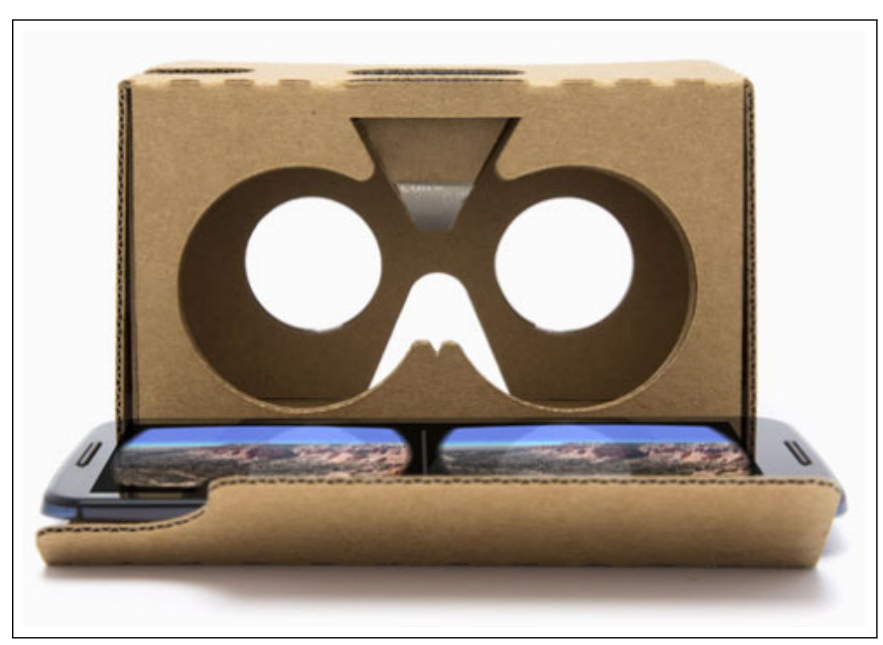

Fonte: Google (2012).

\subsubsection{Monitores autoestereoscópicos}

A obrigatoriedade de se utilizar óculos especiais, vista nas técnicas apresentadas anteriormente, se mostra uma abordagem invasiva que pode gerar certo desconforto ou até mesmo fadiga se usada por muito tempo. Visando o descarte desses óculos ou qualquer outro equipamento na visualização de vídeos 3D, há a tecnologia envolvida na criação de monitores autoestereoscópicos, que como o próprio nome diz, são capazes de gerar sozinhos a sensação de profundidade nas imagens reproduzidas.

\footnotetext{
https://www.oculus.com

http://www.razerzone.com/osvr

https://www.google.com/get/cardboard
} 
Tal feito é obtido, criando-se diferentes visões estéreo de uma mesma cena, vista por ângulos diferentes e limitados a certo segmento do campo de visão do espectador, concebendo que o mesmo veja a cena por outra perspectiva ao movimentar-se para outro campo de visão. Para isso, coloca-se no monitor uma película especial, chamada película lenticular, que é formada por pequenas lentes, as lentículas, que são capazes de direcionar a luz de cada imagem para um ângulo diferente. Além disso, o par de imagens estéreo é submetido a uma técnica chamada interlacing, na qual as imagens são fatiadas em pequenas partes do tamanho das lentículas e são intercaladas. Com isso, cada fatia é direcionada pelas lentículas para o respectivo olho citehutchison:2007.

Figura 14 - Duas imagens iguais em angulação distintas entrelaçadas projetadas no monitor

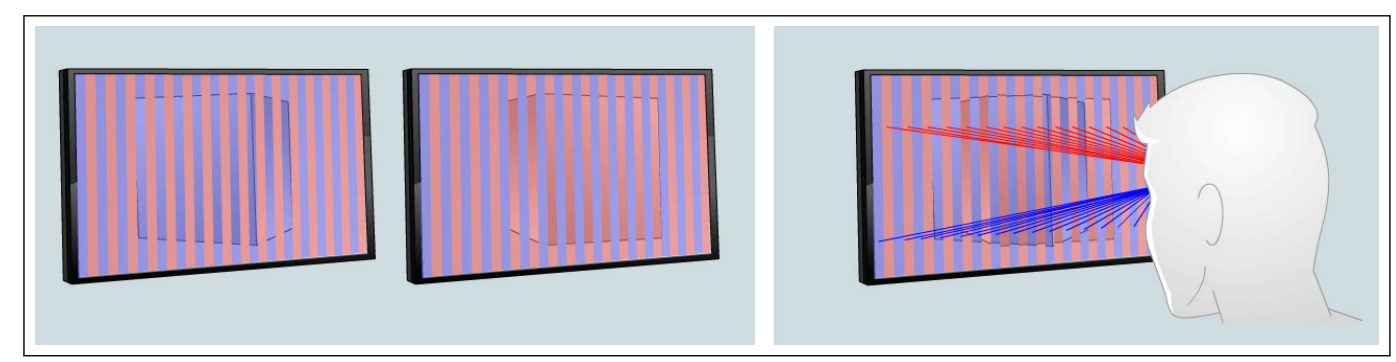

Fonte: Barbosa (2014).

Figura 15 - Monitores autoestereoscópicos

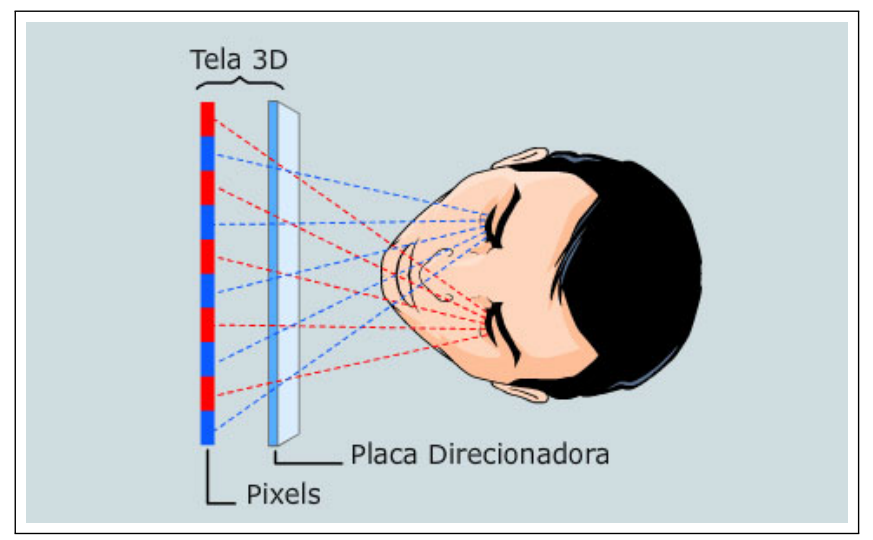

Fonte: Barbosa (2014).

Devido ao alcance limitado do campos de visão fornecido por esta tecnologia, um problema ainda em estudo e enfrentado em monitores autoestereoscópicos, é que o espectador deve situar-se em pontos chaves para ver a imagem 3D. Esses pontos são poucos, e fora deles a imagem aparece borrada. Além disso, ainda é uma tecnologia a ser aprimorada e de alto custo de produção. 


\subsection{Aplicações de conteúdo estereoscópico}

A presença de vídeos estereoscópicos no cinema não é um fato inédito. Houve um crescimento cinematográfico na década de 1950, utilizando-se da técnica de luz polarizada, como uma forma de trazer o público novamente ao cinema, o qual naquela época, iniciava-se um declínio de audiência, devido à popularidade das TVs (LIPTON, 1982). Entretanto, devido à baixa qualidade e tecnologia apresentada, rapidamente caíram em desuso. Atualmente, o vídeo $3 \mathrm{D}$ voltou ao centro de atenção da indústria cinematográfica a partir da estreia do filme Avatar, no qual foi utilizada uma tecnologia mais madura, telas de alta resolução e uma boa estratégia de marketing, mostrando ser muito rentáveis às grandes produtoras como Disney e Warner, em mais uma tentativa de atrair o público.

Dirigindo-se para o lado doméstico, a indústria vem oferecendo televisores de alta definição e preparados para exibição de conteúdo 3D. Em uma de suas pesquisas a DisplaySearch mostrou um aumento constante na venda de Tvs com a tecnologia 3D em todo o mundo, registrando no quarto trimestre de 2012 um aumento nas vendas de 25,7\%, contra 14,2\% registrados no mesmo período do ano anterior. Tal fato tem impulsionado o mercado de filmes 3D nos EUA. Segundo um estudo realizado pela Nielsen, as versões tridimensionais de filmes de grande sucesso no cinema são mais vendidas do que as versões convencionais. Ainda de acordo com o estudo Nielsen VideoScan, a versão 3D do filme Prometheus (20th Century Fox) vendeu em sua primeira semana $25 \%$ a mais do que a versão convencional. Já a Disney com a produção de Os Vingadores 3D, registrou um crescimento de $23 \%$ logo na primeira semana, e até títulos mais antigos, como Thor e Capitão América: O Primeiro Vingador, registraram vendas superiores a $15 \%$ e $13 \%$ respectivamente, quando comparados aos blu-rays convencionais.

O mercado de jogos parece ser um dos que mais serão beneficiados com a utilização de conteúdo 3D, pois, fornece uma nova alternativa de interatividade e imersão dos usuários com os jogos. Os grandes fabricantes de consoles vêm se mostrando interessados em investir nessa tecnologia, como é o caso da Nintendo e seu portátil Nintendo 3DS, que utiliza duas telas, sendo uma delas autoestereoscópica e a outra sensível ao toque; e também o caso da Sony, que em seu console, Playstation 4, permite a reprodução de jogos em 3D e blu-rays 3D.

Na parte científica, os vídeos estereoscópicos têm grande relevância em aplicações médicas, tais como, a análise de imagens de raio X (TOMKOWIAK; LYSEL; SPEIDEL, 2013), desenvolvimento de tecnologias assistivas para deficientes visuais (COSTA et al., 2012) e a visualização de estruturas complexas em $3 \mathrm{D}$, que permite ao médico fazer uma melhor análise de uma cirurgia (OLSSON et al., 2013).

A área de robótica também pode se beneficiar de técnicas estereoscópicas para reconhecimento de imagens e rastreamento de objetos e pessoas, como estudado por Nguyen et al. (2012). Estudos também podem ser encontrados nas áreas de visualização científica (GONO et al., 2012) e em dispositivos de realidade aumentada (STRATER et al., 2014). 


\subsection{Considerações finais}

Foram apresentados neste capítulo, os principais métodos e dispositivos utilizados na visualização estereoscópica, no qual, apesar de funcionarem de formas distintas, possuem como objetivo separar o par esteréo, entregando o vídeo correto para cada um dos olhos. A Tabela 1 apresenta um resumo de cada método citado neste capítulo, levando em consideração a informação de cores, taxa de compressão, o custo e a qualidade da visualização.

Tabela 1 - Comparações entre métodos de visualização estereoscópica

\begin{tabular}{l|c|c|c|c}
\hline Visualização & Inf. de Cores & Taxa de Compressão & Custo & Qualidade Visual \\
\hline Anaglífica & Metade & Alta & Baixo & Boa \\
\hline Luz Polarizada & Completa & Baixa & Alto & Boa \\
\hline Óculos Obturadores & Completa & Baixa & Alto & Excelente \\
\hline HMD & Completa & Baixa & Regular & Excelente \\
\hline Autoestereoscópica & Completa & Baixa & Altíssimo & Boa \\
\hline
\end{tabular}

Fonte: Dados da pesquisa.

Na especificação qualidade visual, os critérios analisados foram a qualidade da imagem e conforto do usuário. O método anaglífico devido à necessidade de óculos e obteve o critério boa. O método autoestereoscópico oferece conforto ao usuário por descartar a utilização de óculos, porém, a limitação dos ângulos que o usuário deve se posicionar diante da tela, resultou no critério bom. O método por obturação apesar da necessidade do uso de óculos oferece imagens com alta qualidade recebendo a qualidade visual excelente. Além qualidade das imagens e o fato dos dispositivos HDM's serem portáteis, determinaram o resultado excelente. Por fim, o método por luz polarizada recebeu o critério bom devido à necessidade de óculos e a perda de luminosidade nas imagens.

O método anaglífico, permite uma alta taxa de compressão, pois, transforma o par estéreo em apenas um fluxo de vídeo, descartando metade das informações de cores presentes no par. Como citado em subseção 2.2.1, tal transformação é feita por meio da combinação de 2 canais de cores de um dos vídeos juntamente com o canal de cor complementar do outro vídeo e a classificação do anáglifo é dada de acordo com a escolha das combinações de cores.

Todos os métodos apresentados neste capítulo utilizam ao menos um par estéreo para possibilitar a visualização estereoscópica. Entretanto, há a ausência de um padrão no formato de organização destes dados, impossibilitando que tais dados sejam utilizados por outro método. Por exemplo, no caso do método anaglífico, o vídeo estéreo é fundido em um único fluxo de dados, impossibilitando que este vídeo seja utilizado em outro método de visualização, tal como, óculos obturadores que necessitam do par estéreo. 


\section{COMPRESSÃO E CODIFICAÇÃO DE VÍDEO DIGITAL}

Este capítulo tem como objetivo apresentar conceitos sobre compressão, codificação e organização dos dados de vídeos digitais necessários para o bom entendimento do trabalho desenvolvido. Adicionalmente são discutidos os trabalhos relacionados ao método proposto.

\subsection{Compressão de vídeos digitais}

Apesar das vantagens, a utilização de vídeos digitais exige, além de uma grande quantidade de bits para a sua representação, uma alta largura de banda para a sua transmissão. $\mathrm{O}$ principal objetivo da compressão é reproduzir uma informação com a menor quantidade de bits possíveis. Como citado na subseção 2.1.3, o par estéreo carrega em si, informações referentes a duas imagens, sendo assim, há a necessidade de um método eficiente de compressão para reduzir a quantidade de informações a ser armazenada, preservando a qualidade da imagem exigida para uma dada aplicação.

A compressão é possível, pois, as imagens digitais possuem em sua representação original uma grande quantidade de informação redundante. Em geral, é possível identificar as seguintes redundâncias (GONZALEZ; WOODS, 2008):

- Redundância espacial: consiste na semelhança dos pixels adjacentes de uma imagem, sendo assim, é possível prever o valor de um pixel a partir do valor dos pixels de sua vizinhança

- Redundância de código: a codificação é considerada ótima caso o número de símbolos resultante for mínimo. Shannon estabelece um limitante que fornece a quantidade mínima de bits por símbolo necessário para codificar uma fonte. Para reduzir tal redundância, o 
processo de codificação estabelece um código binário de tamanho variável para representar uma informação. Quanto mais frequente for o valor na imagem, menor é o número de bits atribuído para representar esta informação

- Redundância temporal: consiste na similaridade existente entre quadros adjacentes em uma sequência de imagens. Tal correlação é explorada pois, geralmente as imagens de uma sequência apresentam um grande número de informação que permanece invariável de um quadro para outro.

- Redundância espectral: explora a correlação entre diferentes bandas espectrais ou planos de cores.

- Redundância psico-visual: o sistema visual humano reage com diferentes intensidades às informações visuais contidas em uma imagem. Algumas informações são menos importantes do que outras, possibilitando assim a sua eliminação, sem que haja uma perda de qualidade significativa da imagem.

O processo de compressão pode envolver compressão com ou sem perda de dados, ou ambas. Apesar da compressão sem perdas obter melhores resultados de qualidade, apenas a sua utilização não é suficiente para atender às demandas das aplicações multimídia (HALSALL, 2000). Por outro lado, apesar de reduzir consideravelmente o volume de dados a ser armazenado, a utilização de compressão com perdas pode prejudicar a percpeção correta da profundidade (ANDRADE; GOULARTE, 2010)(WOODS; YUEN; KARVINEN, 2007), pois tem impacto direto na qualidade do vídeo (RICHARDSON, 2003).

\subsubsection{Espaços de cor}

O espaço de cor é um modelo matemático abstrato que descreve a gama de cores como tuplas de números, geralmente formados por 3 ou 4 componentes de cor, no qual, cada eixo deste sistema refere-se a um componente. A quantidade de um componente necessária para formar uma cor é atribuída a um valor sobre o eixo correspondente.

Nesta seção, serão abordados os espaços de cores RGB e YCbCr por serem comumente utilizados na visualização e codificação de imagens e vídeos digitais. Outros modelos de espaços de cores podem ser encontrados na literatura tal como nos textos de Azevedo e Conci (2003) e Feitosa-Santana et al. (2006).

O espaço de cor RGB consiste em três cores primárias aditivas: vermelha (R de red), verde (G de green) e azul (B de blue), no qual seus componentes espectrais são combinados produzindo assim outras cores. O modelo RGB é representado por um cubo tridimensional onde cada componentes situa-se no canto de cada eixo (Figura 16). A cor preta encontra-se na origem enquanto a cor branca encontra-se na extremidade oposta do cubo, ou seja, a cor branca é obtida quando as cores primárias são misturadas em sua intensidade máxima (valor 255, 8 bits). A 
escala de cinza segue a linha do preto ao branco. Em uma imagem de 24 bits ( 8 bits por canal) por pixel, a cor vermelha é representada por $[255,0,0]$, no qual ela é representada pelo valor 1 no cubo, ou seja, $[1,0,0]$.

Figura 16 - Modelo RGB

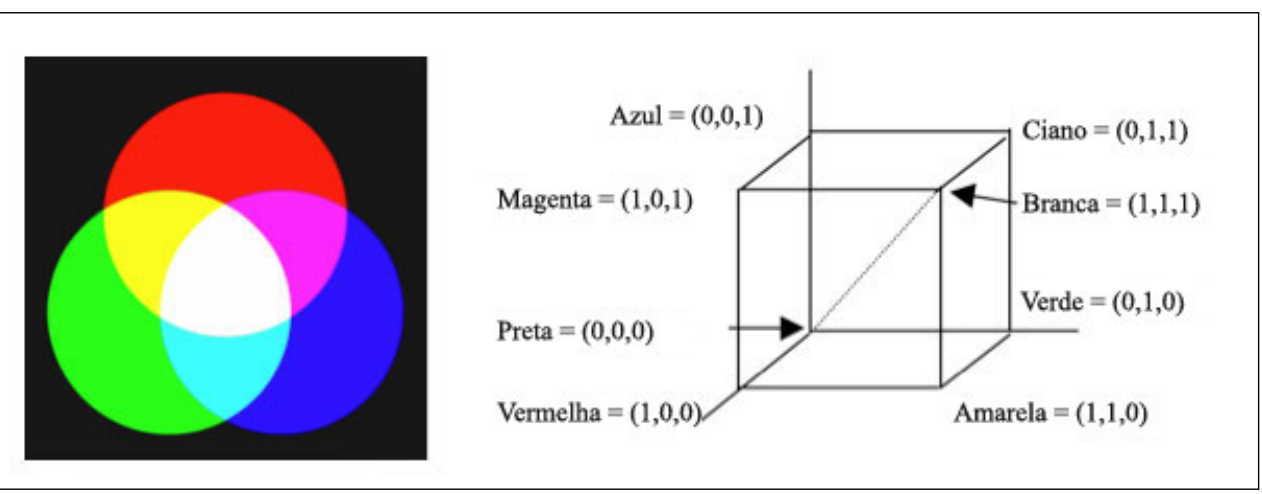

Fonte: Adaptada de Singh et al. (2012).

Este modelo é o mais conhecido e amplamente utilizado por monitores e dispositivos de captura, como por exemplo, câmeras fotográficas (RICHARDSON, 2003).

O espaço de cor YCbCr foi definido devido a crescente demanda por algoritmos digitais a fim de tratar informações de vídeo, e desde então tornou-se um modelo muito utilizado em vídeo digital (SINGH et al., 2012). O YCbCr pertence a família dos espaços de cores para a transmissão de sinal para televisão, no qual pode-se citar também os modelos, YUV e YIQ. A diferença entre eles, se dá pelo modelo YCbCr ser um sistema de cor digital, enquanto o modelo YUV e YIQ são analógicos para os sistemas PAL e NTSC, respectivamente. Estes espaços de cor permitem a separação das informações referentes à luminância das informações referentes à crominância, diferente do RGB no qual a luminância já está associada ao valor de cada componente de cor.

Há uma equivalência matemática entre os padrões RGB e YCbCr (ITU-R, 2002a). Assim os valores das componentes $\mathrm{R}, \mathrm{G}$ e B podem ser convertidas ao espaço de cor YCbCr utilizando a equação Equação 3.1. O processo inverso também se faz possível utilizando a equação Equação 3.2. Cada componente de cor é representada na forma de uma matriz, no qual suas dimensões são as mesmas da imagem que representam. Cada elemento nas matrizes representa um pixel da imagem, sendo assim, cada elemento no espaço RGB possuirá informações sobre cada cor primária no pixel, já no caso do espaço YCbCr o elemento possuirá informações sobre a luminância e a crominância do pixel.

$$
\begin{aligned}
& Y=0,299 R+0,587 G+0,114 B \\
& C b=-0,1687 R-0,3313 G+0,5 B+128 \\
& C r=0,5 R-0,4187 G-0,0813 B+128
\end{aligned}
$$




$$
\begin{aligned}
& R=Y+1,402(C r-128) \\
& G=Y-0,34414(C b-128)-0,71414(C r-128) \\
& B=Y+1,772(C b-128)
\end{aligned}
$$

Sendo:

Y: matriz contendo valores relativos à luminância dos pixels;

$\mathrm{Cb}$ e Cr: matrizes contendo os valores de crominância dos pixels.

R, G e B: matrizes contendo os valores de cor dos pixels de cada componente.

\subsubsection{Subamostragem de crominância}

Como citado na subseção 3.1.1, os componentes do espaço de cor YCbCr carregam em si informações sobre a luminância (Y) e informações de crominância ( $\mathrm{Cb}$ e $\mathrm{Cr}$ ). Obtendo-se separadamente estas informações, é possível explorar uma propriedade do sistema visual humano, que é mais sensível à luminância do que às crominância (SALOMON, 2008). Esta propriedade permite que as informações de crominância (cores) sejam representadas em uma resolução menor do que as informações de luminância (luz), sem causar danos significativos à percepção visual da imagem. Durante a codificação de imagens, este processo é conhecido como subamostragem de crominância (KERR, 2012). De acordo com a subamostragem aplicada, é possível obter uma grande taxa de compressão dos dados a serem armazenados.

Existem diferentes modelos de subamostragem de crominância, no qual, pode-se classificalos de acordo com a quantidade e a forma em que os componentes de crominância são amostrados. A Figura 17 ilustra alguns modelos.

O resultado da aplicação da equação Equação 3.1 é a subamostragem 4:4:4 (para cada amostra de $\mathrm{Y}$, tem-se uma amostra de $\mathrm{Cb}$ e uma de $\mathrm{Cr}$ ), no qual representa um vídeo com a mesma quantidade de informações de luminância e crominância, igualando-se ao modelo RGB. Este modelo não apresenta vantagens e não contribui na compressão, pois, mantém as informações em sua totalidade. Nos formatos 4:4:0 e 4:2:2 (para cada quatro amostras de Y, há duas amostras de $\mathrm{Cb}$ e duas de $\mathrm{Cr}$ ), as amostras de crominância são reduzidas pela metade. A diferença entre estes formatos é dada pela orientação da subamostragem, sendo verticalmente para as amostras 4:4:0 e horizontalmente para as amostras 4:2:2. A mesma razão é aplicada nos modelos 4:2:0 e 4:1:1 no qual as amostras de crominância são reduzidas a um quarto. Por fim, o modelo 4:1:0, reduz as amostras de crominância a um oitavo. É importante destacar que quanto maior a redução das amostras de crominância, maior é a compressão, entretanto, resultará em uma imagem com qualidade inferior.

A subamostragem é uma das etapas no qual ocorre a perda de dados, devido a eliminação dos componentes de cores. O retorno aproximado da imagem $\mathrm{YCbCr}$ subamostrada para o espaço 
Figura 17 - Tipos de subamostragem de crominância

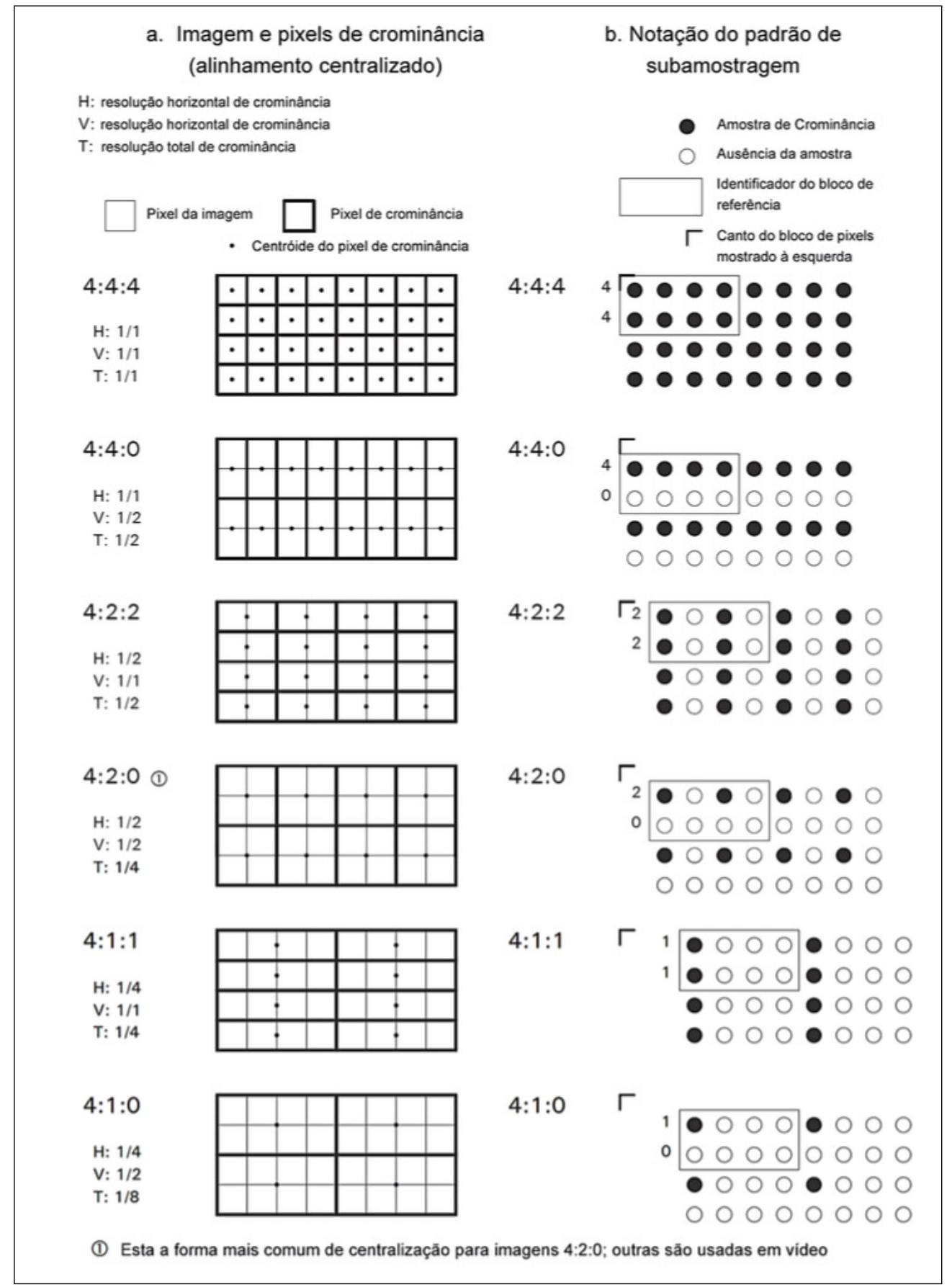

Fonte: Kerr (2012).

de cores RGB, pode ser realizado copiando-se o valor de um dos pixels vizinhos (ou a média entre eles) a cada pixel não amostrado.

\subsubsection{Transformadas matemáticas}

Como citado em seção 3.1, imagens digitais possuem em si dados redundantes, os quais podem ser removidos com a utilização de técnicas de compressão, minimizando assim, a 
quantidade de bytes necessários para representa-las sem degradar a qualidade visual da imagem.

As transformadas matemáticas têm como objetivo procurar informações redundantes na imagem (SYMES, 2003.), a fim de transformar o sinal original em um número reduzido de coeficientes, oferecendo uma maneira de se obter compressão. A utilização de transformadas matemáticas para este fim não é recente, a descoberta da Transformada Discreta dos Cossenos ou Discret Cossine Transform (DCT) em 1974 foi uma conquista importante para a área de compressão de imagens. Em 1992, Joint Photographic Experts Group (JPEG) estabeleceu o primeiro padrão internacional para a compressão de imagens, sendo os codificadores e decodificadores baseados na DCT. Desde então a DCT tem sido utilizada por muitos codificadores de imagem/vídeo, a citar: o JPEG, MPEG e H263 (HALSALL, 2000)(RICHARDSON, 2003). Normalmente a imagem é dividida em blocos de tamanho 8x8 pixels e então todos os blocos, um a um, são submetidos a DCT, que é dada por:

$$
\mathbf{F}[i, j]=\frac{1}{4} C(i) C(j) \sum_{x=0}^{N-1} \sum_{y=0}^{N-1} P[x, y] \cos \frac{(2 x+1) i \pi}{2 N} \cos \frac{(2 y+1) j \pi}{2 N},
$$

sendo:

$$
0 \leq x<8 ; 0 \leq y<8 ; 0 \leq i<8 ; 0 \leq j<8
$$

$$
C(i) e C(j)=\left\{\begin{array}{ll}
\frac{1}{\sqrt{2}} & i, j=0 \\
1 & i, j>0
\end{array} .\right.
$$

A DCT converte os dados de amplitude espacial (os valores dos pixels da imagem) em coeficientes de frequências espaciais, ordenando-os em coeficientes de baixa e alta frequencia, sendo o primeiro coeficiente da DCT (o DC) mais importante do que o $64^{\circ}$ (coeficiente AD de mais alta frequência). Devido a esta hierarquia, pode-se facilmente localizar e eliminar por meio de quantização os coeficientes de alta frequência (redundância psicovisual). Esses últimos não são perceptíveis devido à característica do sistema visual humano que é menos sensível a distorções em regiões com alta frequência espacial, ou seja, se a amplitude, nas altas frequências, está abaixo de um limite, o olho não detecta a informação.

Apesar de ser uma técnica eficiente, quando a Inverse discrete cosine transform (IDCT) é aplicada aos coeficientes quantizados (Equação 3.4), dependendo do grau de compressão, é percepitível a visualização de artefatos que surgem principalmente nos limites dos blocos, efeito intitulado blockiness como é ilustrado na figura Figura 18 (EBRAHIMI; CHAMIK; WINKLER, 2004).

$$
\mathbf{P}[x, y]=\frac{1}{4} \sum_{x=0}^{N-1} \sum_{y=0}^{N-1} C(i) C(j) F[i, j] \cos \frac{(2 x+1) i \pi}{2 N} \cos \frac{(2 y+1) j \pi}{2 N},
$$

onde $0 \leq x<8 ; 0 \leq y<8 ; 0 \leq i<8 ; 0 \leq j<8$; 


$$
C(i) e C(j)=\left\{\begin{array}{ll}
\frac{1}{\sqrt{2}} & i, j=0 \\
1 & i, j>0
\end{array} .\right.
$$

Figura 18 - Efeito blockiness

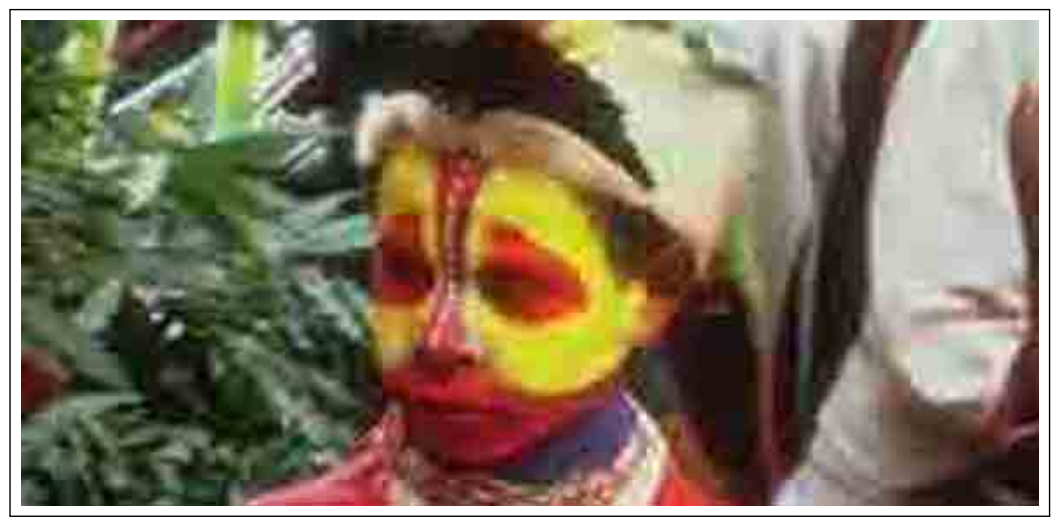

Fonte: Elaborada pelo autor.

A DCT tem sido uma técnica muito utilizada entre os codificadores de imagens/vídeos digitais, entretanto, uma outra transformada tem recebido atenção significativa na área de codificação e compressão de imagens/vídeo e reconhecimento de fala. As transformadas wavelets, também conhecidas como Discrete Wavelet Transform (DWT) exploram tanto a correlação espacial, quanto a correlação de frequência por meio de dilatações (ou contrações) e translações da wavelet mãe aplicada ao sinal de entrada. O conceito principal da transformada wavelet é decompor o sinal de entrada hierarquicamente em componentes de resolução inferior, possibilitando não apenas a análise multiresolução, mas também a transmissão progressiva da imagem. A implementação da wavelet é dada por meio de um banco de filtros digitais passa-baixa (L de low) e outro passa-alta (H de high). A Figura 19 ilustra o exemplo de uma transformada wavelet discreta aplicada a uma imagem bidimensional. A filtragem realizada por meio dos filtros passa-baixa, geram os coeficientes de aproximação, enquanto os filtros passa-alta, resultam nos coeficientes de detalhes. Os coeficientes de aproximação (LL) representam a tendência geral dos valores dos pixels, enquanto os coeficientes de detalhes representam os detalhes verticais (LH), horizontais (HL) e diagonais da imagem (HH).

Após cada iteração, o sinal é subamostrado pelo fator 2, podendo os coeficientes de aproximação serem novamente processados como novos dados de entrada para um banco de filtros subsequente, resultando em um outro conjunto de coeficientes de aproximação e de detalhes em um nível de resolução inferior ao atual.

A cada nível, os coeficientes de aproximação e de detalhes contêm as informações necessárias para reconstruir os coeficientes de aproximação e de detalhes do próximo nível de maior resolução (VILLASENOR; BELZER; LIAO, 1995). Em razão das suas propriedades, as wavelets apenas reorganizam as informações (não alterando-as) do sinal, concentrando sua 
Figura 19 - DWT aplicada a uma imagem bidimensional

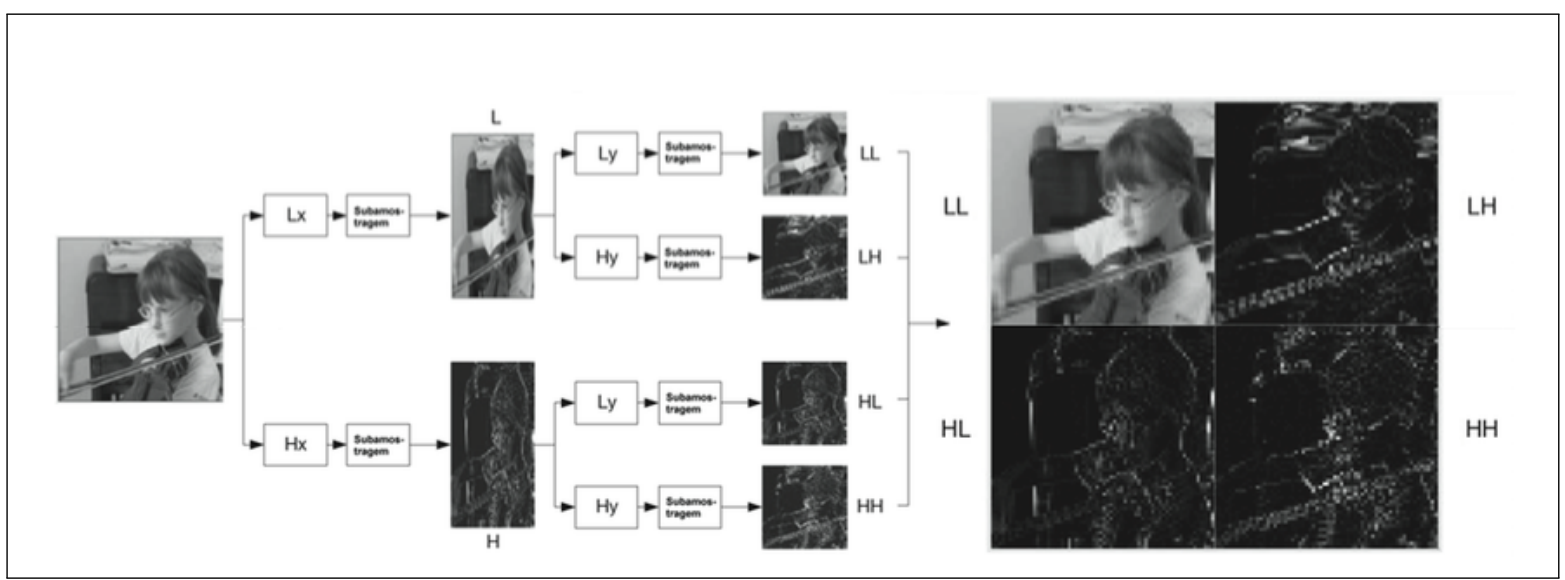

Fonte: Andrade (2012).

Figura 20 - Iterações DWT - sinal de entrada (s); banco de filtros passa-alta (h); banco de filtros passa-baixa (1); coeficientes de detalhes (d); coeficientes de aproximações (a).

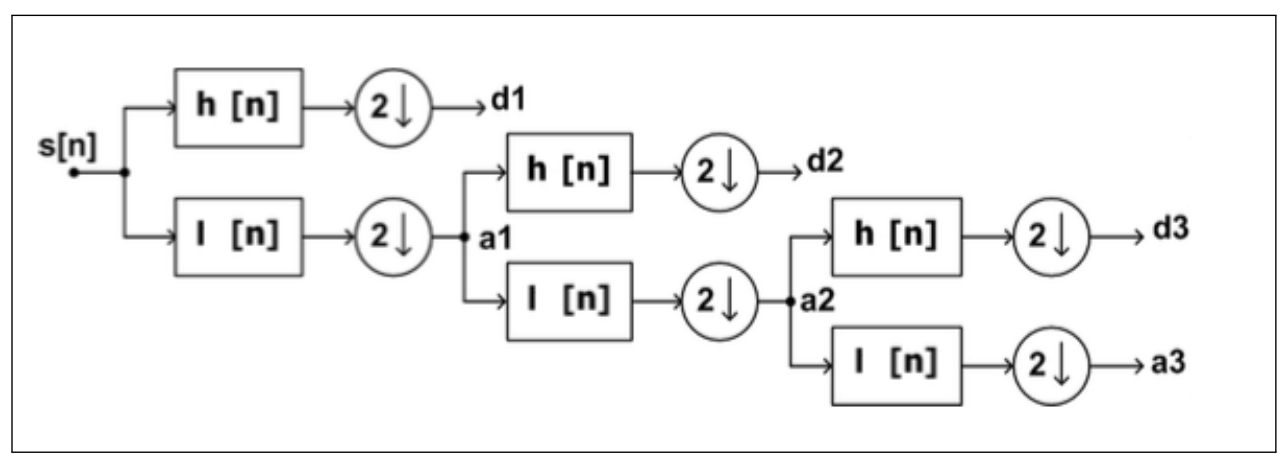

Fonte: Adaptada de Fugivara, Moraes e Almeida (2008).

maior energia nos coeficientes de aproximação (baixas frequências - LL). Adicionalmente, os coeficientes resultantes apresentam uma organização hierárquica em árvores, possibilitando que métodos de codificação explorem o grau de importância das informações (SHAPIRO, 1993).

A primeira wavelet ortogonal compacta (wavelet Haar) foi desenvolvida pelo húngaro Alfred Haar enquanto trabalhava na construção de bases para a representação de funções integráveis quadraticamente. Apesar da teoria ser conhecido desde 1910, as wavelets só ganharam a atenção da comunidade de processamento de sinais em 1986, quando Stéphane Mallat e Yves Meyer introduziram o conceito de análise em multiresolução, proporcionando uma explanação para a construção de wavelets e disponibilizando uma ferramenta para a construção de outras bases (DAUBECHIES, 1992).

$\mathrm{Na}$ forma discreta, a wavelet Haar é relacionada a operações matemáticas chamadas Transformada Haar e os coeficientes são gerados por meio da média (coeficientes de aproximações) e da diferença e divisão por 2 (coeficientes de detalhes) entre os pares de pixels. As equações Equação 3.6 e Equação 3.7, representam o comportamento da wavelet Haar em sua 
decomposição. Considere $S_{n}$ um vetor com $n$ elementos representantes do sinal

$$
\begin{gathered}
\mathbf{S}_{n}=\left(s_{1}, s_{2}, s_{3}, \ldots, s_{n}\right) \\
\mathbf{M}_{n / 2}=\left(m_{1}, m_{2}, \ldots m_{n / 2}\right)=\left(\frac{s_{1}+s_{2}}{2}, \frac{s_{3}+s_{4}}{2}, \ldots \frac{s_{n-1}+s_{n}}{2}\right) \\
\mathbf{D}_{n / 2}=\left(d_{1}, d_{2}, \ldots d_{n / 2}\right)=\left(\frac{s_{1}-s_{2}}{2}, \frac{s_{3}-s_{4}}{2}, \ldots \frac{s_{n-1}-s_{n}}{2}\right)
\end{gathered}
$$

sendo:

$n$ : número de elementos do vetor;

$M$ : vetor contendo as médias dos pares de pixels;

$D$ : vetor contendo as diferenças dos pares de pixels.

Assumindo que um vetor possui os valores [ $\left[\begin{array}{lll}9 & 7 & 3\end{array}\right.$ 5], primeiramente é realizada a média entre os pares de pixels [9 7] e [3 5], resultando nos coeficientes de aproximação [8] e [4], posteriormente os coeficientes de detalhes são obtidos pela diferença e divisão por 2 dos pares, no quais resultam em [1] e [-1].

Os valores [8 4 ll -1] representam a mesma informação, porém, em uma menor resolução. Entretanto, com a aplicação da é possível recuperar a informação em sua resolução original efetuando a soma entre a média do par e diferença do par, para obter-se o primeiro valor, e a diferença entre média do par e a diferença do par, para obter-se o segundo valor como é representado na Equação 3.8 .

$$
\mathbf{S}_{n}=\left(m_{1}+d_{1}, m_{1}-d_{1}, m_{2}+d_{2}, m_{2}-d_{2}, \ldots, m_{n / 2}+d_{n / 2}, m_{n / 2}-d_{n / 2}\right)
$$

O valor [3] é recuperado utilizando a soma entre a média do seu par [4] e o seu coeficiente de detalhe [-1], ou seja, 4+(-1), já o valor [5] é recuperado utilizando a diferença entre a média do seu par [4] e o seu coeficiente de detalhes [-1], ou seja, 4 - (-1). O mesmo é aplicado para recuperação dos valores [9 7], sendo, 8+1 e 8-1 respectivamente. Apesar de apenas uma iteração ter sido realizada neste exemplo, os valores 8 e 4 (coeficientes de aproximações) podem novamente servir de entrada para que o processo seja repetido. Sendo assim, o segundo nível de

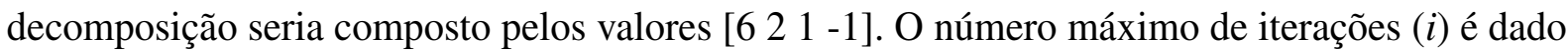
por $2_{i}=N$, sendo $N$ a quantidade total de elementos contidos no fluxo de entrada. A Figura 21 ilustra os valores de um vetor em 3 níveis de decomposição, sendo os coeficientes de detalhes os valores em negrito em cada iteração.

Atualmente existem diferentes wavelets que podem ser utilizadas para fins de compressão, cada uma com diferentes graus de suavidade da onda, compressão e parâmetros. Uma análise 
Figura 21 - DWT Haar em 3 níveis de decomposição

\begin{tabular}{|rrrrrrrr|}
\hline 576 & 704 & 1152 & 1280 & 1344 & 1472 & 1536 & 1536 \\
\hline 640 & 1216 & 1408 & 1536 & -64 & -64 & -64 & 0 \\
\hline 928 & 1472 & -288 & -64 & -64 & -64 & -64 & 0 \\
\hline 1200 & -272 & -288 & -64 & -64 & -64 & -64 & 0 \\
\hline
\end{tabular}

Fonte: Tamboli e Udupi (2013).

sobre aplicação de diferentes DWTs no processo de compressão espacial estereoscópica pode ser encontrada no trabalho realizado por Andrade (2012). A análise realizada teve como objetivo determinar quais DWTs obtêm os melhores resultados objetivos, subjetivos e de compressão.

\subsubsection{Quantização}

No processo de quantização, valores discretos são utilizados para representar um sinal cuja amplitude pode variar entre valores infinitos (JAYANT, 1976). Cada amplitude é alocada ao nível de quantização mais próximo, possibilitando a redução no tamanho das informações. $\mathrm{O}$ número de bits definidos na utilização da codificação resultam em um conjunto de níveis, ou seja, caso o número de bits do sinal quantizado seja 8 , o sinal conterá 256 níveis possíveis.

A quantização causa perda de dados e introduz erros, também chamados de ruídos, entre o sinal original e o sinal quantizado (SEALES; YUAN; BROWN, 1997). Como esta operação é irreversível, a quantização acarreta em uma compressão de dados com perdas. Um mesmo método de quantização pode ocasionar diferentes taxas de erros dependendo do sinal a ser considerado, sendo necessário a busca pelo melhor método de quantização a fim de reduzir os erros provenientes deste processo. A quantização escalar e a quantização vetorial, visam reduzir os ruídos introduzidos no processo de quantização e adequam-se a diferentes tipos de sinais. A quantização escalar efetua a quantização individual de cada amostra, enquanto a quantização vetorial realiza a quantização em um conjunto de blocos de amostras. Em um mesmo esquema de codificação, pode-se afirmar que a quantização vetorial produz resultados iguais ou superiores a quantização escalar, porém, em alguns casos, a complexidade adicional de sua implementação a torna inviável levando-se em consideração o ganho em termos de compressão.

Em compressão espacial de imagens a quantização está associada às tranformadas matemáticas, onde as imagens são divididas em macroblocos de dimensões quadradas e seus valores são transformados. Entre as transformadas comumente utilizadas pode-se citar a DCT e DWT (GONZALEZ; WOODS, 2008), nas quais são abordados na subseção 3.1.3. Após a aplicação da transformada, os macroblocos resultantes são divididos por uma matriz de quantização de mesma dimensão. Esta divisão resulta no surgimento de valores zero na matriz resultante, diminuindo a quantidade de dados a serem armazenados e consequentemente contribuindo na compressão dos 
dados.

Os métodos de quantização relacionados às transformadas wavelets aplicados a dados estereoscópicos desenvolvidos por Nayan, Edirisinghe e Bez (2002) e Thanapirom, Fernando e Edirisinghe (2005) são baseados em três etapas. A primeira etapa a ser realizada é a divisão da imagem em macroblocos (cuja dimensão tradicional é $8 \times 8$ pixels), posteriormente a aplicação de $N$ níveis da DWT é feita sobre os macroblocos. Finalmente os macroblocos resultantes são submetidos uma divisão entre eles e uma constante (THANAPIROM; FERNANDO; EDIRISINGHE, 2005) ou por uma matriz com valores positivos (NAYAN; EDIRISINGHE; BEZ, 2002). A abordagem prosposta por Nayan, Edirisinghe e Bez (2002), considera a aplicação de três níveis fixos da DWT para cada macrobloco, enquanto a abordagem de Thanapirom, Fernando e Edirisinghe (2005) utiliza aplicação de mais de três níveis da DWT para geração de árvores de wavelets, acarretando um aumento no tempo de execução do método.

A matriz de quantização proposta por Nayan, Edirisinghe e Bez (2002) ilustrada na Figura 22, está dividida em subáreas relacionadas a aplicação de três níveis da DWT ao macrobloco da imagem.

Figura 22 - Matriz de quantização proposta por Nayan et al.

$Q_{D W T}=\left[\begin{array}{ccc|cc|cccc|}8 & 7 & 8 & 8 & 34 & 34 & 34 & 34 \\\right.$\cline { 1 - 3 } 7 & 7 & 8 & 8 & 34 & 34 & 34 & 34 \\ \cline { 1 - 3 } 8 & 8 & 12 & 12 & 34 & 34 & 34 & 34 \\ 8 & 8 & 12 & 12 & 34 & 34 & 34 & 34 \\ \hline 34 & 34 & 34 & 34 & 55 & 55 & 55 & 55 \\ 34 & 34 & 34 & 34 & 55 & 55 & 55 & 55 \\ 34 & 34 & 34 & 34 & 55 & 55 & 55 & 55 \\ 34 & 34 & 34 & 34 & 55 & 55 & 55 & 55\end{array}$]$

Fonte: Adaptada de Nayan, Edirisinghe e Bez (2002).

Tanto a Figura 23 (A e B), ilustram as subbandas advindas da aplicação de três níveis de DWT em um macrobloco com dimensões 8 x 8 pixels. Adicionalmente, a Figura 23 (B), ilustra também a quantidade de elementos pertencentes a cada uma das setes subbandas geradas, juntamente com organização dos coeficientes gerados em ordem de importância. A primeira subbanda é representada pelas áreas numeradas de 1 à 4 (LL3, HL3, LH3 e HH3), a segunda e terceira subbanda são representadas pelas áreas 5 (HL2) e 6 (LH2), a quarta subbanda é representada pela área 7 (HH2), a quinta e a sexta subbanda são representadas pelas áreas 8 (HL1) e 9 (LH1) e por fim a sétima subbanda é representada pela área 10 (HH1).

Como pode ser observado na Figura 22, os coeficientes mais importantes sofrem uma quantização mais suave em relação aos coeficientes menos importantes. Relacionando os valores 
Figura 23 - Subáreas da matriz de quantização

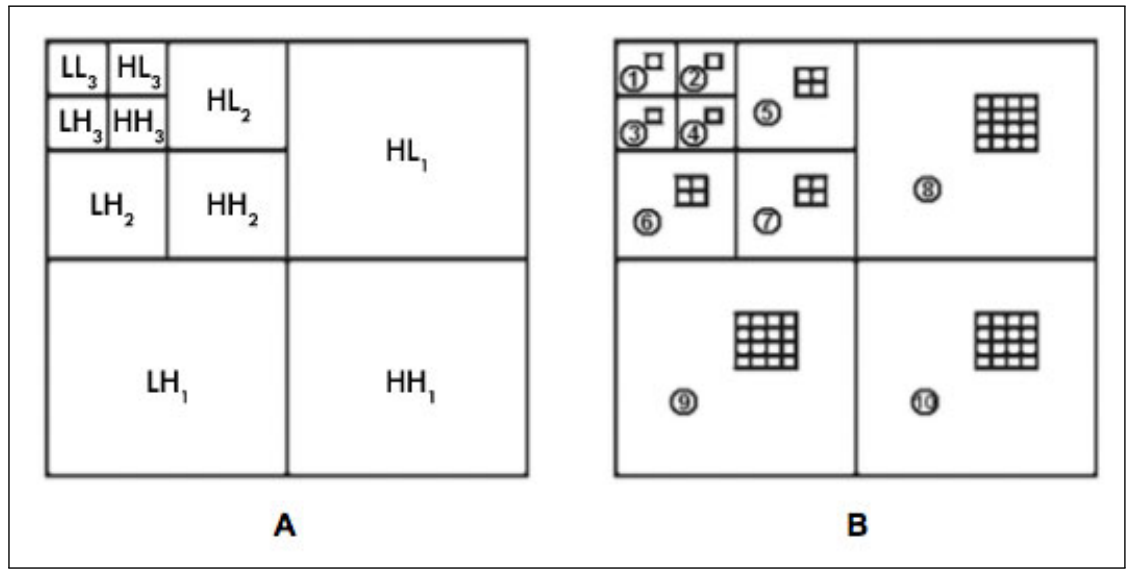

Fonte: Adaptada de Andrade (2012).

das áreas numeradas de 1 à 10 da Figura 23 (B), com os valores da matriz de quantização representrados na figura Figura 22, para a primeira subbanda seriam atribuídos os valores 8, 7, 7 e 7; para a segunda e terceira subbandas seria atribuído o valor 8; para a quarta subbanda seria atribuído o valor 12; para a quinta e sexta subbandas, seria atribuído o valor 34, e para a sétima seria atribuído o valor 55. Os blocos processados são transformados em vetores nos quais a sua ordem de leitura é dada pela ordem de importância dos coeficientes. A Figura 24 apresenta a ordem de leitura realizada em uma imagem reorganizada pela aplicação de três níveis de uma DWT.

Figura 24 - Ordem de construção de um vetor, sendo a leitura realizada em uma imagem processada por três níveis de uma DWT

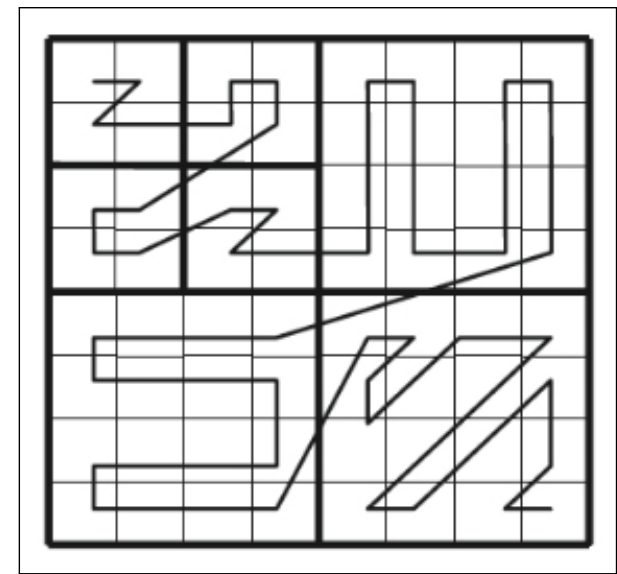

Fonte: Nayan, Edirisinghe e Bez (2002, p. 3).

\subsubsection{Codificação por entropia}

A codificação por entropia visa a compressão dos dados e pode ser aplicada a qualquer tipo de informação binária, não resultando na perda de informações (HALSALL, 2000). Existem três tipos principais de codificação por entropia, sendo elas: técnicas de supressão de sequências 
repetitivas, técnicas de codificação estatística e técnicas baseadas em dicionários (RIBEIRO; TORRES, 2007). A técnica de supressão de sequências repetitivas funciona em dois passos e baseia-se na produção de códigos de comprimento fixo. Inicialmente é realizada a detecção de sequências repetitivas de bits/bytes. Em seguida, é feita a substituição destas sequências pela quantidade de vezes no qual o número se repete. A supressão de sequências repetitivas é dividida em duas técnicas: a técnica de supressão de zeros/espaços e técnica de codificação por carreiras - Run-Lenght Encoding (RLE). No primeiro caso o método assume apenas um caractere (byte) predeterminado que aparece frequentemente e é repetido. Em dados numéricos este caractere pode ser zero ou espaços em dados textuais. Assim, uma série de $n$ espaços, ou zeros, sucessivos é substituído por um caractere especial (flag ou meta character) seguido pelo número de ocorrências desse caractere. A codificação por carreira possibilita que qualquer sequência de caracteres repetidos seja substituído por uma forma abreviada, não limitando-se apenas a zeros ou espaços. Consequentemente, esta técnica baseia-se em substituir uma série de $n$ caracteres $c$ consecutivos, pelo próprio caractere $c$ precedido por um carácter especial (a flag ou escape character) que, por sua vez, é seguido pelo número $n$ de ocorrências do caractere repetido. Este grupo de 3 caracteres no qual substitui a sequência repetida, é chamado token, e representa-se pelo caracter !. Esta técnica não deve ser utilizada em casos, nos quais o caractere é repetido apenas duas vezes, visto que resultaria em uma sequência menos comprimida do que a sequência original. Igualmente, a sua utilização em sequências de três caracteres sucessivos não acarreta nenhuma vantagem. Sendo assim, conclui-se que a sua aplicação deve ser realizada caso o número de ocorrências sucessivas de um caractere seja igual ou superior a quatro.

Na codificação estatística, os padrões de bits ou bytes são substituídos de acordo com a frequência com que ocorrem, sendo este o motivo porque se designa codificação estatística. As técnicas de codificações estatísticas baseiam-se, primeiramente, em identificar os padrões de bits ou bytes que ocorrrem com mais frequência em um determinado fluxo de dados e, posteriormente, realizar a codificação de cada padrão com um número menor de bits do que o número de bits necessários para representar o fluxo de dados original. Os padrões mais frequentes utilizam códigos menores, enquanto os padrões menos frequentes utilizam códigos maiores para a sua representação. Há várias formas nas quais a codificação estatística pode ser implementada, incluindo-se a substituição de padrões (destinada exclusivamente à codificação de informação textual), codificação de comprimento variável, sendo Huffman e Shannon-Fano os métodos mais conhecidos e a codificação aritmética que propicia uma ótima compressão do ponto de vista do valor de entropia de uma sequência de dados, determinado pelos métodos da teoria da informação (RIBEIRO; TORRES, 2007).

As técnicas baseadas em dicionários utilizam uma seleção de sequências de símbolos e uma codificação destas sequências como um token, recorrendo a um dicionário para armazenar as sequências de símbolos. Entre os métodos mais utilizados encontra-se o

Após a codificação por entropia, existem meios de se organizar em arquivo as informações 
do par estéreo, objetivando-se armazena-las no disco ou transmiti-las pela rede. Os modos de organização de informações estereoscópicas são descritos na seção 3.2.

\subsection{Organização dos dados estereoscópicos}

A atenção e o apelo comercial voltado ao vídeo 3D tem novamente crescido, como é visto principalmente na produção de filmes em 3D para o cinema e nas ofertas de televisores de alta definição que possibilitam a sua reprodução. Com isso, foi necessário o desenvolvimento de outros métodos de codificação de vídeo para suprir as novas tecnologias que vêm surgindo. Atualmente, novos modos de codificação estão sendo definidos e outros ampliados, porém, cada um visa atender um tipo específico de aplicação ou técnica estereoscópica. Apresenta-se nesta seção algumas dessas codificações como expostas por (SMOLIC et al., 2009)(FEHN et al., 2002)(VETRO; WIEGAND; SULLIVAN, 2011), divididas, em convencional, na qual os vídeos não sofrem alteração no formato de representação e a baseada em vídeo e profundidade, em que novas camadas de dados estão presentes junto ao sinal de vídeo.

\subsubsection{Codificação convencional}

É a codificação mais comum e utilizada na produção de vídeos para canais de TV e filmes. Pode ser subdividida em Conventional Stereo Video (CSV) e Multiview Video Coding (MVC) (SMOLIC et al., 2009). A CSV utiliza dois vídeos de uma mesma cena, cujas imagens apresentam diferentes ponto de vista, tendo como objetivo apresentar um vídeo distinto para cada olho. Criado por Lipton (1997) os dados estéreos podem ser organizados em lado-a-lado, sobreposto ou entrelaçado. Como ilustrado na Figura 25, a diferença entre os modos lado-a-lado e o sobreposto se dá pela forma no qual os dados são armazenados, sendo o par estéreo armazenado horizontalmente ou verticalmente, respectivamente.

Em ambos formatos a ordem convencional para o armazenamento das visões é: direita e esquerda. No modo entrelaçado, ambas visões são armazenadas em um único vídeo bidimensional, sendo que as linhas ímpares são as informações correspondentes ao olho direito e as linhas pares referentes ao olho esquerdo (Figura 26).

A desvantagem da codificação CSV, é que a mesma cena é vista pelo usuário independente da posição onde ele se encontra frente à tela.

\subsubsection{Codificações em múltiplas visões}

A MVC surge como uma extensão da CSV, com o objetivo de utilizar mais de duas visões para uma mesma cena, conseguindo fornecer diferentes pontos de vista baseado na localização do usuário em frente à tela, o que é denominado Free Viewpoint Video (FVV). Para tal, se faz necessário a captação sincronizada de diversas câmeras posicionadas sequenciamente a uma 
Figura 25 - Par estéreo armazenado lado-a-lado e sobreposto

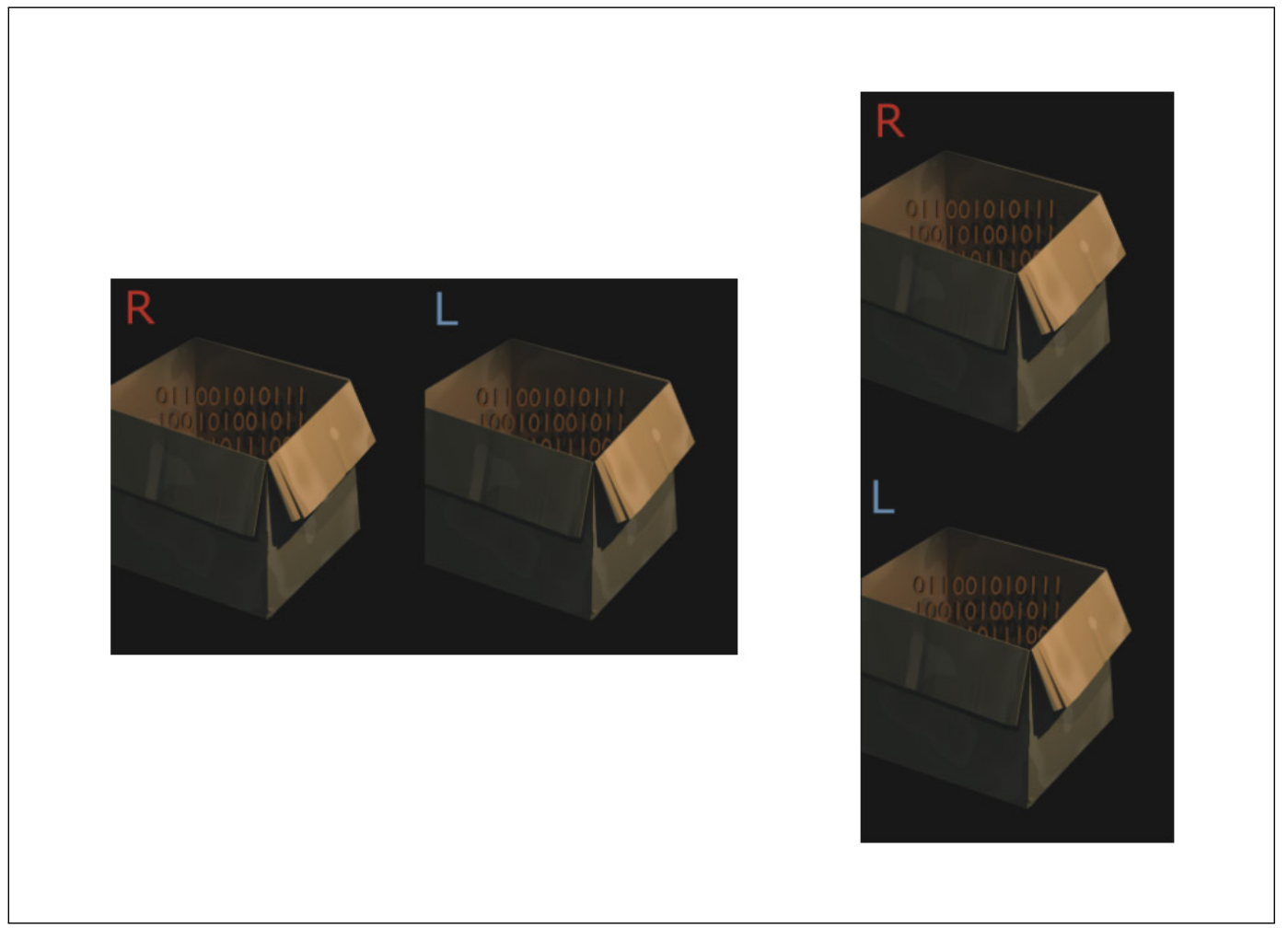

Fonte: Andrade (2012).

Figura 26 - Par estéreo armazenado entrelaçado

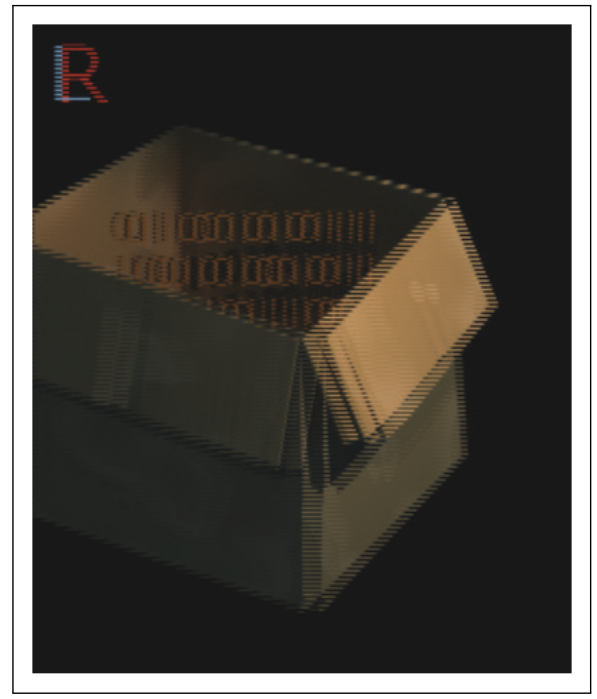

Fonte: Andrade (2012).

distância determinada. Neste método há um aumento significativo no volume de dados, já que cada visão carrega consigo um par estéreo. Por fornecer diferentes pontos de vista, a multivisão é uma tendência de uso em dipositivos autoestereoscópicos.

A maioria das técnicas que utilizam MVC, exploram não apenas as redundâncias temporariais existentes entre os quadros de uma determinada visão, mas também as semelhanças 
entre os quadros sucessivos, utilizando a abordagem de compressão espacial, temporal e de disparidade.

O problema da codificação em múltiplas visões encontra-se no número de pontos de vista limitado e que acarreta um aumento no tamanho do arquivo final dependendo do número de vídeos comportados. Normalmente, a quantidade de visões codificadas de maneira eficaz é limitada a duas ou três visões (MULLER; MERKLE; WIEGAND, 2011).

\subsubsection{Codificação baseada em vídeo e profundidade}

Na codificação baseada em vídeo e profundidade, além do vídeo bidimensional, é enviado um sinal contendo um mapa de profundidade. Neste caso, em vez de armazenar-se o par estéreo, armazena-se apenas um dos sinais de vídeo junto com seu respectivo mapa de profundidade de pixels, o qual pode ser entendido como um sinal de vídeo auxiliar, com dados monocromáticos, em que o valor do pixel pertecente a um intervalo em entre dois extremos, denominados $Z_{\text {near }}$ e $Z_{\text {far }}$, indicando a sua distância em relação à câmera de captura. Os valores de profundidade do pixel são representados com 8 bits, sendo o ponto mais próximo representado pelo valor 255 e o ponto mais distante representado pelo valor 0 . Assim, o mapa de profundidades é uma imagem em tons de cinza. A Figura 27 apresenta um exemplo de duas imagens codificada com esta técnica.

Figura 27 - Codificação mapa de profundidades

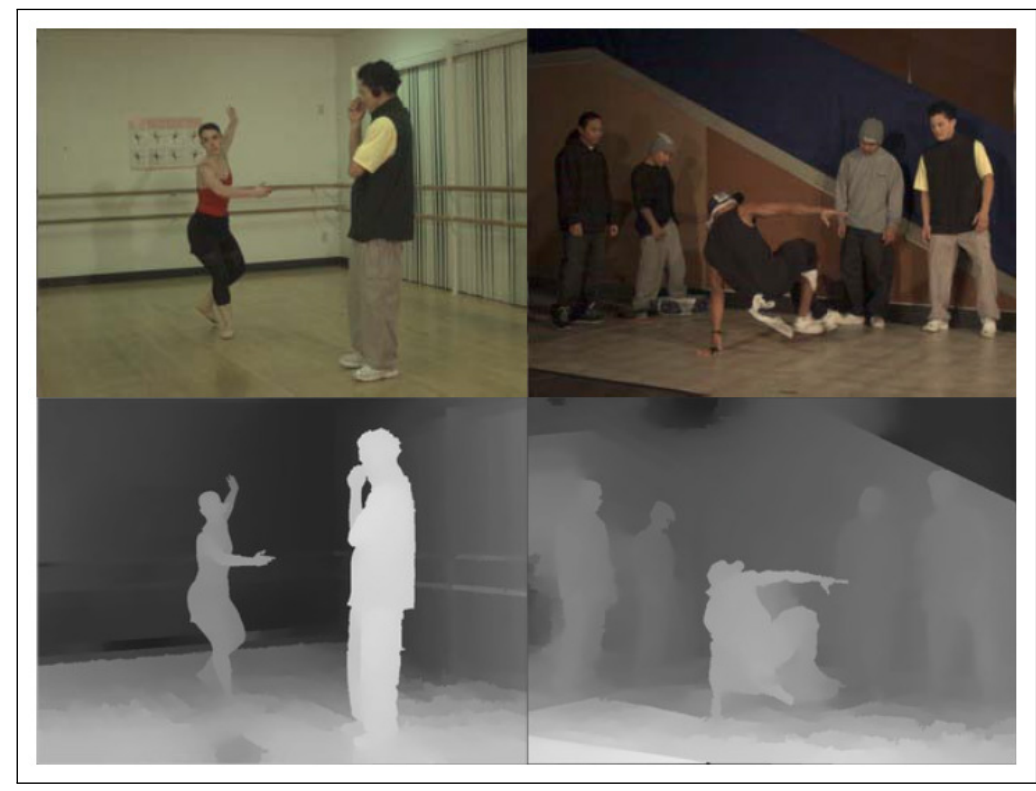

Fonte: Zhan-wei et al. (2007).

O projeto Advanced Three-Dimensional Television System Technologies (ATTEST)(REDERT et al., 2002), é um dos primeiros trabalhos com este tipo de organização. Neste projeto, ao mesmo tempo em que a câmera captura o sinal de vídeo RGB, o infravermelho (acoplado a câmera) efetua a mapeamento do ambiente, gerando outro sinal de vídeo contendo dados de distancia- 
mento dos objetos em relação a câmera. Mediante ao mapa de profundidades, é possível recriar o segundo vídeo do par estéreo, ou até mesmo novas visões. Por conter apenas dados de luminância, possui tamanho menor em relação a um vídeo colorido (o segundo vídeo do par estéreo, neste caso). O mapa de profundidades é obtido com cálculos que mapeiam a cena fazendo a estimativa de disparidade e profundidade dos objetos nela contidos. Esses cálculos oneram o dispositivo por adicionarem processos de síntese e rendering tanto na codificação quanto no processo reverso. Além disso, os algoritmos são complexos e ainda propensos a erros e podem ser divididos em três: Video Plus Depth (V+D), MultiView Plus Depth (MVD) e Layered Depth Video (LDV) (SMOLIC et al., 2009).

$\mathrm{O} \mathrm{V}+\mathrm{D}$ foi o primeiro disponível e cuja funcionalidade foi supracitada: junto ao sinal do vídeo segue um mapa de profundidades que habilita o dispositivo à criação do segundo vídeo tendo em vista a produção da estereopsia.

Uma extensão do anterior, o MVD combina enviar no sinal de vídeo múltiplas visões de uma mesma cena, cada qual com seu próprio mapa de profundidades. Novas visões podem ser criadas combinando-se duas outras existentes. Com isso, tem-se a possibilidade de disponibilizar várias visões ao usuário, sendo uma boa opção a ser utilizada por monitores autoestereoscópicos.

O LDV inclui no sinal, além da camada do vídeo e seu mapa de profundidades, nomeadas como visão principal, novas camadas responsáveis por outras visões, como dados contendo informações referentes à cena vista de outras direções. Tudo isso é processado para a criação de diferentes visões. A complexidade dos algoritmos aumenta, porém, o arquivo final é menor do que o do MVD pois, as camadas conseguem eliminar visões que elas mesmas conseguem processar. Apesar de diminuir em dois terços em média os dados do segundo vídeo do par-estéreo, as desvantagens gerais deste método de codificação, são os algoritmos complexos e ainda propensos a erros, passíveis de um melhor estudo. Além disso, tem-se alta carga de processamento, tanto no lado transmissor quanto no receptor, exigindo equipamentos mais robustos e caros.

\subsection{Compressão}

Nesta seção serão abordados métodos de compressão espacial e temporal 2D, os quais podem ser utilizados tanto para imagens/vídeos $2 \mathrm{D}$, quanto para vídeos estereoscópicos. Adicionalmente, são apresentadas técnicas que exploram redundâncias características de vídeos estereoscópicos.

\subsubsection{Compressão 2D}

Um fluxo de vídeo, é na verdade uma sequência de imagens. Tais imagens, também conhecidas como quadros, quando exibidas a certa frequência, passam a sensação de movimento. Tendo isso em vista, o primeiro passo na compressão de vídeo digital, é utilizar em cada quadro a compressão aplicada em imagens para eliminar as informações de redundância que estas 
apresentam - a chamada compressão espacial. Isso pode envolver tanto métodos de compressão sem perdas, quanto com perdas, o que influencia na qualidade da imagem resultante.

O processo de compressão de imagens envolve aplicar um método de a redução do espaço de cor (subseção 3.1.1), tendo em vista diminuir a quantidade de informações para promover compressão, sendo portanto com perdas. Logo após, há aplicação de uma transformada, uma função matemática que muda a representação dos dados em função da sua freqüência, e posterior quantização, que visa eliminar as frequências mais altas do que um certo limiar. Dependendo do limiar estabelecido, o olho humano pode não perceber diferenças significativas, ou seja, obtém-se maior ou menor qualidade. Exemplos de transformadas comumente utilizadas são descrita na subseção 3.1.3. Vale lembrar que a compressão é feita na etapa de quantização, a qual elimina dados - método com perdas. Por fim, realiza-se a remoção de redundância estatística, sem perda, a qual atribui o número de bits para o código gerado para cada dado conforme a frequência deste dado. Dados mais frequentes possuem códigos com menos bits e dados menos frequentes possuem códigos com um número maior de bits, garantindo assim compressão. Das técnicas estatísticas, as mais conhecidas são Huffman, LZW e Run-length (GONZALEZ; WOODS, 2008).

Além de aplicar a compressão em cada imagem, os vídeos possuem um outro tipo de redundância a ser explorada: a redundância temporal. Esta é representada pela similaridade entre quadros vizinhos em uma sequência. Como os quadros adjacentes são similares, codificase apenas alguns quadros e prediz-se como serão os próximos, reduzindo a quantidade de informação a ser codificada.

Na compressão temporal, os quadros são classificados em I, P ou B (CHAPMAN; CHAPMAN, 2004). Os quadros I (Intracoded frames) são aqueles que sofrem apenas a compressão espacial. Os quadros P (Predictive frames) são codificados em relação a um quadro I ou P, obtendo-se uma estimativa do que mudou entre ele e seu antecessor (estimativa de movimento), ou seja, excluí-se este quadro restando apenas com os dados da estimativa de movimento. Como essa predição envolve erros, é também codificada uma tabela de compensação de movimento, contendo a diferença entre a posição estimada e a posição real dos objetos. Como outros quadros $\mathrm{P}$ podem ser codificados a partir de um quadro $\mathrm{P}$ anterior, há uma propagação de erros, e por essa razão, deve-se estabelecer um limite de criação de quadros $\mathrm{P}$ consecutivos, chamado de Prediction Span. Por fim, os quadros B (Bidirectional frames) são codificados tanto em relação ao um quadro $\mathrm{P}$ ou I anterior quanto em relação a um quadro $\mathrm{P}$ ou I posterior, obtendo-se uma taxa maior de compressão, porém, impactando no tempo de processamento, já que é necessário aguardar que os quadros $\mathrm{P}$ ou I posteriores serem processados para o seu cálculo.

Padrões de compressão de vídeo tais como, MPEG (1, 2 e 4) e H.26x (H.261, H.262), utilizam como base o processo de compressão espacial e temporal descrito. 
Figura 28 - Compressão IPB

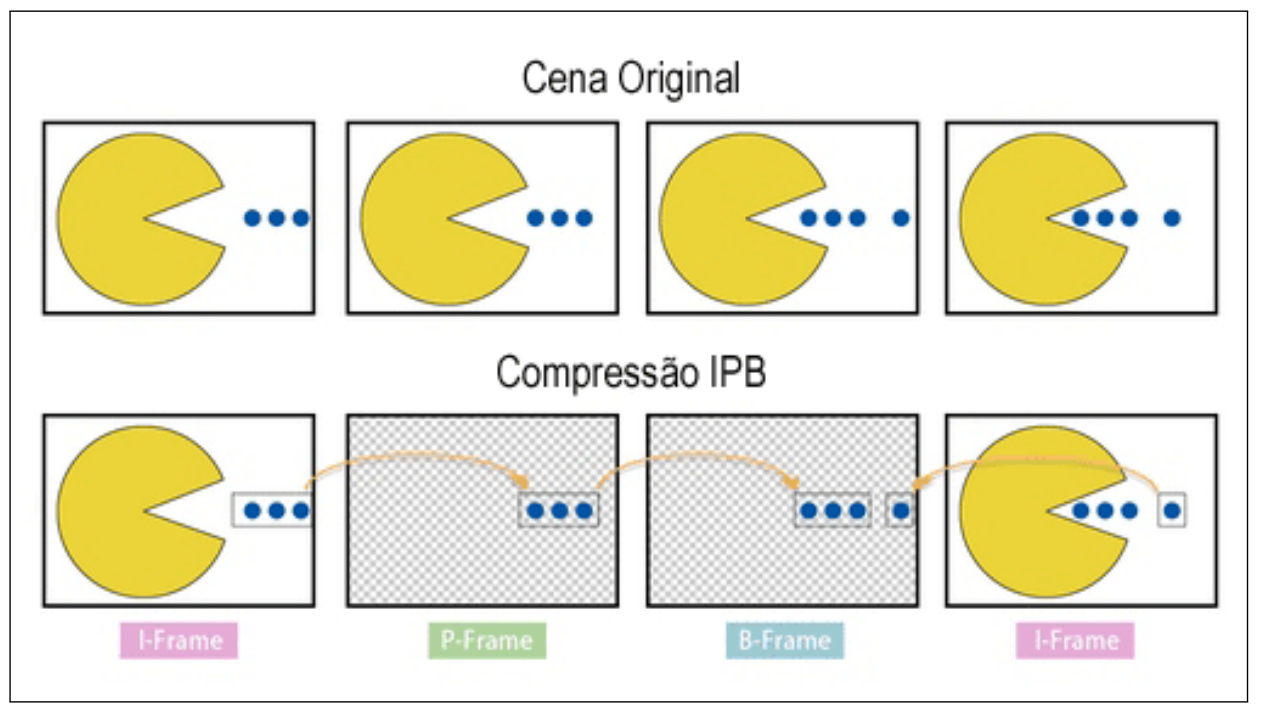

Fonte: Adaptada de Canon (2010).

\subsubsection{Compressão estereoscópica}

Com abordado na seção 3.2, há diversas maneiras de organizar informações estereoscópicas, da mesma forma, a compressão estereoscópica pode ser realizada de diferentes modos. Uma primeira abordagem é aplicar métodos de compressão para vídeos bidimensionais diretamente no par estéreo. O problema com essa abordagem é que o nível de compressão obtido não é suficiente já que o par estéreo possui no mínimo o dobro de informações de um vídeo bidimensional.

Similar à redundância espacial, os vídeos estereoscópicos que carregam consigo o par estéreo, são acrescidos de uma redundância não presente em vídeos bidimensionais, a redundância entre as visões (inter-view). Devido ao par estéreo ser composto por duas imagens muito semelhantes, que diferem apenas pelo deslocamento horizontal resultante pela distância no qual cada imagem foi capturada. É possível predizer uma das imagens baseando-se na outra, desta forma, não se faz necessário o armazenamento de ambas imagens. Tal processo, denominado predição entre as visões é ilustrado na Figura 29 (VETRO; WIEGAND; SULLIVAN, 2011).

Um dos fluxos do vídeo é codificado em quadros I, P e B, conforme abordado na subseção 3.3.1 e é denominado visão base, já o fluxo de vídeo complementar é denominado visão virtual e é composto por quadros $\mathrm{P}$ e $\mathrm{B}$. Na visão virtual os quadros $\mathrm{P}$ são gerados por meio de seu quadro correspondente na visão base, enquanto, os quadros B são gerados de um quadro correspondente na visão base juntamente com um quadro anterior na visão virtual. Por utilizar apenas compressão bidimensional, a visão base é compatível com dispositivos que não reproduzem vídeos multivisão e estereoscópicos. A predição entre visões é escalável a codificação multivisões, e é especificada pelo padrão H.264/MPEG-4 na extensão AVC para a codificação MVC.

A codificação baseada em vídeo e profundidade citada na subseção 3.2.3, possui além do 
Figura 29 - Predição entrevisões. Uma das visões se torna a base e é utilizada para predizer a outra visão do par estéreo

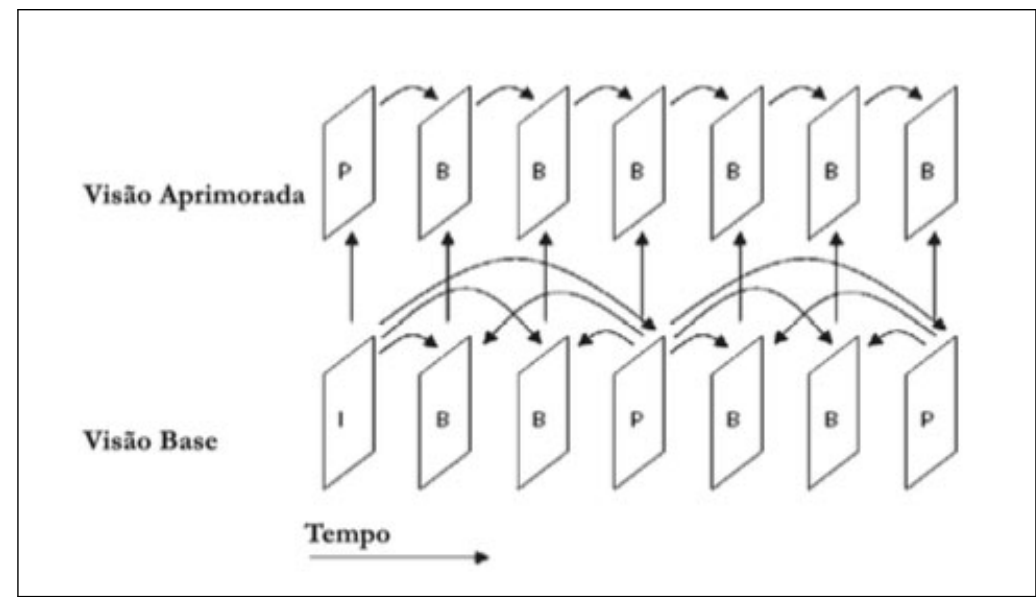

Fonte: Vetro, Wiegand e Sullivan (2011, p. 4).

vídeo bidimenssional um fluxo de vídeo codificado apenas com uma componente de cor, sendo assim, a sua própria estrutura de organização dos dados propicia a compressão estereoscópica, acarretando uma redução de dois terços em comparação à um vídeo estereoscópico. Em 2007, o contêinere ISO/IEC 23002-3 Representation of Auxiliary Video and Supplemental Information (MPEG-C Parte 3), foi especificado dentro do MPEG, padronizando a codificação de um vídeo com mapa de profundidades. Adicionalmente, outros métodos para codificação de profundidades foram propostas, tal como, abordagens utilizando wavelets (DARIBO; TILLIER; PESQUETPOPESCU, 2008) (MAITRE; DO, 2010)e funções matemáticas denominadas Wedgelet e Platelet.

Os métodos apresentados nesta seção, demonstram que cada tipo de organização de dados utiliza diferentes aspectos dos vídeos estereoscópicos a fim de atingir uma maior compressão. Entretanto cada técnica é particular para determinada utilização, podendo aumentar a incompatibilidade entre o formato de codificação e o método de visualização.

\subsection{Trabalhos relacionados}

Atualmente dois problemas podem ser observados na codificação de vídeos estereoscópicos. O primeiro é a quantidade de dados a ser armazenada, no qual, dependendo da tecnologia de visualização a ser utilizada, emprega-se o uso de dois ou mais fluxos de vídeo. O segundo é dado pelos métodos tradicionais de compressão de vídeo monocular com perdas, o qual produzem artefatos prejudicando a percepção de profundidade quando aplicadas a vídeos estereoscópicos; do mesmo modo, novas técnicas criadas especificamente para codificação estereoscópica produzem boa taxa de compressão, entretanto, são exclusivas para um método particular de visualização. Os trabalhos descritos nesta seção visam solucionar parte desses problemas e estão, assim, relacionados a este projeto. 


\subsubsection{Codificador HDB2}

O método HDB2 desenvolvido por Andrade (2012) tem como objetivo explorar a compressão espacial em dados estereoscópicos, atingindo boa taxa de compressão e resultando em vídeos com qualidade suficiente para serem utilizados pela visualização anaglífica, mantendo a percepção de profundidade (sem o surgimento de artefatos). A Figura 30 apresenta uma esquematização da compressão espacial a partir da codificação anaglífica, destacando as etapas do processo do HDB2. Vale ressaltar que em seu trabalho, Andrade (2012) analisa e discute cada uma das seis etapas que compõem o HDB2, apontando onde ocorrem perdas e até que ponto elas são toleradas para não prejudicar a percepção de profundidade.

Figura 30 - Esquematização da codificação do HDB2

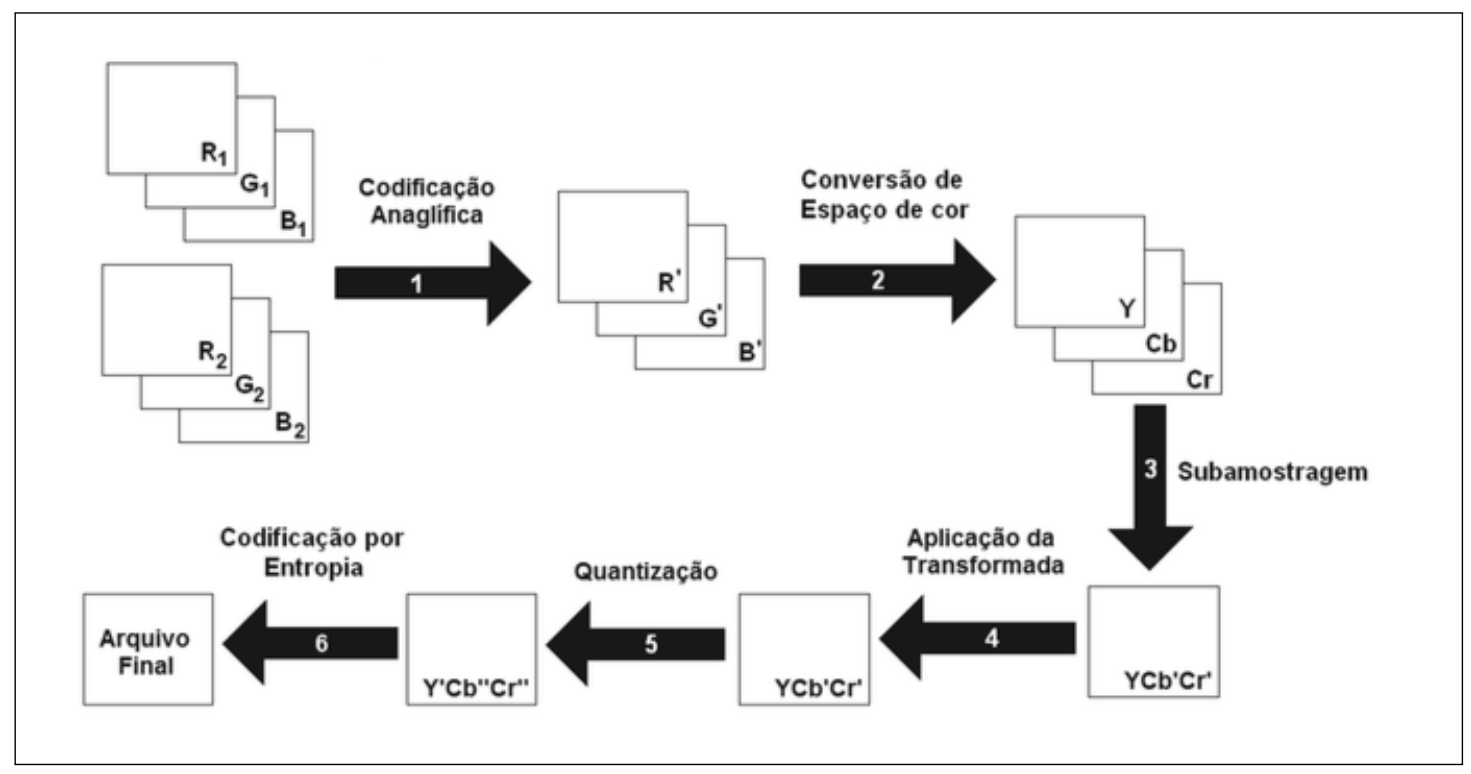

Fonte: Andrade (2012).

A primeira etapa do processo do método HDB2 envolve a conversão do par estéreo em um anáglifo. Como descrito na subseção 2.2.1, durante o processo de codificação anaglífica, existem diferentes tipos de anáglifos, sendo que, a escolha do anáglifo pode influenciar na correta percepção da profundidade. Tal fato é decorrente de que a codificação anaglífica é baseada na fusão das componentes de cores do par estéreo e, os filtros utilizados para desfazer tal fusão possuem comportamentos distintos para diferentes comprimentos de onda, podendo gerar artefatos que interferem na correta visualização estereoscópica Andrade e Goularte (2010).

No trabalho realizado por Andrade e Goularte (2010), foram analisadas as combinações anaglíficas vermelho-ciano e verde-magenta e os resultados evidenciam que o anáglifo verdemagenta mostra-se superior em termos de qualidade, sendo este, o anaglífico escolhido pelo codificador.

Após a geração do anáglifo verde-margenta, a fim de explorar uma propridade do sistema visual humano, o qual é mais sensível à luminância do que à crominância, é realizada 
a conversão do espaço de cor RGB para YCbCr (subseção 3.1.1). Sendo assim, é possível realizar a subamostragem de crominância, obtendo uma redução no volume de dados. Conforme discutida na subseção 3.1.2, o formato 4:4:4 preserva a qualidade original da imagem, porém, não apresenta ganhos em termos de compressão, por outro lado, os formatos 4:2:0 e 4:1:1 resultam em melhores resultados em termos de compressão, contudo, a qualidade visual da imagem diminui podendo afetar a correta percepção dos vídeos estereoscópicos.

Andrade (2012) realizou testes objetivos e subjetivos de modo a mensurar qual o formato de subamostragem possui o melhor resultado em termos de percepção de profundidade e compressão. Nesta análise os vídeos da base (ANDRADE; CORDEBELLO; GOULARTE, 2010) foram submetidos à subamostragem de crominância nos formatos 4:4:0, 4:2:2, 4:2:0 e 4:1:1. Como esperado, após a realização da análise objetiva, os formatos 4:2:0 e 4:1:1 apresentaram as médias de PSNR inferiores às médias dos formatos 4:4:0 e 4:2:2, afinal a sua utilização demanda uma menor quantidade de dados para a representação da imagem, elevando a taxa de compressão, porém, quando submetidos aos testes subjetivos, tais modelos apresentaram serrilhamentos nas regiões de borda, prejudicaram em diversos casos a percepção de profundidade. Já os modelos 4:4:0 e 4:2:2 obtiveram resultados objetivos e subjetivos bem próximos, com uma pequena vantagem para o modelo 4:4:0, obtendo uma vantagem média de $0,25 \mathrm{~dB}$ no teste objetivo e 0,11 no teste subjetivo, superando os valores do formato 4:2:0 (mesmo este sendo o modelo utilizado pela maioria das técnicas de codificação de vídeo digital) (GONZALEZ; WOODS, 2008). Adicionalmente, a influência dos serrilhamentos em regiões de borda oriundos da subamostragem de crominância foi notada de forma menos intensa neste modelo (4:4:0). Por obter os melhores resultados, o HDB2 utiliza o modelo 4:4:0 para a subamostragem de crominância.

Em seguida é aplicada uma transformada wavelet para que seja realizada a reordenação das informações de frequência espacial de maior e de menor importância, possibilitando que as informações de menor importância sofram uma quantização mais rígida, contribuindo com a taxa de compressão. Nesta etapa, também foram realizadas análises da aplicação de diferentes famílias de transformadas wavelets, no processo de compressão espacial estereoscópica, sendo elas as seguintes DWT's: Haar, Daubechies (2 a 4), Biorthogonal (1,3, 1,5, 2,2, 2,4, 2,6, 2,8, 3,1 e 3,3), Coiflets (1 a 3) e Symlets (2 a 4), totalizando 18 DWT's. Antes de submeter as componentes para a aplicação da DWT, elas são divididas em macroblocos de tamanhos fixos, sendo suas dimensões potência de 2 ( 32 x 32, 64 x 64, 128 x 128 ou 256 x 256 pixels). Em seguida, há a aplicação de 2 e 3 níveis da DWT sobre cada macrobloco e realizada a quantização.

As perdas ocasionadas pela quantização podem acarretar em arfetatos, que prejudicam a percepção dos vídeos estereoscópicos, sendo assim, se faz necessário definir um processo de quantização que não interfira na qualidade de vídeos estereoscópicos anaglíficos. Como abordado na subseção 3.1.4, alguns métodos foram desenvolvidos a fim de tratar a quantização em vídeos estereoscópicos. Em razão do tempo de execução, a abordagem Nayan, Edirisinghe e Bez (2002) aplica 3 níveis de DWT sobre cada macrobloco, enquanto a abordagem de Thanapirom, Fernando 
e Edirisinghe (2005) que utiliza árvores de wavelets trabalha com mais níveis. A aplicação de mais de 3 níveis da DWT eleva muito o tempo de processamento, sem que este aumento tenha impacto propocional na qualidade final da imagem (THANAPIROM; FERNANDO; EDIRISINGHE, 2005) (MANDAL, 2003). Por essa razão a abordagem de Nayan, Edirisinghe e Bez (2002) foi escolhida por Andrade (2012) para servir de base para o desenvolvimento de um novo método de quantização capaz de ser aplicado a macroblocos com dimensões maiores do que 8 x 8 pixels sem que seja notada perda significativa de qualidade.

A ampliação da matriz de quantização desenvolvida por Andrade (2012) considerou o mesmo modelo da subdivisão em 10 subáreas ilustrado na Figura 23. Inspirada no fato da decomposição das waveletes utilizarem o formato de onda como primitiva, os valores das subáreas 2 a 4 foram ampliados a fim de seguir o formato de onda. Como exemplo, a quantização definida, é ilustra na Figura 31.

Figura 31 - (A) Valores da diagonal correspondente às subáreas de 1 a 4 da matriz de quantização do HDB2; (B) Valores das subáreas de 1 a 4 da nova matriz de quantização, com dimensões de 8 x 8 pixels

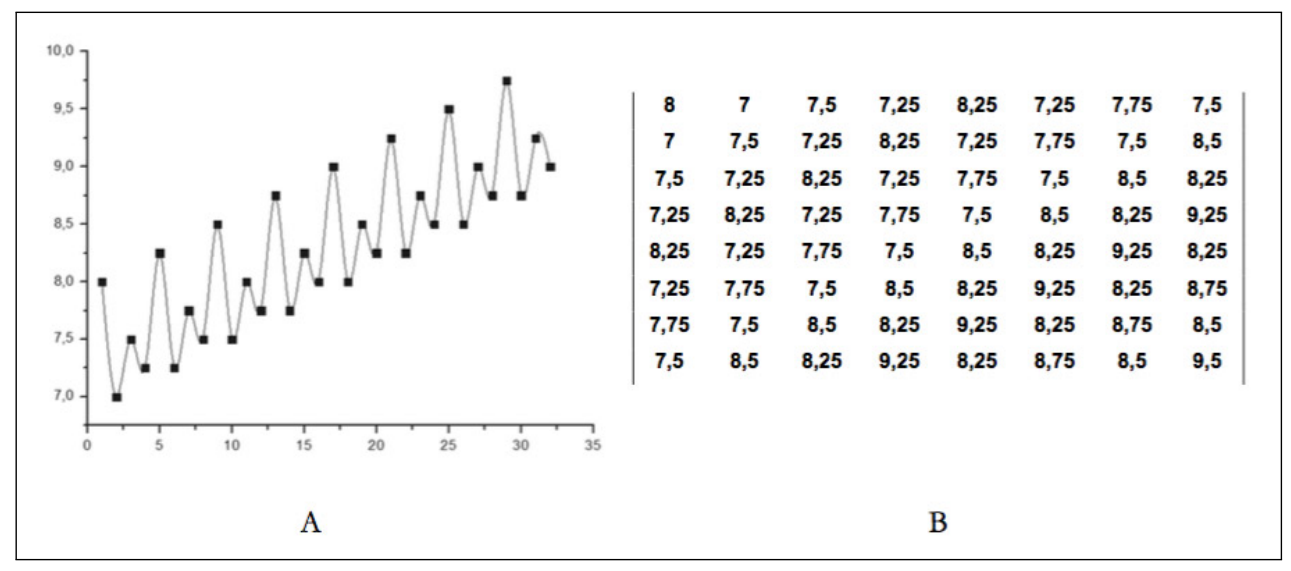

Fonte: Andrade (2012).

Advindo da abordagem de Nayan, Edirisinghe e Bez (2002), o primeiro valor da matriz é 8, em seguida, os valores são gerados pelo seguinte algoritmo: 1) Subrataia 1; 2) Some 0,5; 3) Subtraia 0,25 ; 4) Some 1; 5) Retorne ao passo 1 . Em relação às subáreas de 5 a 10, diversos valores foram empiracamente testados, sendo os melhores resultados os valores potência 2: 16, $16,32,64,64$ e 128. Tais alterações no processo de quantização tornaram a matriz de quantização ajustável a dimensão do macrobloco e obtiveram melhores resultados de qualidade e compressão.

Após a quantização, as melhores taxas de compressão, em ordem crescente de compressão são obtidas pelos macroblocos com dimensões 64 x 64, 128 x 128, 32 x 32 e 256 x 256 pixels. Entre as DWT's analisadas, os melhores resultados foram obtidos pela a Haar e a Db2. Ao comparar-se as duas DWT's em relação às medidas objetivas, o valor PSNR da transformada Haar supera a Db2 em menos de 1 dB. Já em teste subjetivos, a Db2 apresenta uma pequena vantagem média de 0,13 em relação a Haar.

Por fim, é aplicada a compressão de dados sem perda utilizando a codificação variável 
de Huffman, a qual atenua as redundâncias estatísticas das informações, reduzindo o volume de dados a ser armanezado no arquivo final. $\mathrm{O}$ arquivo resultante é um vídeo anaglífico mantendo a percepção de profundidade sem o surgimento de artefatos.

\subsubsection{RevGlyph}

Proposta por Zingarelli (2013), a RevGlyph visa ser compatível com todos os modos de visualização estereoscópica. Para este fim, a abordagem utilizada na RevGlyph modifica o processo de transformação de um par estéreo em um anáglifo, adicionando duas novas estruturas chamadas de Cabeçalho de Consulta de Cores e Diferença de Luminâncias. Essas estruturas armazenam dados complementares que são utilizados na reversão anaglífica para a reconstrução do par estéreo.

A estrutura nomeada de Cabeçalho de Consulta de Cores é responsável por armazenar parte dos dados que seriam descartados durante a conversão anaglífica. No anáglifo gerado na Figura 7 (verde/magenta) o Cabeçalho de Consulta de Cores é formado pelos dados dos canais de cores $\mathrm{R}_{1} \mathrm{G}_{2} \mathrm{~B}_{1}$ (informações de cores não utilizadas na geração do anáglifo principal). Juntos estes canais $\left(\mathrm{R}_{1} \mathrm{G}_{2} \mathrm{~B}_{1}\right)$ geram um novo anáglifo chamado "anáglifo complementar", deixando a denominação "anáglifo principal"para aquele a ser de fato utilizado em combinação com os óculos.

A preservação do anáglifo complementar na estrutura de codificação tem como consequência a perda da característica de compressão, sendo que neste caso, todas informações do par estéreo são armazenadas (alterando-se apenas a ordem dos canais de cores). Com o objetivo de reduzir a quantidade de dados a ser armazenada no Cabeçalho de Consulta de Cores, a estratégia utilizada pela RevGlyph, é converter o anáglifo complementar ao espaço de cor YCbCr. Assim sendo, além de separar as informações de crominância do anáglifo complementar, a conversão do espaço de cor possibilita a realização da subamostragem de crominância, reduzindo a quantidade de dados de $\mathrm{Cb}$ e $\mathrm{Cr}$ a ser armazenada no Cabeçalho de Consulta de Cores. Como citado na subseção 3.4.1 a subamostragem 4:4:0 é a melhor opção para vídeos estereoscópicos. Além de reduzir pela metade os dados contidos em cada componente, o modelo 4:4:0 não causa prejuízos na percepção de profundidade (ANDRADE, 2012).

De modo a contribuir com a taxa de compressão do arquivo codificado, os processos de conversão de espaço de cor ( $\mathrm{RGB} \Rightarrow \mathrm{YCbCr}$ ) e subamostragem de crominância (4:4:0) também são aplicadas ao anáglifo principal.

As informações de luminância presentes no anáglifo principal, são muito semelhantes as presentes no anáglifo complementar. A fim de explorar esta propriedade, é realizada a diferença entre os pixels homólogos em cada anáglifo. A Figura 32 ilustra as informações de luminância do anáglifo principal $\left(\mathrm{Y}_{\mathrm{p}}\right)$, do anáglifo complementar $\left(\mathrm{Y}_{\mathrm{c}}\right)$ e o resultado das diferenças entre as suas luminâncias $\left(\mathrm{Y}_{\mathrm{d}}\right)$. 
Figura 32 - Exemplo de redundância existente entre as componentes de luminância dos anáglifos formados a partir de um par estereoscópico

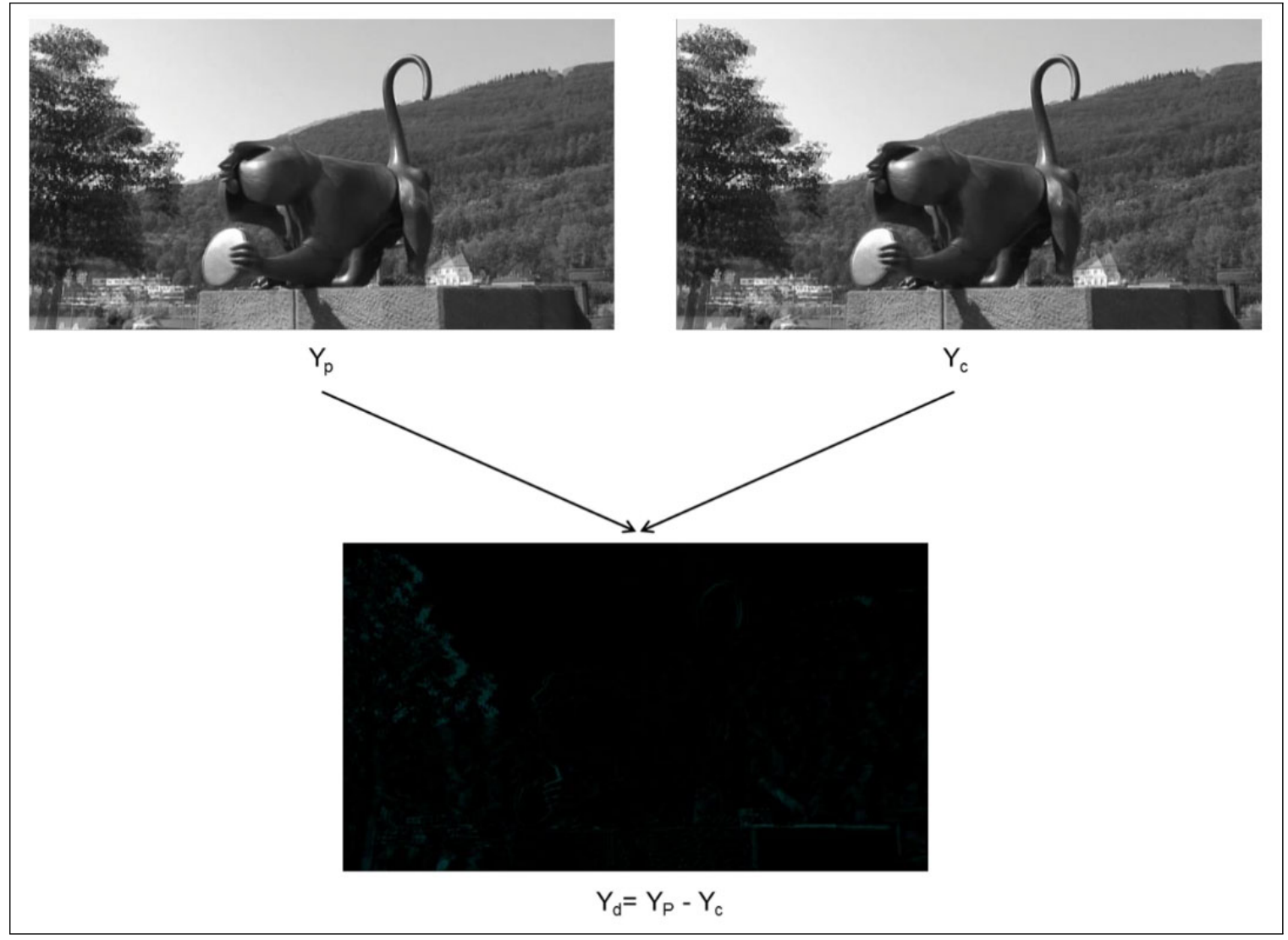

Fonte: Zingarelli (2013).

A diferença entre as luminâncias resultam em valores próximos de zero e também muito próximos entre si. De modo a explorar a proximidade entre esses valores, em vez dos valores serem armazenados individualmente na estrutura Diferença de Luminâncias, um agrupamento de intervalos de valores sequenciais é realizado. O agrupamentos dos valores se assemelha ao algoritmo por carreiras (run-length), em que, há a criação de blocos de repetição formados por um par de coordenadas que contém o valor e a quantidade de vezes que ele se repete. Diferente da codificação por carreiras, neste caso, os valores não precisam ser exatamente iguais para serem agrupados em um mesmo bloco, apenas próximos. Valores sucessivos cuja a diferença não ultrapasse um determinado limiar são considerados iguais e agrupados dentro de um mesmo bloco. O valor final do bloco é representado pela média aritmética dos valores agrupados neste bloco.

A Figura 33 (A) ilustrada um fragmento da diferença de luminâncias entre os anáglifos (original e complementar) gerados a partir de um par estéreo. $\mathrm{Na}$ abordagem, o primeiro valor é fixado como base de comparação, e então é realizada a diferença entre os valores sequenciais e o valor base. O resultado é comparado ao limiar estabelecido, neste exemplo, o valor 2. Caso o resultado absoluto da diferença entre um valor da sequência e a base for menor ou igual a 2 , esse valor é considerado como sendo igual à base e pertencente ao mesmo agrupamento. Este 
processo é seguido por todo o vetor. Quando o valor da diferença entre o valor sequencial e a base ultrapassar o limiar, encerra-se um bloco e inicia-se outro bloco, tendo agora como valor base o valor sequencial que resultou a diferença maior que o limiar estabelecido.

Figura 33 - Exemplo da aplicação do agrupamento por limiar de aceitação nos valores da Diferença de Luminâncias

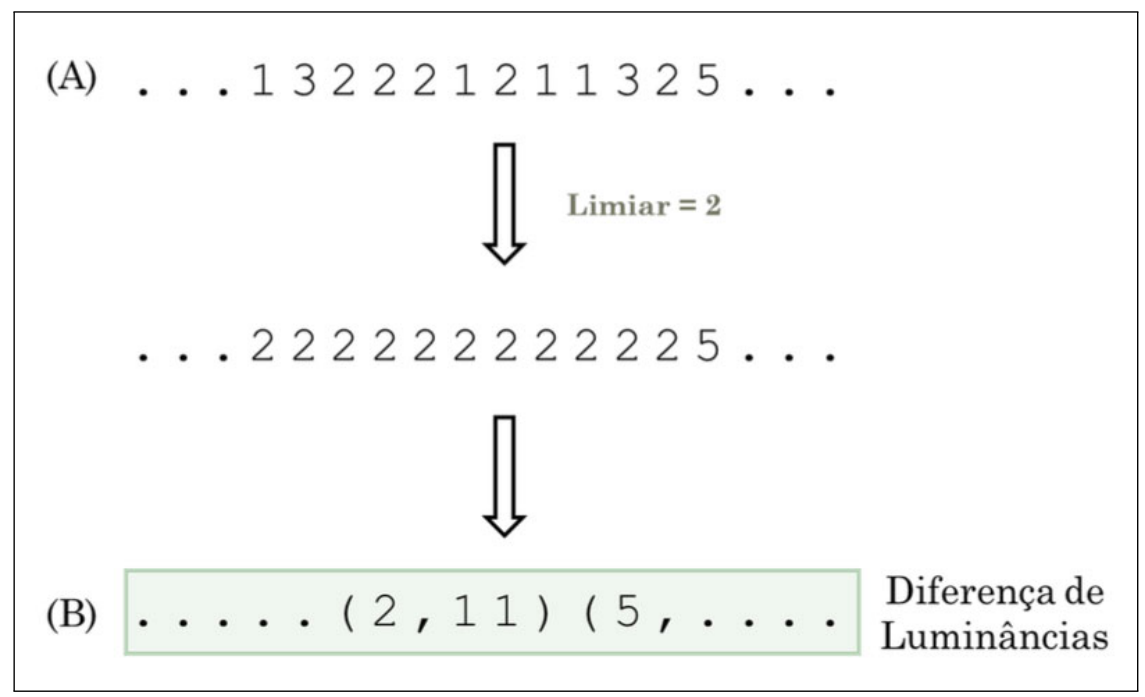

Fonte: Zingarelli (2013).

Por fim, o anáglifo principal, o Cabeçalho de Consulta de Cores e a Diferença de Luminâncias passam pela etapa de compressão sem perdas utilizando os algoritmos Lempel-Ziv-Storer-Szymanski (LZSS) e Prediction by Partial Matching (PPM) e são agrupados em um único arquivo comprimido.

Como visto, a RevGlyph mantém as informações de luminância do anáglifo principal $\left(\mathrm{Y}_{\mathrm{p}}\right)$ íntegras. Como dito na subseção 3.1.2, o sistema visual humano é mais sensível a luminância do que a crominância, portanto, quando mais ruído for adicionado às componentes de luminância, mais perceptível será a degradação visual da imagem.

Nota-se que as novas estruturas propostas pela RevGlyph durante a codificação anaglífica (Cabeçalho de Consulta de Cores e Diferença de Luminâncias) são resultados de transformações realizadas nas informações que seriam descartadas no processo tradicional de codificação anaglífica, sendo que, apenas a quantidade mínima de informações para a reversão do processo é armazenada.

Deste modo, a reversão anaglífica, proposta Zingarelli (2013) ilustrada na Figura 34, baseia-se na extração das informações armazenadas no Cabeçalho de Consulta de Cores e na Diferença de Luminâncias, recriando o anáglifo complementar, obtendo assim uma aproximação do par estéreo original correspondente.

Com as informações contidas na Diferença de Luminâncias é possível reconstruir a matriz de luminância $Y_{d}$. Este processo é realizado repetindo os valores na quantidade de vezes indicadas no seu par de coordenadas. A diferença entre $Y_{p}$ e matriz resultante neste processo 
deriva a componente $Y_{c}$. A união entre $Y_{c}$ e os valores de crominância armazenadas no Cabeçalho de Consulta de Cores recupera o anáglifo complementar.

As informações de cores de ambos anáglifos encontram-se subamostrados. Com a intenção de voltarem para o modelo 4:4:4, tais informações passam por um processo de recomposicão de crominância. Neste processo os valores contidos em cada componente são duplicados linha a linha a fim de terem a sua dimensão original. Após a recomposição de crominância, a reversão do espaço de cor $\mathrm{YCbCr} \Rightarrow \mathrm{RGB}$ é realizada, resultando nos canais $\mathrm{R}_{2} \mathrm{G}_{1} \mathrm{~B}_{2}$ (anáglifo principal) e $\mathrm{R}_{1} \mathrm{G}_{2} \mathrm{~B}_{1}$ (anáglifo complementar). A reordenação dos canais retornam a aproximação do par estéreo.

Figura 34 - Esquematização da codificação e decodificação da técnica RevGlyph

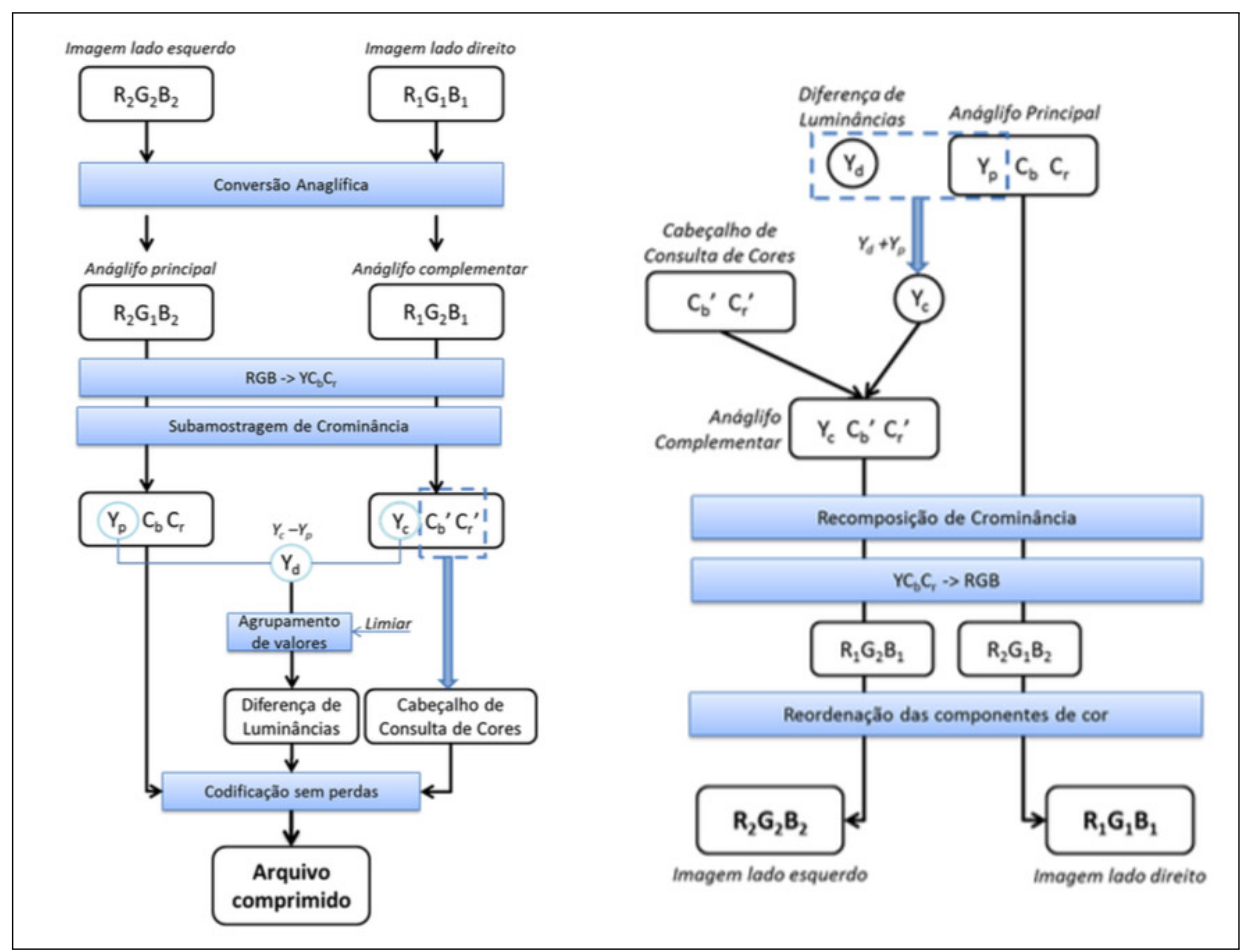

Fonte: Zingarelli (2013).

\subsection{Desafios da reversão anaglífica}

O método de codificação anaglífica descrito na subseção 2.2.1, é considerada a técnica mais simples de codificação/visualização estereoscópica. Isto se deve ao fato de que, a codificação deste método não necessita de nenhum processamento complexo e a sua reprodução pode ser realizada em qualquer tela, facilitando a sua visualização. Em comparação aos outros métodos, o anaglífico, resulta em uma melhor compressão dos dados, afinal metade das informações contidas no par estéreo são descartadas no processo, tornando a transformação anaglífica relevante para a área de codificação estereoscópica. 
Todavia, durante o processo de transformação anaglífica, é realizada a combinação entre os canais de cores contidos no par estéreo, impossibilitando que o anáglifo gerado seja utilizado por outros métodos de visualizações estereoscópicas - tais métodos necessitam do par estéreo íntegro. A reconstrução do par estéreo a partir do anáglifo, possibilitaria que outros métodos de visualização usufruíssem do par recuperado, tornando a codificação eficiente em termos de compressão e independente de um método específico de visualização. O objetivo do método proposto é tornar possível a reversão anaglífica, tornando-se um método genérico de codificação estereoscópica. Entretanto, para que a reversão anaglífica seja possível, se faz necessário recuperar as informações descartadas durante a transformação do par estéreo em um anáglifo. A Figura 35 A, ilustra um anáglifo verde-magenta, no qual é resultado da combinação do canal verde $\left(\mathrm{G}_{1}\right)$ da imagem referente à visão do olho esquedo do par estéreo, juntamente com os canais vermelho $\left(\mathrm{R}_{2}\right)$ e azul $\left(\mathrm{B}_{2}\right)$ da imagem referente à visão do olho direito, resultando em um anáglifo contendo as informações $R_{2} G_{1} B_{2}$. A recuperação dos dados descartados nesta transformação $\left(\mathrm{R}_{1} \mathrm{G}_{2} \mathrm{~B}_{1}\right)$ não é trivial.

Como cada canal representa não apenas informações de cores, mas também informações espaciais (que carregam em si o deslocamento na captura de cada imagem gerando ângulos e pontos de visões distintos para cada imagem), a simples duplicação das informações de $\mathrm{R}_{2} \mathrm{G}_{1} \mathrm{~B}_{2}$ como forma de substituir as informações perdidas $\left(\mathrm{R}_{1} \mathrm{G}_{2} \mathrm{~B}_{1}\right)$, apenas replica o anaglífico gerado, como é ilustrado na Figura $35 \mathrm{~B}$. Consequentemente, o problema da reversão anaglífica, encontra-se em como recuperar as informações perdidas durante o processo da codificação anaglífica.

Figura 35 - Resultado da replicação dos canais de cores de um anáglifo verde-magenta na tentativa de recriar o par estéreo

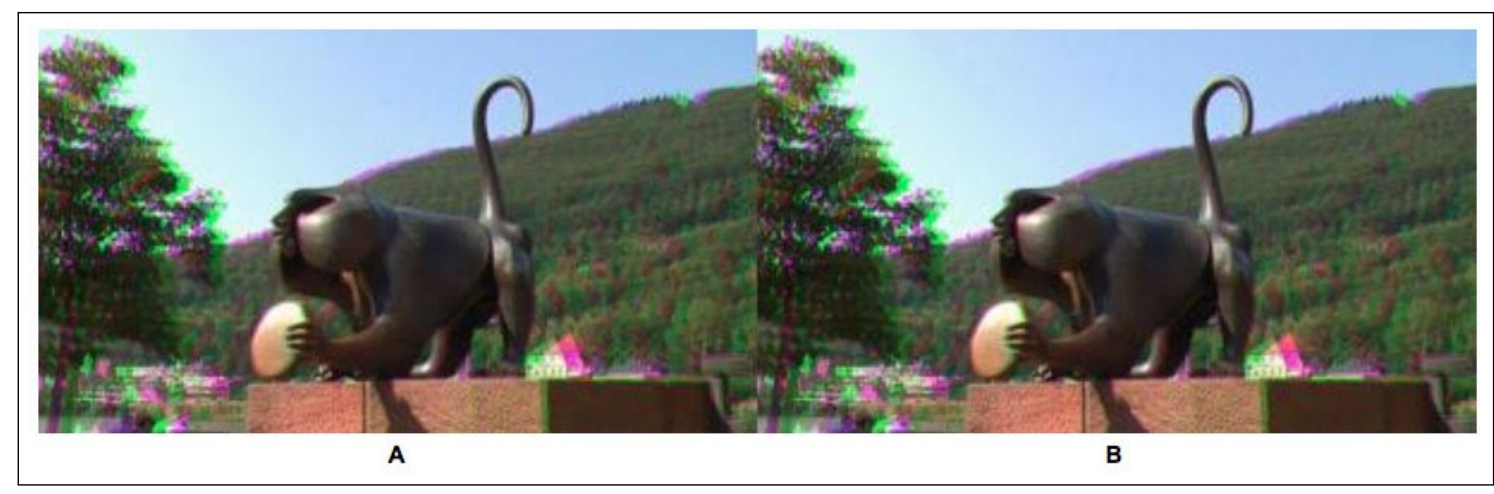

Fonte: Elaborada pelo autor.

Como descrito na subseção 3.4.2, proposta com Zingarelli (2013), a Revglyph torna a reversão anaglifica, alterando o processo de transformação do par estéreo em um anáglifo. O anáglifo resultante da RevGlyph são revertidas ao par estéreo com base na extração das informações contidas em duas novas estruturas que são criadas durante o processo de codificação anaglífica, o Cabeçalho de Consulta de Cores e a Diferença de Luminâncias, nos quais armazenam em si informações que seriam descartadas durante a transformação anaglífica. 


\subsection{Métricas de avaliação de qualidade e de compressão}

A avaliação de qualidade da imagem é um ponto importante em várias aplicações de processamento de imagem, afinal, imagens e vídeos digitais estão sujeitos a vários tipos distorções durante o seu processamento, compressão, armazenamento e reprodução, nos quais podem degradar as informações afetando diretamente a qualidade visual da imagem.

Esta seção tem como objetivo descrever as métricas de avaliação utilizadas para mensurar a qualidade das imagens recuperadas pelo método proposto.

\subsubsection{Métricas Objetivas}

Avaliações objetivas são modelos matemáticos utilizados por algoritmos a fim de qualificar automaticamente a qualidade de imagem, dispensando a interação humana. Entre as métricas mais utilizadas para este fim, encontra-se o PSNR, no qual se baseia na diferença de pixels entre duas imagens (original e processada), resultando em um valor medido em decibéis (dB). O PSNR é definido pela Equação 3.9

$$
\operatorname{PSNR}=10 \log _{10} \frac{\left(2^{d}-1\right)^{2} W H}{\sum_{i=1}^{W} \sum_{j=1}^{H}\left(p[i, j]-p^{\prime}[i, j]\right)^{2}}
$$

sendo:

$d:$ profundidade de bits do pixel;

$W$ : largura da imagem;

$H$ : altura da imagem;

$p[i, j], p^{\prime}[i, j]: i$-linha $j$-coluna do pixel da imagem original e da imagem processada, respectivamente.

A escala utilizada por esta métrica varia de 0 à $100 \mathrm{~dB}$, no qual, quanto maior o número, menor o nível de ruído encontrado na imagem processada, isto é, mais semelhante (a nível de pixel) a imagem processada é da imagem original. Apesar de ser uma métrica muito utilizada em trabalhos relacionados e bem sucedida para analisar a adição de ruídos em imagens, o PSNR não leva em consideração a percepção visual humana. Sendo assim não é possível afirmar que quanto maior o PSNR melhor a qualidade da percepção visual da imagem. A figura Figura 44 ilustra 4 fotos, sendo uma original e outras três processadas. É perceptível que segunda foto (PSNR 34,67 dB) contida na imagem possui qualidade superior a terceira foto (PSNR 29,73 dB) bem como seu valor PSNR. Porém ao analisar a comparação entre a segunda e a última foto (PSNR 38,58 dB), nota-se que, apesar do valor PSNR ser superior, a última foto encontra-se com o rosto da criança desfocado. Caso a prioridade seja dada no rosto da criança, a escolha da foto com melhor qualidade seria a segunda opção em vez da última (mesmo esta possuindo seu valor PSNR superior). 
Figura 36 - PSNR

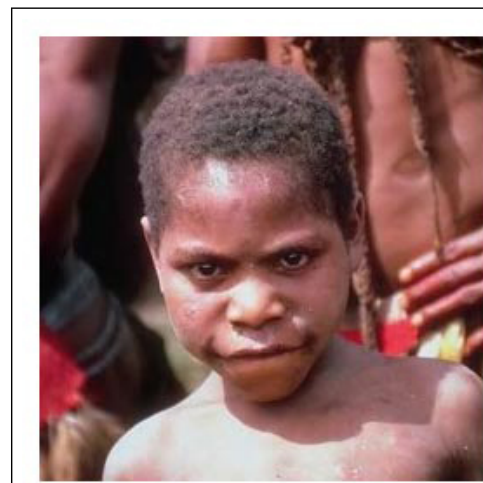

Imagem Original

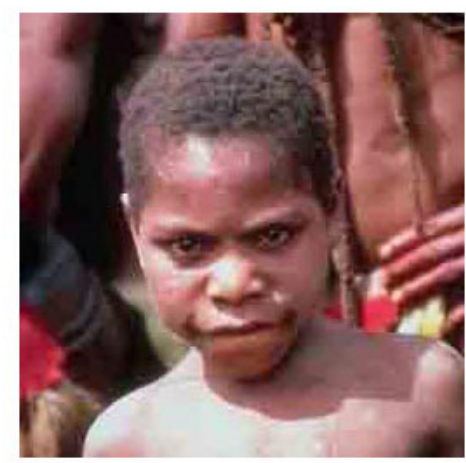

PSNR: $29,73 \mathrm{~dB}$

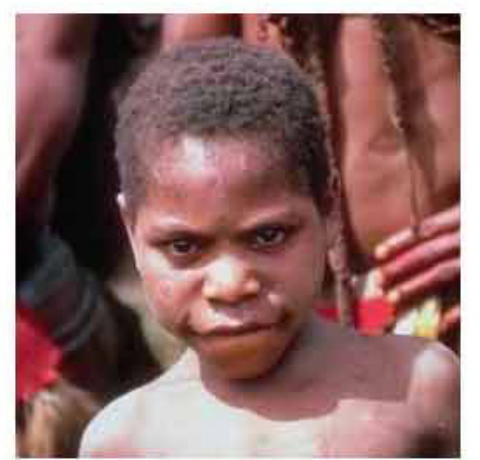

PSNR: $34,67 \mathrm{~dB}$

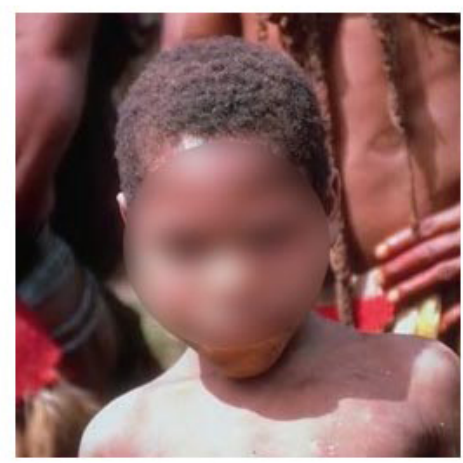

PSNR: $38,58 \mathrm{~dB}$

Fonte: Elaborada pelo autor.

\subsubsection{Métricas subjetivas}

Para aplicações nos quais o público alvo são usuários/espectadores, o método correto para quantificar a qualidade visual da imagem é por meio de avaliações subjetivas (WANG et al., 2004). Segundo a recomendação ITU-R BT.500-11 (ITU-R, 2002b), a mensuração da qualidade de codificação de imagens estéreoscópicas deve ser realizada utilizando-se a métrica DSCQS. Inicialmente montam-se estruturas de vídeo ABAB sendo A o vídeo original e B o vídeo processado. Os vídeos são mostrados por um tempo fixo e intercalados com trechos de tela cinza, como ilustra a figura Figura 37.

Figura 37 - Estrutura de vídeo utilizada para medida subjetiva

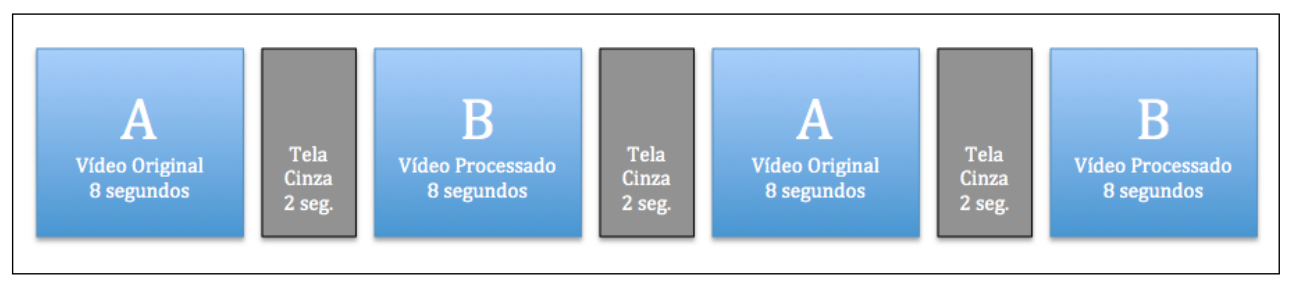

Fonte: Elaborada pelo autor.

O grupo de avaliadores utilizam uma tabela de pontuação de cada vídeo, no qual, possui 
escala de 1 à 5 , contendo 5 subdivisões de intervalos, classificando o vídeo de péssimo à excelente (Figura 38). Por fim, a estimativa média é obtida utilizando o Mean Opinion Score (MOS), ou seja, a média de valores atribuídos aos vídeos pelos avaliadores.

Figura 38 - Tabela de classificação de vídeo

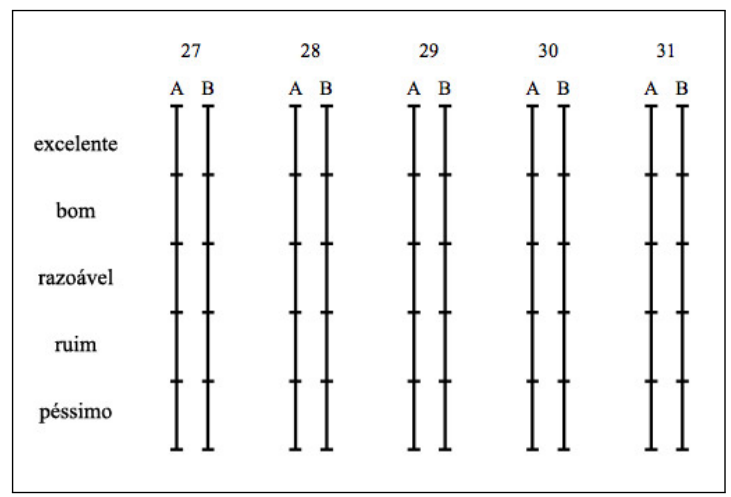

Fonte: Elaborada pelo autor.

Alguns procedimentos foram adotados para a realização a avaliação:

(i) Teste de acuidade visual utilizando o teste de cores de Ishihara ${ }^{1}$ (WANDELL, 1995);

(ii) Treinamento e apresentação das possíveis imparidades que podem ser encontradas;

(iii) Apresentação da sequência de teste.

\subsubsection{Desenvolvimento dos testes objetivos e subjetivos}

Há na literatura diversas bases de vídeos bidimensionais para que sejam realizados testes objetivos e subjetivos, todavia, o mesmo não ocorre para vídeos estereoscópicos. Para este fim, a realização de ambos testes utilizou-se a base de vídeos construída por Andrade, Cordebello e Goularte (2010), a qual contém 32 pares de vídeos estereoscópicos no formato lado-a-lado, sendo a sua construção seguida pelos critérios estabelecidos pela ITU-T (ITU-T, 2008). Uma imagem foi extraída de um quadro de cada um dos vídeos, formando assim a base de testes composta por 32 imagens estereoscópicas.

Após a execução da conversão anaglífica da HaaRGlyph, a taxa de compressão é dada por meio da divisão do total de bytes do arquivo codificado pelo total de bytes do par estéreo original. Em seguida, o processo de reversão anaglífica é realizado a fim de obter o valor PSNR entre o par estéreo original e o par estéreo recuperado.

Os procedimentos adotados para a análise subjetiva são citado na subseção 3.6.2, sendo as 32 amostras exibidas à um grupo de 30 pessoas, de ambos os sexos com idade variando entre 17 e 55 anos, todos sem prévia experiência com processamento de imagens e vídeos digitais, nos quais utilizaram o cardboard, citado na subseção 2.2.4, para que cada imagem do 
par estéreo fosse direcionado ao olho correspondente. O tempo médio gasto para cada um dos testes subjetivos foi de 27 minutos.

\subsection{Considerações finais}

Este capítulo abordou aspectos de diferentes métodos de compressão e codificação aplicados a imagens e vídeos estereoscópicos, utilizando não apenas técnicas empregadas em vídeos bidimensionais, mas também técnicas que exploram redundâncias presentes no par estéreo. Adicionalmente, são descritas as métricas de avaliação utilizadas neste trabalho para mensurar a qualidade objetiva e subjetiva do par estéreo recuperado pela HaaRGlyph, bem como, quais os procedimentos foram adotados para a sua aplicação.

Com relação a subamostragem de crominância, dependendo da redução de crominância realizada, a qualidade visual da imagem pode ser afetada. Após a análise da influência da subamostragem de crominância na percepção de profundidade de imagens estereoscópicas, Andrade et al. (2014), conclui a subamostragem 4:4:0 como sendo o modo que melhor apresenta qualidade para a visualização estereoscópica, não prejudicando a percepção de profundidade. Complementarmente o trabalho demonstra a aplicação de 18 tipos de DWT's no processo de compressão espacial estereoscópica, no qual, a wavelet Haar obteve os melhores resultados juntamente com a wavelet Daubechies 2.

Com exceção da RevGlyph abordada na subseção 3.4.2, os métodos de organização e codificação de dados estéreos apresentados, satisfazem a um formato específico de visualização, porém, são insatisfatórios ou incompatíveis quando submetidos a outro método de visualização, atestando a ausência de um método de codificação estereoscópico genérico.

Apesar da HDB2 ter apresentado ótimos resultados, ter explorado a compressão espacial aplicada a vídeos estereoscópicos e de comprovar a possibilidade de reversão anaglífica com a técnica RevGlyph, não há uma integração entre ambas técnicas, limitando a HDB2 a apenas um tipo de visualização estereoscópica, a anaglífica. A RevGlyph por sua vez, possibilita a reversão anaglífica, tornando-a uma técnica de visualização estereoscópica genérica, contudo, nenhum tipo de compressão (com exceção da codificação por entropia e subamostragem de crominância) é aplicada aos componentes dos anáglifo principal e aos componentes $\mathrm{Cb}$ e $\mathrm{Cr}$ do anáglifo complementar. A técnica proposta visa não apenas integrar ambas técnicas, sendo um método de reversão anaglifica que explora características das transformadas wavelets para obter-se compressão, mas também, modificar partes dos processos propostos pelas técnicas, a fim de investigar quais modelos apresentam melhores resultados em questão de qualidade objetiva e taxa de compressão, sem reduzir a qualidade visual do par estéreo recuperado. 
Este capítulo apresenta os conceitos e processos que compõem a HaaRGlyph, uma técnica de codificação anaglífica utilizando DWT, que possibilita a reversão de um anáglifo em uma aproximação de seu correspondente par estéreo. A seção 4.1 expõe o processo de codificação e decodificação anaglífica utilizada pela HaaRGlyph, enquanto a seção 4.2 traz informações sobre a implementação da técnica proposta.

\subsection{A técnica HaaRGlyph}

A técnica HaaRGlyph tem como objetivo reduzir as lacunas apontadas no Capítulo $1 \mathrm{e}$ possibilitar a reversão anaglífica. Assim sendo, pretende-se que a técnica alcance boas taxas de compressão espacial (comparadas às de trabalhos relacionados) sem que haja perdas significativas na percepção de profundidade e possibilitar a recuperação do par estéreo, tornando-se uma técnica de codifição estereoscópica genérica, viabilizando a sua utilização por quaisquer métodos de visualização estereoscópica.

Para tanto, a HaaRGlyph propõe um meio de integrar dois métodos advindos de trabalhos relacionados: HDB2 (ANDRADE, 2012) e RevGlyph (ZINGARELLI, 2013). Os métodos em questão não são compatíveis, pois, além de terem objetivos diferentes, ambos são implementados de modos diferentes.

A imagem Figura 39 ilustra as etapas (enumeradas de 1 à 7) que constituem a HaaRGlyph. Dado que as três primeiras etapas (codificação anaglífica, conversão do espaço de cor $\mathrm{RGB} \Rightarrow \mathrm{YCbCr}$ e subamostragem de crominância utilizando o modelo 4:4:0) constituem um método comprovado de compressão anaglífica sem perda significativa de qualidade e, que são utilizadas também pela RevGlyph (ZINGARELLI, 2013), propõe-se que a HaaRGlyph utilize também tais etapas como proposto por Andrade (2012). As discusões sobre os métodos e respectivas etapas podem ser consultadas nas seções seção 3.1 e seção 3.4. Vale ressaltar que após a etapa 
1, a HDB2 (ANDRADE, 2012) mantém apenas um fluxo de dados (intitulado anáglifo principal na Figura 39), enquanto 2 fluxos de dados são mantidos tanto pela RevGlyph (ZINGARELLI, 2013) quanto pela HaaRGlyph.

Figura 39 - Esquematização da codificação da técnica HaaRGlyph

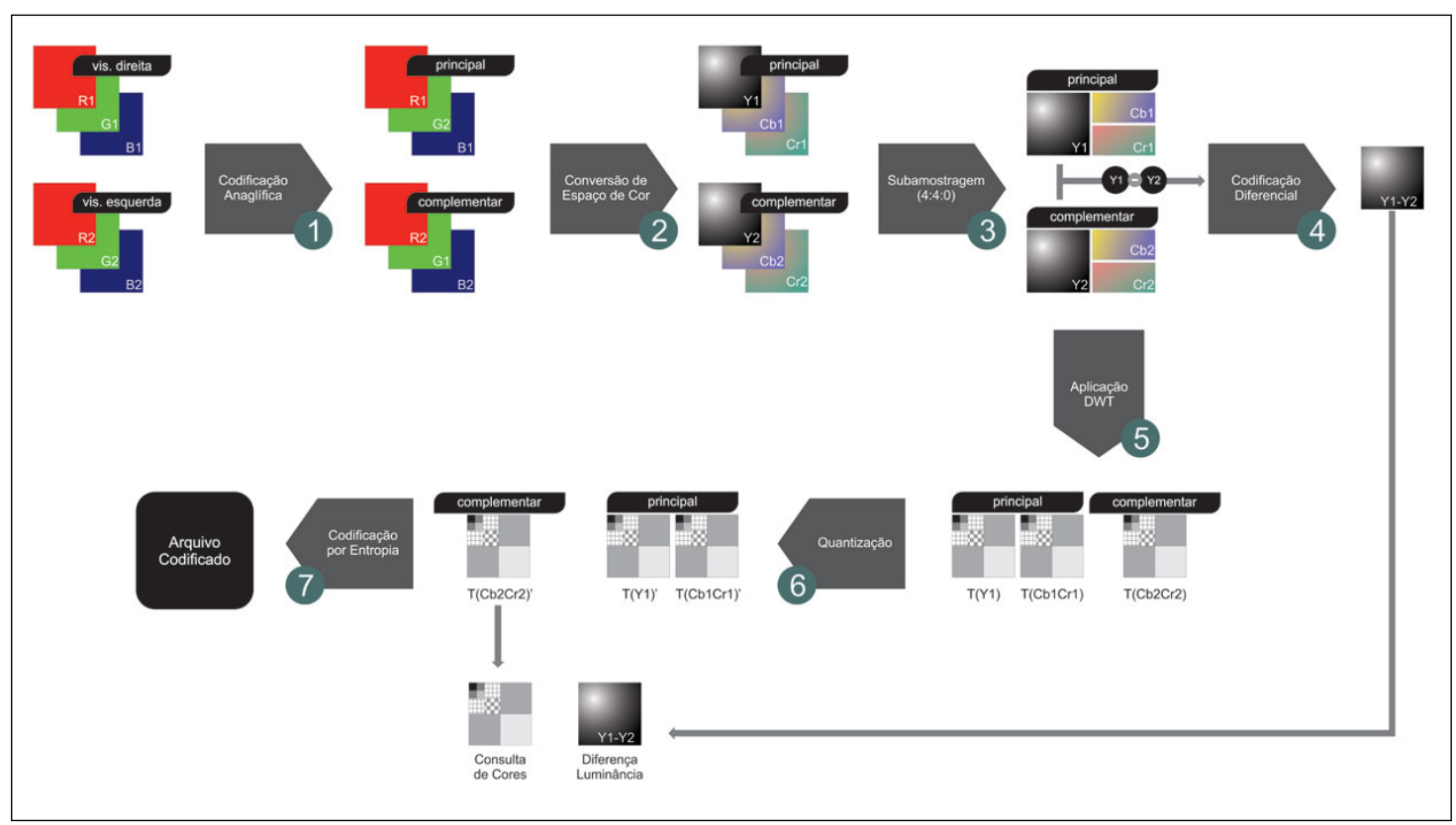

Fonte: Elaborada pelo autor.

Após a etapa 3, o vídeo já está subamostrado, no espaço de cor YCbCr. Segundo o método HDB2, seria possível aplicar a transformada wavelet e a quantização em todas as componentes. Contudo, este procedimento inviabilizaria a posterior comparação entre a HaaRGlyph e a RevGlyph (ZINGARELLI, 2013), visto que, RevGlyph dá tratamento diferente para as componentes de luminância em relação às de crominância. Com exceção do agrupamento dos valores de acordo um limiar (citado na subseção 3.4.2), nenhum método de codificação com perdas é aplicado pela RevGlyph (ZINGARELLI, 2013) na estrutura Diferença de Luminâncias. Sendo assim, para fins de comparação, a etapa 4 da HaaRGlyph é composta pela codificação diferencial entre as componentes $\mathrm{Y}_{1}$ e $\mathrm{Y}_{2}$ seguindo os mesmos procedimentos adotados por Zingarelli (2013).

Após a codificação diferencial a componente $\mathrm{Y}_{2}$ é descartada no processo, e em seguida, é realizada a divisão das componentes em macroblocos, utilizando três possíveis dimensões: 32 x 32, 64 x 64 ou 128 x 128 pixels. Em análises realizadas por Andrade (2012) macroblocos com dimensões 16 x 16 pixels resultaram na presença de artefatos em regiões de borda. Por essa razão, macroblocos de 16 x 16 pixels não foram considerados na técnica proposta.

Então, na etapa 5, realiza-se a aplicação da transformada wavelet nos macroblocos das componentes. Como citado na subseção 3.4.1, entre 18 tipos de DWT's, a wavelet Haar obteve os melhores resultados juntamente com a wavelet Daubechies 2 nas análises objetivas, subjetivas e de compressão espacial estereoscópica. Além de obter ótimos resultados, ser conceitualmente 
simples e rápida, a aplicação inversa da transformada Haar, não gera ruídos nas bordas da imagem, sendo um problema comum em outras transformações wavelet. Estas razões levaram a DWT Haar ser a escolhida para fazer parte do método proposto. Assim, na etapa 5, a DWT Haar é aplicada às componentes refentes ao anáglifo principal e também às componentes de crominância apenas do anáglifo complementar. Como resultado obtém-se então matrizes de coeficientes DWT.

Na etapa 6 realiza-se a quantização dos coeficientes gerados como resultado da etapa 5 , em um processo que resulta em perda de dados (compressão com perdas). O processo de quantização depende de uma matriz (matriz de quantização). A matriz utilizada na etapa 6 manteve os conceitos abordado por Andrade (2012). Conforme discutido na subseção 3.4.1, a dimensão e os valores da matriz são ajustados de acordo com o tamanho do macrobloco a fim de não comprometer a qualidade visual das imagens neste processo, visto que o método de quantização desenvolvido por Nayan, Edirisinghe e Bez (2002) quando aplicados na codificação de vídeos anaglíficos, apresentam o efeito blockiness, prejudicando a percepção de profundidade nas imagens (ANDRADE, 2012). A última etapa (7) tem como objetivo eliminar redundâncias de código por meio de um método de codificação sem perdas baseado no algoritmo LZ77 proposto por Ziv e Lempel (1977). Após todas as etapas, os dados encontram-se comprimidos e armazenados em um arquivo binário.

A reversão anaglífica é realizada aplicando-se o processo inverso da codificação. O primeiro passo é obter as estruturas armazenadas no arquivo codificado, sendo elas: informações do anáglifo principal, a estrutura Cabeçalho de Consulta de Cores e a estrutura Diferença de Luminâncias. Com as informações do anáglifo principal, a reconstrução do anáglifo complementar se faz necessária para a recuperação de uma aproximação do par estéreo original. A extração das informações armazenadas nas estruturas Cabeçalho de Consulta de Cores e Diferença de Luminâncias propiciam tal recuperação.

Tanto as informações do anáglifo principal, quanto as informações de crominância do anáglifo complementar encontram-se transformadas e quantizadas. Sendo assim, de acordo com a dimensão do macrobloco e a quantidade de níveis da DWT utilizada na codificação, ambas informações passam pelo processo inverso da quantização seguida pela IDWT.

A componente de luminância do anáglifo complementar $\left(\mathrm{Y}_{2}\right)$ é recuperada por meio da diferença entre os dados da componente de luminância do anáglifo principal e os dados que compõem a estrutura Diferença de Luminâncias. Porém, como citado anteriormente, a Diferença de Luminâncias contém dados agrupados de acordo com a repetição dos valores sucessivos. Portanto, os valores a serem utilizados na diferença são reconstruídos repetindo-se os valores na quantidade de vezes indicadas no seu par de coordenadas.

É importante ressaltar que a componente de luminância recuperada é uma aproximação das informações de luminância do anáglifo complementar original, visto que a componente de luminância do anáglifo principal $\left(\mathrm{Y}_{1}\right)$ que é utilizada na recuperação, sofreu perda de in- 
formações ocasionadas pela etapa quantização. Adicionalmente, devido ao agrupamento de valores (dependendo da escolha do limiar) que compõem a Diferença do Luminância, ruídos são adicionados em sua recuperação, reproduzindo os ruídos na componente de luminância do anáglifo complementar.

A união de $\mathrm{Y}_{2}$ juntamente com os valores de crominância do anáglifo complementar $\left(\mathrm{Cb}_{2}\right.$ e $\mathrm{Cr}_{2}$ - armazenados no Cabeçalho de Consulta de Cores) formam o anáglifo complementar. Nesta etapa tem-se os valores de luminância e de crominância de ambos anáglifos (principal e complementar), porém, devido ao processo de subamostragem de crominância 4:4:0 realizada na codifição, as informações de crominância encontram-se com metade das informações de luminância. A recomposição de cores é aplicada às componentes de crominância, de modo que todas as componentes possuam a mesma dimensão e quantidade de pixels. Para este propósito, é realizada duplicação dos valores de cada linha para a linha seguinte das componentes $\mathrm{Cb}$ e Cr de cada anáglifo, tornando a dimensão das componentes de crominância a mesma das componentes de luminância. Em seguida reversão de espaço de cor $\mathrm{YCbCr} \Rightarrow \mathrm{RGB}$ é realizada ao componentes resultando em seis canais, $R_{1} G_{2} B_{1}$ para o anáglifo princial e $R_{2} G_{1} B_{2}$ para $o$ anáglifo complementar. A reordenação das componentes resultam em uma aproximação do par estéreo original $\left(\mathrm{R}_{1} \mathrm{G}_{1} \mathrm{~B}_{1}\right.$ e $\left.\mathrm{R}_{2} \mathrm{G}_{2} \mathrm{~B}_{2}\right)$.

\subsection{Implementação da HaaRGlyph}

Os trabalhos relacionados citados na seção 3.4 não encontram-se integrados pois utilizam ferramentas que diferem entre si. O desenvolvimento de um módulo intermediário com o intuito de integrar as técnicas acarretaria em um processamento extra desnecessário na codificação. Adicionalmente, o arquivo codificado pelo HDB2 possui apenas informações do anáglifo, impossibilitando a reversão anaglífica realizada pela RevGlyph - como citado na subseção 3.4.2 a RevGlyph necessita ter como entrada o par estéreo. Por estes motivos, optou-se implementar a técnica proposta sem reuso de código.

A HaaRGlyph é implementada na linguaguem de programação C, sem o auxílio de bibliotecas voltadas ao processamento digital de imagens e visão computacional. Sendo assim, com exceção da codificação por entropia, cada etapa foi implementada neste trabalho.

Inicialmente é realizada a leitura das componentes RGB da imagem BMP contendo o par estéreo lado-a-lado. Os 14 primeiros bytes dos arquivos BMP contém o cabeçalho de arquivo, que possui informações como: a assinatura do arquivo, o tamanho do arquivo em bytes e a especificação do deslocamento em bytes para o início da área de dados da imagem. Os próximos 40 bytes constituem o cabeçalho de mapa de bits, contendo informações da imagem, tais como: a dimensão da imagem (altura e largura), quantidade de bits por pixel, tamanho dos dados em bytes e o tipo de compressão utilizada. Em seguida, encontra-se a paleta cores que contém os valores RGB de cada pixel da imagem, sendo a sua ordem de leitura linha a linha, da esquerda 
pra direita e na ordem BGR. O primeiro pixel refere-se a posição inferior esquerda da imagem, enquanto o último pixel refere-se a posição superior direita da imagem.

Cada componente de cor do par estéreo é armazenado em um vetor, sendo eles, $R_{1}, G_{1}$, $B_{1}, R_{2}, G_{2}$ e $B_{2}$. Em seguida, de acordo com o anáglifo escolhido, os componentes de cores são submetidos ao processo de conversão do espaço de cores conforme Equação 3.1, resultando em seis novos vetores, ou seja, caso o anáglifo verde-magenta seja o escolhido, os componentes $R_{1} G_{2} B_{1}$ e $R_{2} G_{1} B_{2}$ são submetidos a conversão para o espaço de cor YCbCr resultando nos vetores $\mathrm{Y}_{1}, \mathrm{Cb}_{1}$, e $\mathrm{Cr}_{1}$, nos quais carregam em si as informações do anáglifo principal e $\mathrm{Y}_{2}, \mathrm{Cb}_{2}$, e $\mathrm{Cr}_{2}$, contendo as informações do anáglifo complementar.

Com as informações de luminância separadas das informações de crominância, os dados de crominância $\left(\mathrm{Cb}_{1}, \mathrm{Cr}_{1}, \mathrm{Cb}_{2}\right.$ e $\mathrm{Cr}_{2}$ ), são submetidos a subamostragem 4:4:0 (etapa 3 da Figura 39 e descrita na seção seção 4.1). Para isto, os elementos dos vetores são calculados a partir da média aritmética entre os valores de um pixel de linha par e outro pixel de linha ímpar. Em seguida é realizada a codificação diferencial entre as informações de luminância $\left(\mathrm{Y}_{1}\right.$ e $\left.\mathrm{Y}_{2}\right)$. $\mathrm{O}$ resultado desta diferença é armazenada em uma estrutura chamada Diferença de Luminâncias (etapa 4 ilustrada na Figura 39, e descrita na seção 4.1). Com os valores de crominância subamostrados, ou seja, possuindo metade da sua dimensão original, os vetores referentes ao anáglifo principal $\left(\mathrm{Y}_{1}, \mathrm{Cb}_{1}\right.$ e $\left.\mathrm{Cr}_{1}\right)$ juntamente com os vetores de crominância $\left(\mathrm{Cb}_{2}\right.$ e $\left.\mathrm{Cr}_{2}\right)$ do anáglifo complementar são divididos em macroblocos de tamanhos fixos e então submetidos a DWT Haar (etapa 5 da Figura 39).

Na etapa seguinte cada componente é quantizada pelo processo de quantização, sendo realizada a divisão entre cada componente pela matriz de quantização (subseção 3.1.4). Após a quantização dos componentes $\mathrm{Y}_{1}, \mathrm{Cb}_{1}, \mathrm{Cr}_{1}, \mathrm{Cb}_{2}$ e $\mathrm{Cr}_{2}$, as informações de crominância do anáglifo complementar é armazenada na estrutura intitulada Cabeçalho de Consulta de Cores (descrita na subseção 3.4.2). Por fim, o arquivo codificado é resultado da codificação por entropia do anáglifo principal, juntamente com as estruturas Cabeçalho de Consulta de Cores e Diferença de Luminância. Os dados que constituem o arquivo codificado são estruturados em regiões nos quais são ilustrados na Figura 40.

Figura 40 - Estrutura do arquivo codificado com a HaaRGlyph

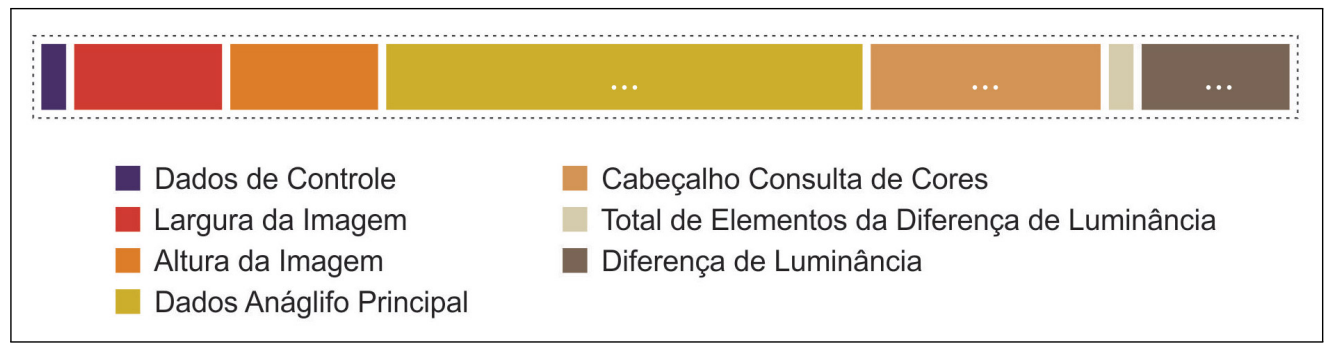

Fonte: Elaborada pelo autor.

A estrutura nomeada Dados de Controle é armazenada em 1 byte e contém informações 
a respeito do tipo de anáglifo gerado, formato do par estéreo, subamostragem de crominância, dimensão do macrobloco e a quantidade de níveis da DWT aplicada a imagem. Essas são informações importantes para realizar a reversão anaglífica e reconstruir o par estéreo corretamente. A divisão entre os dados e a representação de cada bit do Dados de Controle é ilustrada na Figura 41.

Figura 41 - Representação de cada bit da região Dados de Controle.

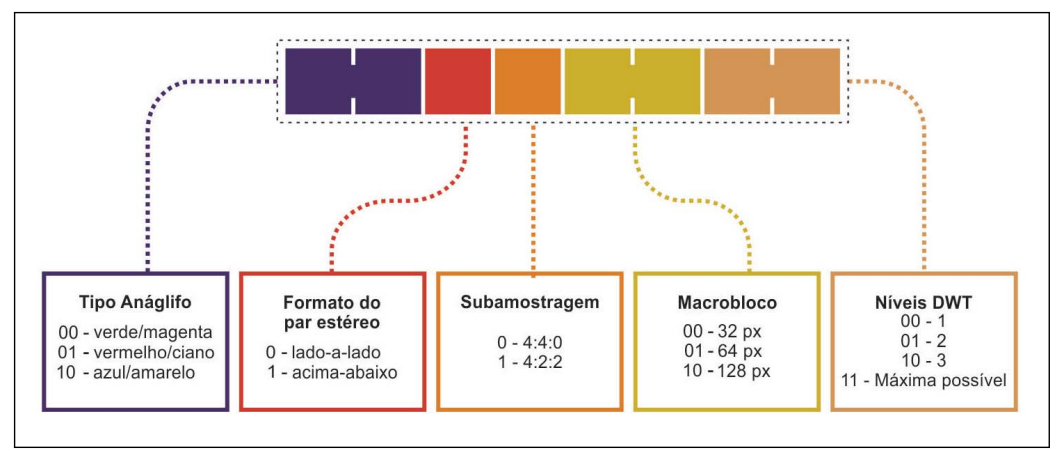

Fonte: Elaborada pelo autor.

Como visto, a estrutura está apta a receber qualquer tipo de anáglifo e qualquer tipo de formato estéreo. Dados como altura e largura são variáveis do tipo inteiro e referem-se a dimensão do anáglifo gerado. Isto significa que na reconstrução do par estéreo a largura ou a altura (dependendo do tipo do par estéreo) é dobrada para a sua reconstrução. Os dados do anáglifo principal estão armazenados em um fluxo de dados, sendo sua ordem de armazenamento $\mathrm{Cb}, \mathrm{Cr}$ e Y. Devido aos valores de Cb e Cr serem reduzidos pela metade (resultado da quantização 4:4:0), juntos, estes componentes possuem a mesma dimensão da componente Y (que é armazenada integralmente). Em seguida, são armazenadas as informações de crominância ( $\mathrm{Cb}$ e $\mathrm{Cr}$ ) do anáglifo complementar. Por fim, são armazenadas a quantidade de elementos criados na estrutura Diferença de Luminância seguida pela própria estrutura. A quantidade de elementos que compõe a Diferença de Luminância varia de acordo com o valor do limiar escolhido e de acordo com os valores de luminância da imagem, tornando a quantidade de dados contidos na Diferença de Luminâncias varíavel.

A decodicação do arquivo inicia-se separando as estruturas ilustradas na Figura 40 em variáveis (no caso das informações contidas na estrutura dados de controle, largura, altura da imagem e total de elementos contidas na diferença de luminância) e em vetores individuais (no caso das informações de luminância e cromância dos anáglifos). Sendo assim, os vetores $\mathrm{Cb}_{2} \mathrm{Cr}_{2}, \mathrm{Yd}, \mathrm{Y}_{1}$ e $\mathrm{Cb}_{1} \mathrm{Cr}_{1}$ contêm respectivamente, informações de crominância do anáglifo principal, dados da diferença de luminância, informações de luminância do anáglifo principal e por fim, informações de crominância do anáglifo principal. Uma vez adquirido as estruturas, os componentes $\mathrm{Cb}_{2} \mathrm{Cr}_{2}, \mathrm{Y}_{1}$ e $\mathrm{Cb}_{1} \mathrm{Cr}_{1}$ são divididos em macroblocos e submetidos ao processo inverso da quantização, no qual, é realizado o produto entre cada componente e a matriz de quantização. Posteriormente, com os componentes ainda divididos em macroblocos, os 
componentes passam pelo processo inverso da transformação wavelet conhecido como Inverse Discrete Wavelet Transform (IDWT). Em seguida, é realizada a recuperação do componente $\mathrm{Y}_{2}$. Os dados contidos na estrutura Diferença de Luminância (Yd) encontram-se agrupados com o número de vezes no qual o valor da diferença entre $\mathrm{Y}_{1}$ e $\mathrm{Y}_{2}$ é repetido, seguido do valor desta diferença, ou seja, os valores [3, 2, 2, 5], representam o vetor [2, 2, 2, 5, 5]. Desta maneira, a reconstrução do componente Yd é realizada repetindo-se os valores na quantidade de vezes indicadas em seu par. A recuperação do componente $\mathrm{Y}_{2}$ é realizada efetuando a diferença entre $\mathrm{Y}_{1}$ e $\mathrm{Yd}$. Nesta etapa tem-se as estrutura $\mathrm{Y}_{1}$ e $\mathrm{Y}_{2}$ com sua dimensão real enquanto as componentes $\mathrm{Cb}, \mathrm{Cr}$, Cb e Cr encontram-se quantizadas, ou seja, com metade da sua dimensão original. Todas as componentes de crominância são submetidas ao processo de recomposição de cores, de modo a voltarem ao modelo 4:4:4. Para este fim, os valores dos pixels existentes são replicados a cada linha par e ímpar do vetor. Com os valores dos vetores em seu tamanho real, as componentes passam para a reversão do espaço de cor, de $\mathrm{YCbCr}$ para $\mathrm{RGB}$, tendo como resultado os vetores $\mathrm{R}_{1} \mathrm{G}_{2} \mathrm{~B}_{1}$ e $\mathrm{R}_{2} \mathrm{G}_{1} \mathrm{~B}_{2}$ (no caso do anáglifo verde-magenta), ou seja, anáglifo principal e complementar respectivamente. Por fim, os vetores são reordenados, resultando no par estéreo, sendo a imagem do olho esquerdo $R_{1} G_{1} B_{1}$ e a imagem do olho direito $R_{2} G_{2} B_{2}$.

\subsection{Considerações finais}

Este capítulo apresentou o método HaaRGlyph como proposta de codificação de imagens estereoscópicas, no qual possibilita a recuperação do par estéreo, preservando a percepção de profundidade da imagem e alcançando uma boa taxa de compressão. A reversão anaglífica se torna possível devido a utilização das novas estruturas (Cabeçalho de Consulta de Cores e a Diferença de Luminâncias) criadas durante a codificação anaglífica. O armazenamento de ambas estruturas é realizado de modo a comprometer minimamente a compressão obtida com a utilização da codificação anaglífica. A HaaRGlyph se destaca por ser genérica, podendo ser utilizada por qualquer método de visualização estereoscópica e por obter alta taxa de compressão 

CAPÍTULO

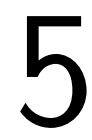

(2)

\section{ANÁLISE DA HAARGLYPH}

Este capítulo tem como objetivo demonstrar que os processos inseridos à RevGlyph (ZINGARELLI, 2013), não prejudicam a percepção de profundidade e que propiciam maiores taxas de compressão. Para isso, cada etapa do processo de codificação é analisada separadamente, possibilitando identificar a quantidade de ruído introduzida em cada parte do processo. Em seguida, utilizando a métrica PSNR (subseção 3.6.1), é apresentada uma análise comparativa entre os resultados objetivos alcançados entre HaaRGlyph e a RevGlyph prosposta por Zingarelli (2013). Por fim, a métrica DSCQS (subseção 3.6.2) é empregada para quantificar a qualidade visual da imagem e são apresentados os resultados subjetivos das imagens estereoscópicas analisadas.

\subsection{Análise da conversão e reversão do espaço de cores}

A segunda etapa no processo de codificação HaaRGlyph consiste em efetuar a conversão do espaço de cor RGB para YCbCr. Posteriormente, no processo de codificação é realizada a reversão do espaço de cor YCbCr para RGB, conforme ilustrado na Figura 42. Ambas conversões são realizadas por meio de transformações matemáticas, conforme as equações Equação 3.1 e Equação 3.2.

Figura 42 - Análise da conversão e reversão do espaço de cores

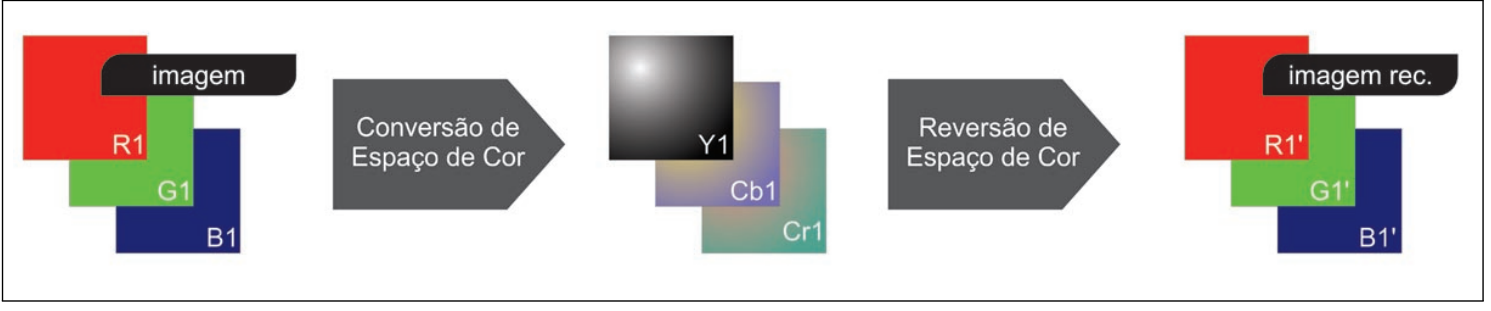

Fonte: Elaborada pelo autor. 
Apesar da conversão de espaço de cores, envolver apenas a transformações dos dados, espera-se que não haja perda de dados após as transformações $\mathrm{RGB} \Rightarrow \mathrm{YCbCr} \Rightarrow \mathrm{RGB}$, porém, as equações envolvem cálculos com valores decimais que ocasionam tais perdas. A utilização das equações sem o tratamento de arredondamento devido, pode ocasionar perda de dados, gerando ruídos na imagem resultante. $\mathrm{O}$ teste foi realizado implementando-se a conversão do espaço de cor $\mathrm{RGB} \Rightarrow \mathrm{YCbCr} \Rightarrow \mathrm{RGB}$ e posteriormente calculado o PSNR (subseção 3.6.1), entre a imagem original e a processada. $\mathrm{O}$ objetivo do teste é analisar a quantidade de ruídos adicionado a imagem após esta tranformação, com isto, é possível, mensuar isoladamente a influência da conversão de espaço de cor em comparação as outras etapas que constituem a HaaRGlyph.

A aplicação da conversão de espaços de cores não são restritas a imagens estereoscópicas, sendo qualquer imagem digital passível de tal transformação. Por este motivo, além da base de imagens estereoscópicas criada por Andrade, Cordebello e Goularte (2010), citada na subseção 3.6.3, buscou-se também uma base com imagens variadas (pessoas, paisagens, animais, comidas, etc) com diferentes resoluções, sendo escolhida a biblioteca Corel1000 ${ }^{1}$, utilizada por Wang, Li e Wiederhold (2001). A biblioteca Corel1000 é constituída por 1000 imagens no formato JPEG, as quais, antes de de serem submetidas ao processo de conversão de espaço de cor, foram convertidas para o formado BMP mantendo a resolução e a profundidade de 24 bits por pixel, ou seja, 8 bits em cada componente de cor. O resultado dos valores PSNR do teste aplicado é apresentado na tabela Tabela 2, separados por componentes e sucedido por sua média aritmética.

Tabela 2 - Análise PSNR da conversão $\mathrm{RGB} \Rightarrow \mathrm{YCbCr} \Rightarrow \mathrm{RGB}$

\begin{tabular}{l|c|c|c|c}
\hline Base Imagens & $\mathrm{Y}(\mathrm{dB})$ & $\mathrm{Cb}(\mathrm{dB})$ & $\mathrm{Cr}(\mathrm{dB})$ & Média(dB) \\
\hline Corel 1000 & 100 & 100 & 100 & 100 \\
Andrade et al. & 100 & 100 & 100 & 100 \\
Média & 100 & 100 & 100 & 100 \\
\hline
\end{tabular}

Os dados apresentados mostram que o tratamento dado na implementação da HaaRGlyph aos arredondamentos feitos na execução da conversão são satisfatórios, pois não houve a introdução de ruídos na imagem recuperada, sendo a imagem recuperada, idêntica a imagem original.

\subsection{Análise da subamostragem de crominância}

Por não afetar a qualidade visual da imagem Andrade (2012), a subamostragem de crominância escolhida para a aplicação na etapa 3 da HaaRGlyph, é o modelo 4:4:0. Conforme descrito na seção subseção 3.1.2, este modelo reduz a resolução de crominância pela metade, sendo eliminados $50 \%$ dos dados referentes ao componente $\mathrm{Cb}$ e outros $50 \%$ referentes ao componente $\mathrm{Cr}$. Com a finalidade de obter a quantidade de ruído adicionada à imagem por este 
processo, a análise foi realizada adicionando a subamostragem de crominância ao processo de conversão do espaço de cores (seção 5.1). Sendo assim, para a realização da análise, a imagem original foi convertida do espaço de cor RGB para $\mathrm{YCbCr}$, em seguida é realizada a aplicação da subamostragem 4:4:0 aos componentes com posterior recomposição 4:4:4. Por fim a reversão do espaço de cor YCbCr para RGB é realizada (Figura 43).

Figura 43 - Análise da subamostragem de crominância

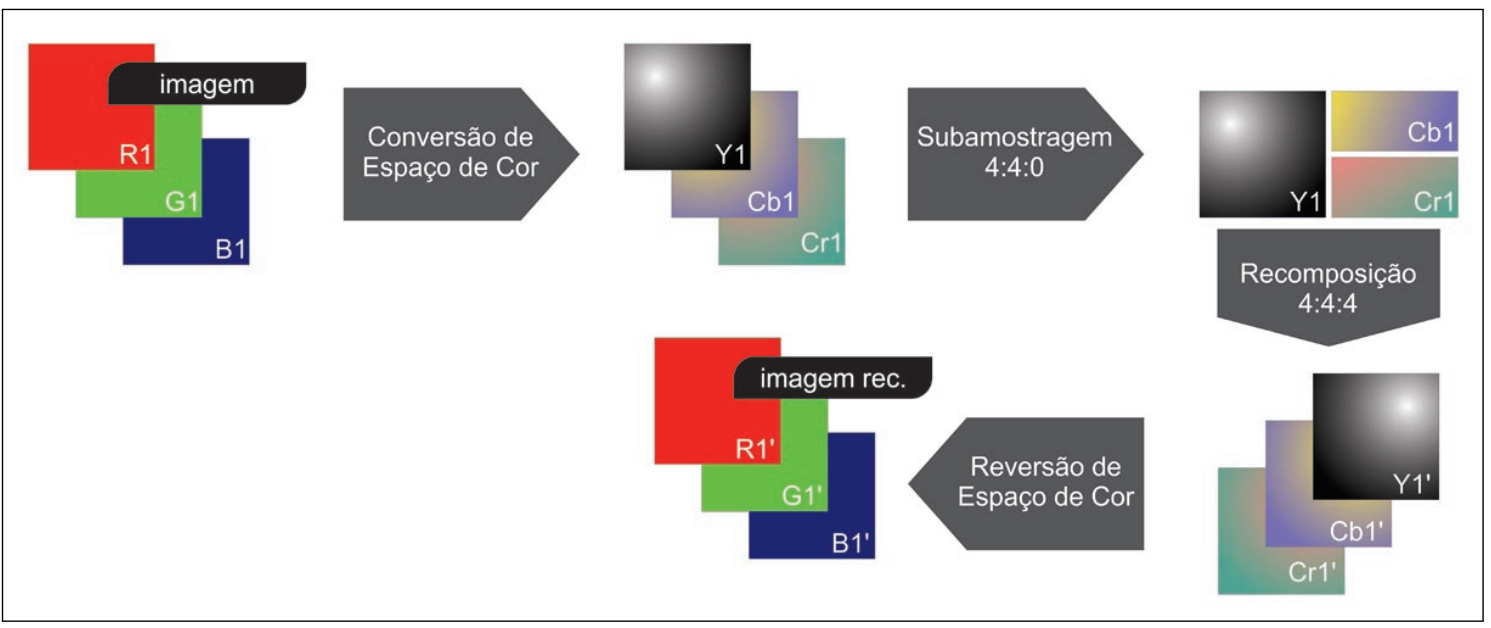

Fonte: Elaborada pelo autor.

A Tabela 3 exibe os resultados do teste, com os valores divididos por componentes sucedidos pela sua média aritmética.

Tabela 3 - Análise PSNR da conversão $\mathrm{RGB} \Rightarrow \mathrm{YCbCr} \Rightarrow \mathrm{RGB}$ juntamente com subamostragem de crominância

\begin{tabular}{l|c|c|c|c}
\hline Base Imagens & $\mathrm{Y}(\mathrm{dB})$ & $\mathrm{Cb}(\mathrm{dB})$ & $\mathrm{Cr}(\mathrm{dB})$ & Média $(\mathrm{dB})$ \\
\hline Corel 1000 & 74,99 & 66,91 & 71,74 & 70,88 \\
Andrade et al. & 52,30 & 52,25 & 54,39 & 52,98 \\
Média & 63,65 & 59,58 & 63,00 & 62,07 \\
\hline
\end{tabular}

Fonte: Dados da pesquisa.

Apesar de apenas os dados de crominância serem submetidas a redução de resolução, a tabela mostra que o PSNR do componente Y também sofreu uma queda, indicando que há a adição de ruídos neste componente. Isto se deve ao fato de que o PSNR, é calculado no espaço de cores $\mathrm{YCbCr}$, sendo assim para que o PSNR seja calculado, a imagem processada (que passou pela conversão de espaço de cores $\mathrm{RGB} \Rightarrow \mathrm{YCbCr}$, quantização e retornou ao espaço de cor $\mathrm{RGB}$ ) é novamente submetida ao processo de conversão do espaço de cores $\mathrm{RGB} \Rightarrow \mathrm{YCbCr}$. O valor de Y é calculado utilizando-se os valores R, G e B (Equação 3.1), os quais possuem ruídos gerados do processo de subamostragem, repercutindo ruídos nos valores do componente Y.

A diminuição dos dados de crominância pela metade, reduziu em média o PSNR das imagens em 37,93 dB, comprovando que a etapa de subamostragem de crominância afeta diretamente a qualidade objetiva da imagem. Entretanto, a perda visual na imagem subamostrada 
é quase imperceptível. A Figura 44 (A) e (B) ilustram a imagem da biblioteca Corel 1000 que alcançou a pior média PSNR (57,85 dB). Em (A) encontra-se a imagem original e em (B) a imagem subamostrada. Os valores PSNR de Y, Cb e Cr obtidos por esta imagem são 61,58 dB, $56,30 \mathrm{~dB}$ e 55,66 dB, respectivamente.

Figura 44 - (A) Imagem Original; (B) Imagem Subamostrada

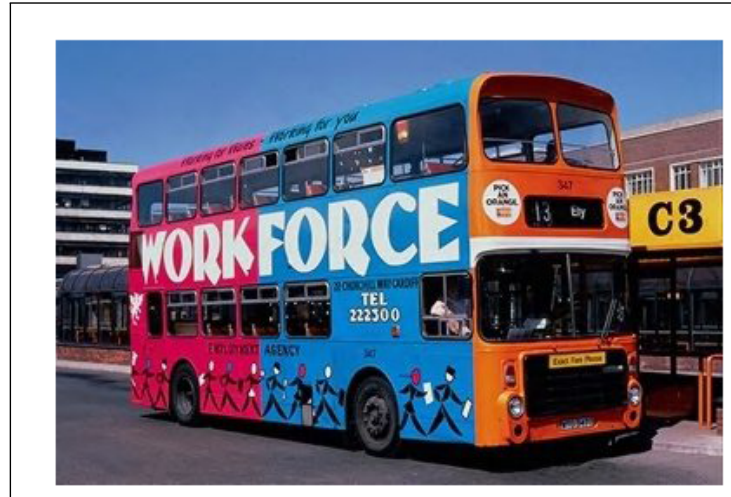

(A)

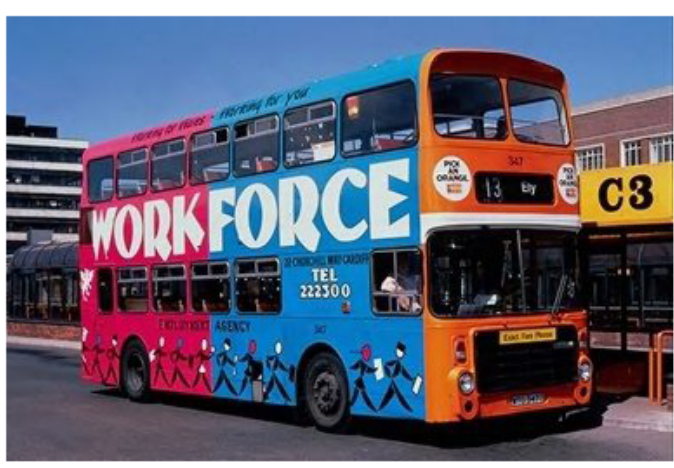

(B)

Fonte: Elaborada pelo autor.

Apesar dos baixos valores valores PSNR da imagem, a diferença entre as imagens é tênue, sendo ambas muito próximas entre si.

\subsection{Análise da DWT e quantização}

A análise da transformada wavelet com posterior quantização é ilustrada na Figura 43 e tem como objetivo determinar quais dimensões de macroblocos e a quantidade de níveis da DWT possibilitam melhores resultados de qualidade objetiva e de compressão. Nesta análise, diferente das análises anteriores, apenas as imagens estereoscópicas foram utilizadas não sendo necessária a omissão da etapa de conversão anaglífica (etapa 1 da HaaRGlyph).

Antes da submissão à DWT, cada uma das 32 imagens estereoscópicas foi dividida em três possíveis tamanhos (dimensões) de macroblocos, sendo eles, 32 × 32, 64 x 64, 128 x 128 pixels. Para cada variação de tamanho do macrobloco foram aplicados diferentes níveis da DWT, sendo: 1, 2, 3 e a quantidade máxima. A combinação entre cada tamanho de macrobloco e cada quantidade de iteração resulta em 12 possíveis testes, sendo o processo de DWT e quantização adicionadas ao processo descrito na seção 5.2. Por fim, é realizada a média entre cada componente das 32 imagens estereoscópicas.

A utilização da transformada wavelet gera valores com casas decimais, necessitando que tais valores sejam armazenados em variáveis do tipo float. Ao utilizar os valores em ponto fluante gerados pela DWT, sem arredondatmentos, o valor PSNR alcançado pelos 12 testes foi de $46,14 \mathrm{~dB}$, apresentando divergência apenas a partir da sexta casa decimal. Isso comprova que a 
Figura 45 - Análise da DWT e quantização

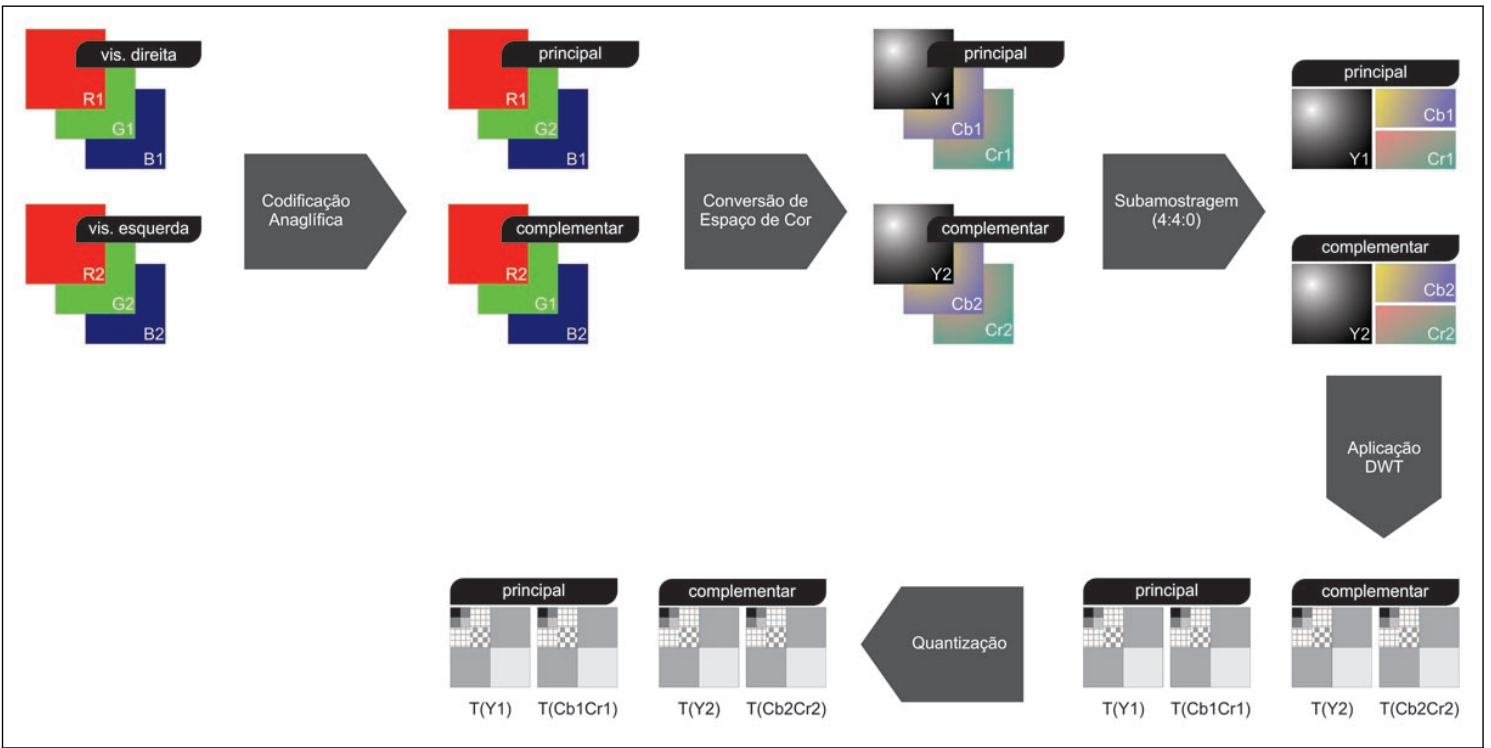

Fonte: Elaborada pelo autor.

dimensão dos macroblocos não influencia na qualidade imagem, porém, em virtude dos valores serem do tipo float (4 bytes para cada valor), a quantidade de bytes a ser armazenada aumenta significativamente. A alternativa para a compressão de tais dados é efetuar o arredondamento dos valores, armazendo inteiros em vez de valores em ponto flutuante. A Tabela 4 apresenta os resultados de PSNR dos 12 testes, com o acréscimo do arredondamento nos valores resultantes da DWT.

Tabela 4 - Análise PSNR da conversão $\mathrm{RGB} \Rightarrow \mathrm{YCbCr} \Rightarrow \mathrm{RGB}$ juntamente com subamostragem de crominância, transformada wavelet $\mathrm{e}$ quantização

\begin{tabular}{l|c|c|c}
\hline Macrobloco (pixel) & Níveis DWT & PSNR $(\mathrm{dB})$ & Compressão (\%) \\
\hline 32 × 32 & 1 & 38,09 & 86,34 \\
$32 \times 32$ & 2 & 39,25 & 86,55 \\
$32 \times 32$ & 3 & 39,28 & 86,73 \\
$32 \times 32$ & Máxima & 39,16 & 86,96 \\
\hline 64 × 64 & 1 & 38,02 & 86,63 \\
$64 \times 64$ & 2 & 39,05 & 86,73 \\
$64 \times 64$ & 3 & 39,33 & 86,88 \\
64 x 64 & Máxima & 39,31 & 87,05 \\
\hline $128 \times 128$ & 1 & 38,35 & 85,44 \\
$128 \times 128$ & 2 & 39,27 & 85,45 \\
128 × 128 & 3 & 39,56 & 85,56 \\
128 x 128 & Máxima & 39,53 & 85,57 \\
\hline
\end{tabular}

Fonte: Dados da pesquisa.

O melhor resultado em relação ao valor PSNR foi alcançado por macroblocos com dimensão 128 x 128 pixels com a aplicação de 3 níveis da DWT, o qual, obteve uma pequena vantagem de 1,54 dB em relação ao pior resultado PSNR alcançado por macroblocos de dimensão 
64 x 64 pixels e com a aplicação de apenas 1 nível de DWT. Em relação a taxa de compressão, o melhor resultado foi apresentado por macroblocos com tamanho 64 x 64 pixels e com a aplicação da quantidade máxima de níveis da DWT. Já a pior taxa de compressão é obtida na aplicação de 1 nível da DWT em macroblocos de dimensão 128 x 128 pixels, sendo 1,61\% a diferença entre a melhor e a pior taxa de compressão. Adicionalmente, os dados apresentados na Tabela 4 evidenciam que para cada dimensão de macrobloco os melhores resultados de compressão foram obtidos aplicando-se a quantidade máxima de níveis da DWT, enquanto os melhores resultados PSNR foram obtidos aplicando-se três níveis da DWT aos blocos.

Analisando o melhor resultado PSNR (39,56 dB), o processo da transformada wavelet juntamente com a quantização resulta em um acréscimo de ruído no valor de 13,42 dB em relação a etapa de subamostragem de crominância (52,98 dB). A diminuição no valor do PSNR nesta etapa já era esperado, visto que este processo visa eliminar informações a fim de se obter compressão. A Figura 46 (A) refere-se ao par estéreo original e (B) o par estéreo recuperado utilizando macroblocos com dimensão 128 x 128 pixels com a aplicação de 3 níveis da DWT.

Figura 46 - (A) Par estéreo original; (B) Par estéreo recuperado.

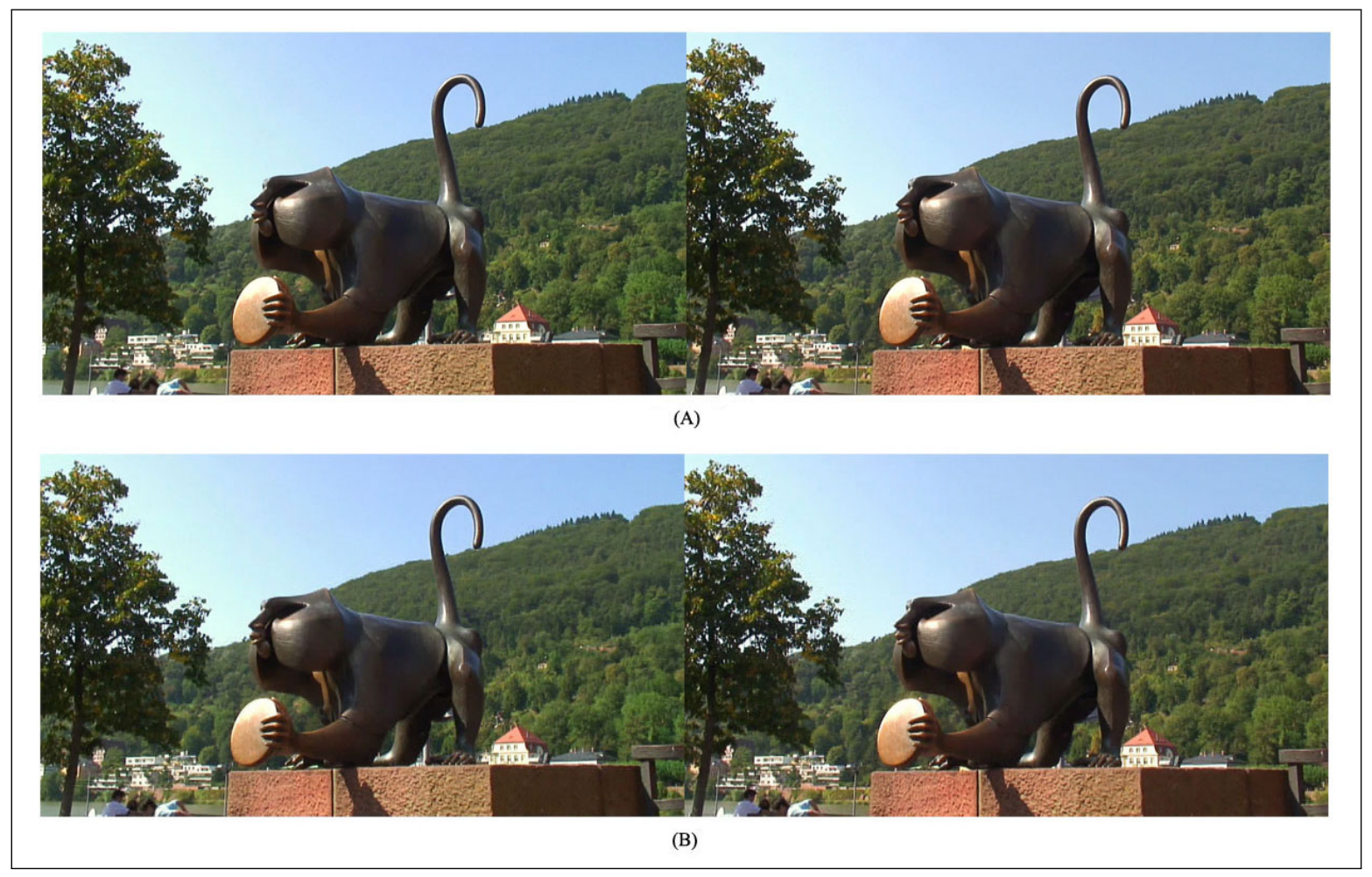

Fonte: Elaborada pelo autor.

\subsection{Análise da Diferença de Luminâncias}

Nesta seção analisa-se como a etapa denominada "Diferença de Luminância" (etapa 4, Figura 39) afeta a qualidade e a taxa de compressão do quadros de vídeo no processo de 
codificação. O objetivo dessa etapa, segundo proposto por Zingarelli (2013), é aplicar codificação diferencial, entre os valores das componentes $\mathrm{Y}$ dos anáglifos principal e complementar ( $\mathrm{Y}_{1}$ e $\mathrm{Y}_{2}$, respectivamente), como meio de obter compressão. Os conceitos envolvidos, incluindo o uso de diferentes limiares, estão detalhados na subseção 3.4.2.

Para a realização da análise, aplicou-se limiares com valores inteiros, em uma escala de 0 a 5 , sendo que, no limiar 0 , nenhuma diferença é aceitável entre o valor base e o valor consecutivo, enquanto no limiar 5, a diferença aceitável é de máximo 5 entre os valores. Experimentos realizados por Zingarelli (2013), mostram que limiares acima do valor 5, resultam em poucas mudanças na compressão e qualidade objetiva das imagens, este motivo levou a escolha dos limiares estarem entre 0 e 5.

Quando um valor da sequência ultrapassa o valor do limiar, um novo agrupamento é feito e este valor é utilizado como base de comparação para os valores posteriores. Os procedimentos adotados para a realização da análise são ilustrados na Figura 39. Para cada limiar, três dimensões de macroblocos foram utilizadas, sendo elas, 32 x 32, 64 x 64 e 128 x 128 pixels. Análises realizadas por Andrade (2012) confirmam que tais dimensões de macroblocos apresentam melhores resultados objetivos e de taxa de compressão na utilização da DWT Haar. Para cada macrobloco foram aplicados 1, 2, 3 e a quantidade máxima possível ${ }^{2}$ de níveis da DWT. As combinações entre as opções de limiar, dimensão dos macroblocos e a quantidade de iterações totalizam 72 testes possíveis. Para cada um dos testes utilizou-se 32 imagens estereoscópicas que compõem a base de dados estereoscópicas desenvolida por Andrade, Cordebello e Goularte (2010). Após a aplicação de cada teste, a média aritmética de cada componente (Y, Cb e Cr) das 32 imagens é calculada, sendo por fim realizada a média aritmética entre as três componentes. A Tabela 5 mostra em ordem decrescente os 2 melhores resultados de compressão para cada limiar, enquanto a Tabela 6 mostra em ordem decrescente os 2 melhores resultados de PSNR para cada limiar. As colunas da tabela representam respectivamente o tamanho do macrobloco utilizado, a quantidade de níveis da DWT, o limiar utilizado, o valor PSNR e a taxa de compressão.

Em termos de compressão, os macroblocos com dimensões de 64 x 64 e 32 x 32 pixels, com a aplicação máxima de níveis da DWT (6 e 5 níveis respectivamente), são os que apresentam os melhores resultados independente do limiar escolhido para o agrupamento dos valores que compõem a Diferença de Luminância. Após a aplicação da transformada, os coeficientes que carregam pouca energia(informação) são eliminados na quantização, resultando em uma melhor taxa de compressão. A cada nova iteração, a DWT concentra a maior energia em seus coeficientes de aproximação, reduzindo a energia contida nos coeficientes de detalhe. Tal fato explica o porquê a quantidade máxima de iterações obtém a melhor taxa de compressão para cada limiar. A aplicação da quantidade máxima de iterações da DWT a um determinado macrobloco, resulta em apenas um coeficiente de aproximação (com alta energia), sendo os demais coeficientes de

$\overline{2}$ O número máximo de iterações $(i)$ é dado por $2^{i}=N$, sendo $N$ a quantidade total de elementos contidos no fluxo de entrada de dados 
Tabela 5 - Melhores resultados de compressão da HaaRGlyph para os diferentes limiares

\begin{tabular}{l|c|c|c|c}
\hline Macrobloco (pixel) & Limiar & Níveis DWT & PSNR $(\mathrm{dB})$ & Compressão (\%) \\
\hline 64 x 64 & 0 & Máxima & 39,31 & 87,05 \\
32 x 32 & 0 & Máxima & 39,16 & 86,96 \\
\hline 64 x 64 & 1 & Máxima & 39,36 & 88,85 \\
32 x 32 & 1 & Máxima & 39,18 & 88,76 \\
\hline 64 x 64 & 2 & Máxima & 39,26 & 90,01 \\
32 x 32 & 2 & Máxima & 39,27 & 89,93 \\
\hline 64 x 64 & 3 & Máxima & 39,19 & 90,73 \\
32 x 32 & 3 & Máxima & 39,23 & 90,65 \\
\hline 64 x 64 & 4 & Máxima & 38,99 & 91,22 \\
32 x 32 & 4 & Máxima & 39,03 & 91,14 \\
\hline 64 x 64 & 5 & Máxima & 38,92 & 91,57 \\
32 x 32 & 5 & Máxima & 39,05 & 91,49 \\
\hline
\end{tabular}

Tabela 6 - Melhores resultados de PSNR da HaaRGlyph para os diferentes limiares

\begin{tabular}{l|c|c|c|c}
\hline Macrobloco (pixel) & Limiar & Níveis DWT & PSNR $(\mathrm{dB})$ & Compressão (\%) \\
\hline $128 \times 128$ & 0 & 3 & 39,56 & 85,56 \\
$128 \times 128$ & 0 & Máxima & 39,53 & 85,57 \\
\hline $128 \times 128$ & 1 & 3 & 39,42 & 87,36 \\
$128 \times 128$ & 1 & Máxima & 39,40 & 87,37 \\
\hline $128 \times 128$ & 2 & 3 & 39,45 & 88,52 \\
$128 \times 128$ & 2 & Máxima & 39,34 & 88,53 \\
\hline $128 \times 128$ & 3 & 3 & 39,39 & 89,24 \\
$128 \times 128$ & 3 & 2 & 39,25 & 89,12 \\
\hline $128 \times 128$ & 4 & 3 & 39,34 & 89,74 \\
$128 \times 128$ & 4 & Máxima & 39,10 & 89,74 \\
\hline $128 \times 128$ & 5 & 3 & 39,24 & 90,10 \\
$128 \times 128$ & 5 & 2 & 39,12 & 89,98 \\
\hline
\end{tabular}

Fonte: Dados da pesquisa.

detalhe (com baixa energia).

Quanto à análise da qualidade objetiva, os macroblocos com dimensões de 128 x 128 pixels são os que se destacam. Os coeficientes gerados pelos macroblocos de 128 x 128 pixels, guardam em si valores que não favorecem a sua eliminação na etapa de quantização. Por eliminar uma quantidade menor de informação, o resultado PSNR alcançado torna-se superior aos demais. Contudo, reduz a taxa de compressão.

Os melhores resultados do par estéreo recuperado levando-se em consideração a compressão são apresentados da Figura 47 à Figura 52 
Figura 47 - Par estéreo recuperado utilizando limiar 0

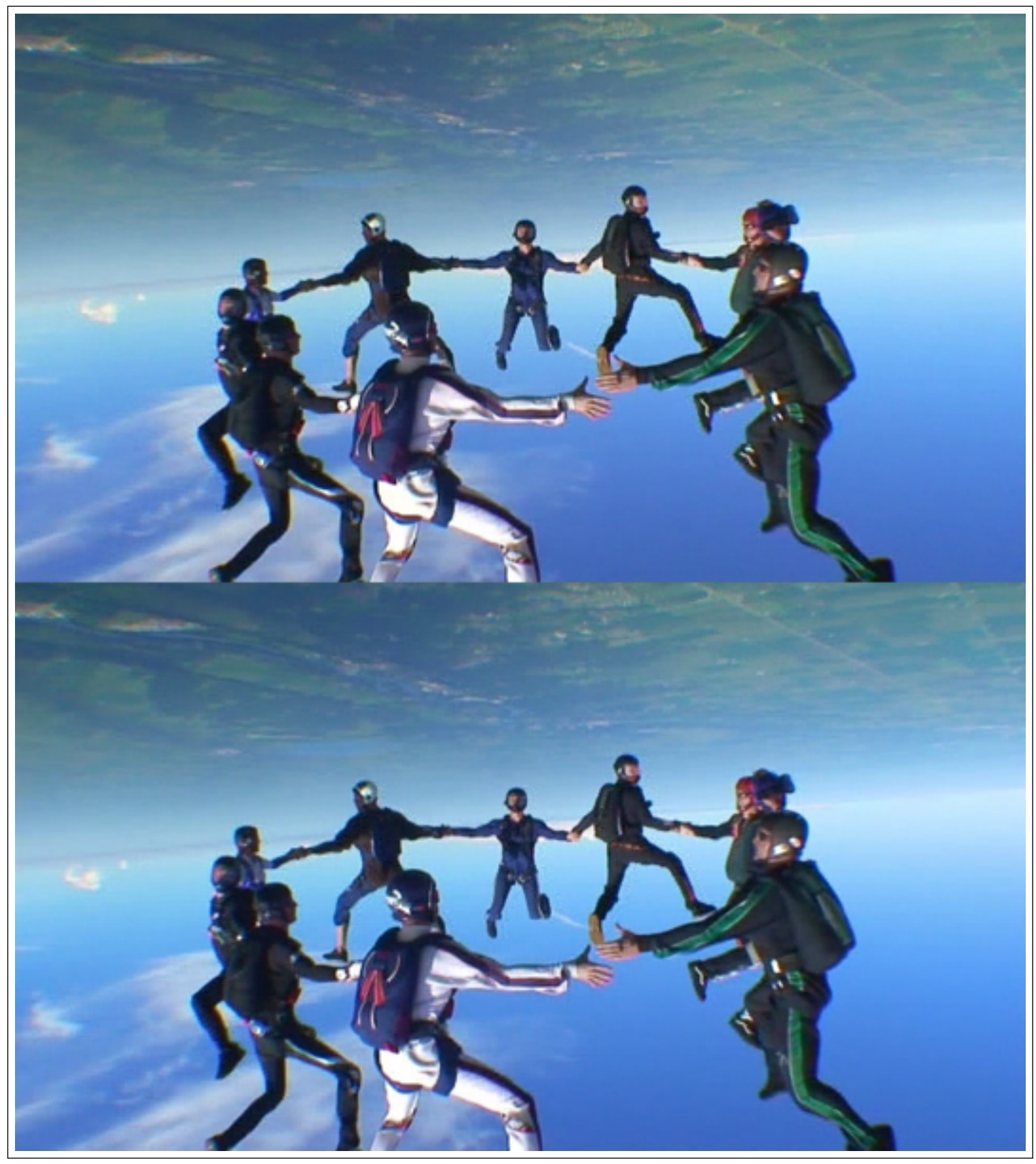

Fonte: Elaborada pelo autor. 
Figura 48 - Par estéreo recuperado utilizando limiar 1

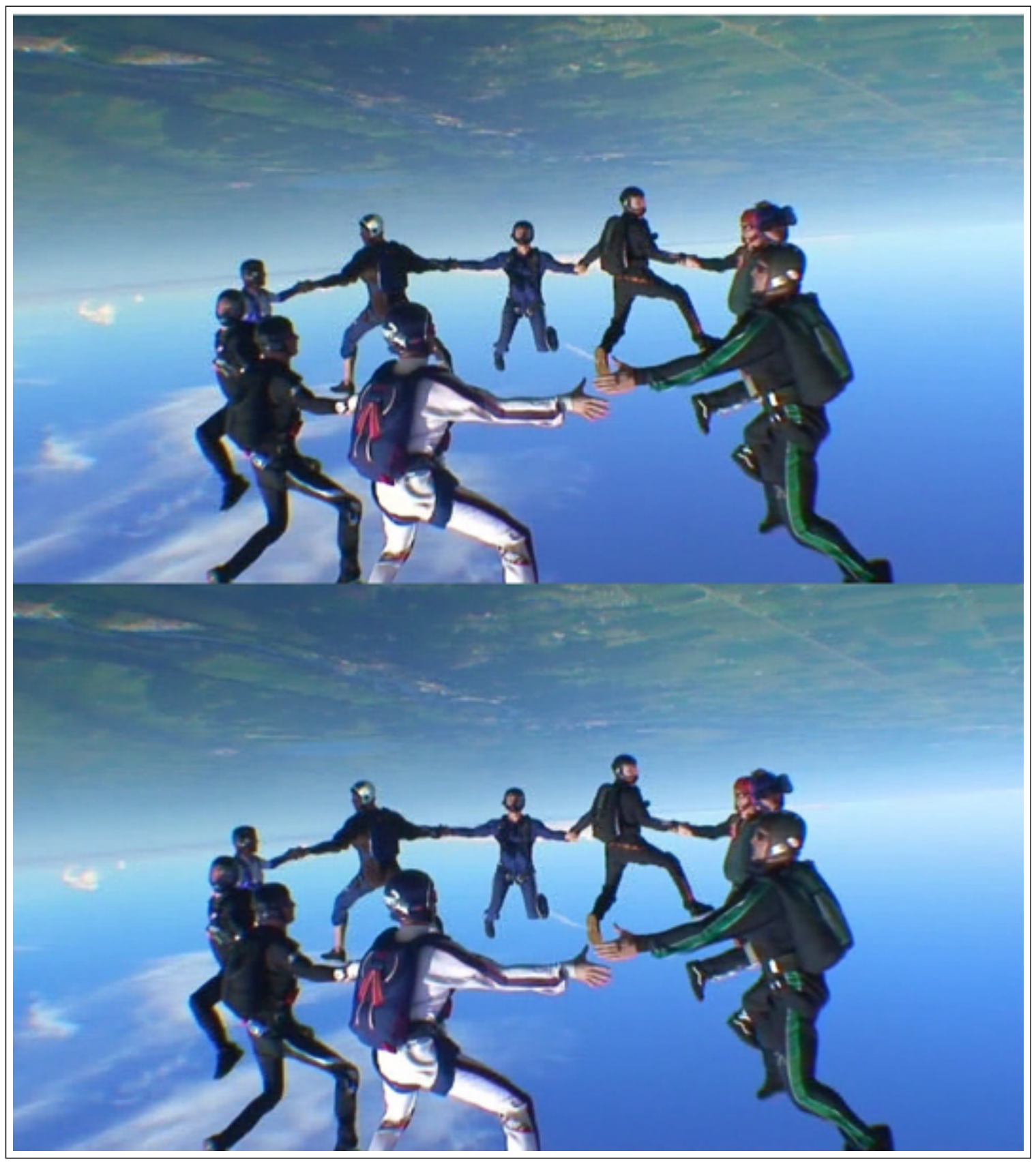

Fonte: Elaborada pelo autor. 
Figura 49 - Par estéreo recuperado utilizando limiar 2

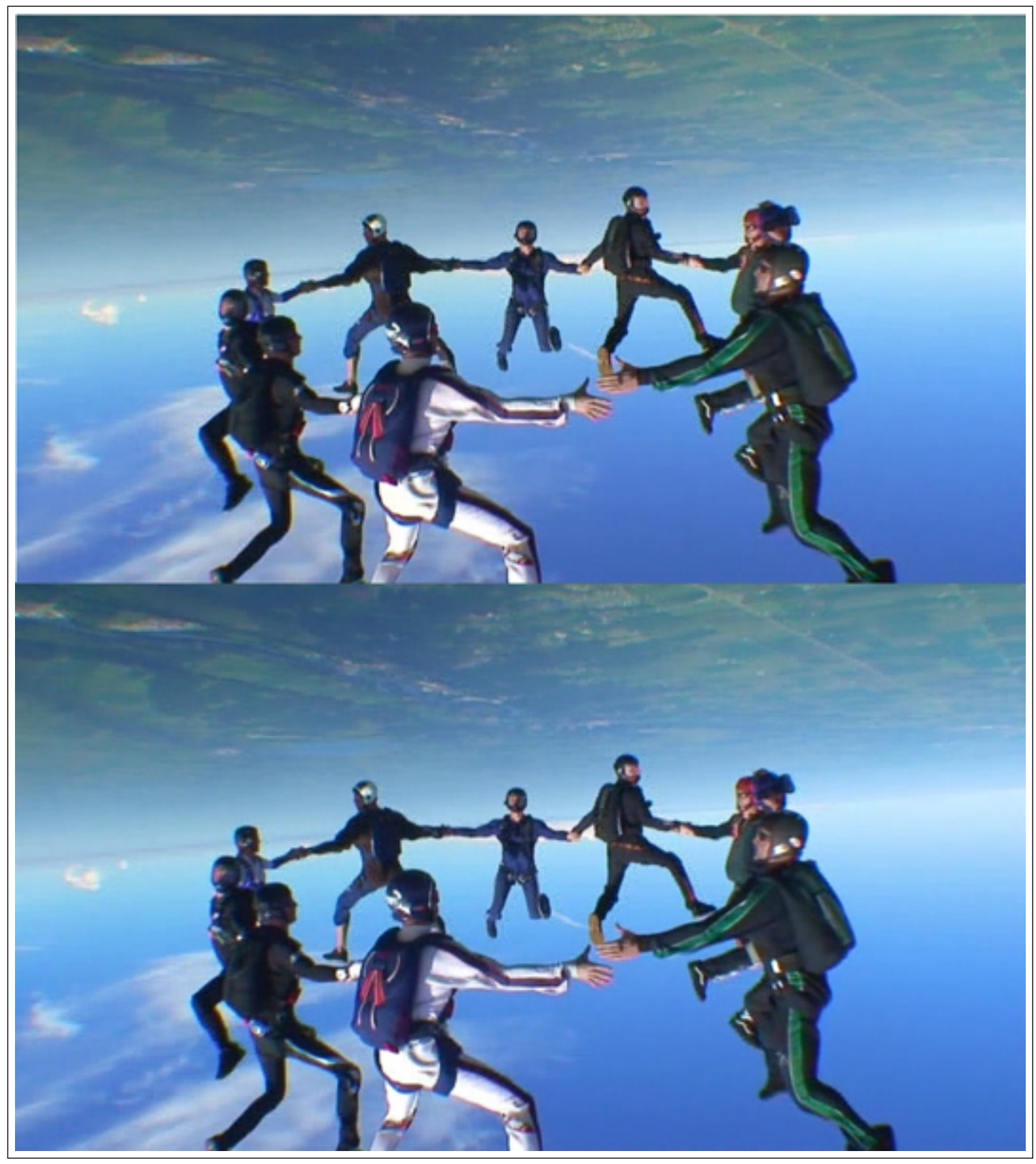

Fonte: Elaborada pelo autor. 
Figura 50 - Par estéreo recuperado utilizando limiar 3

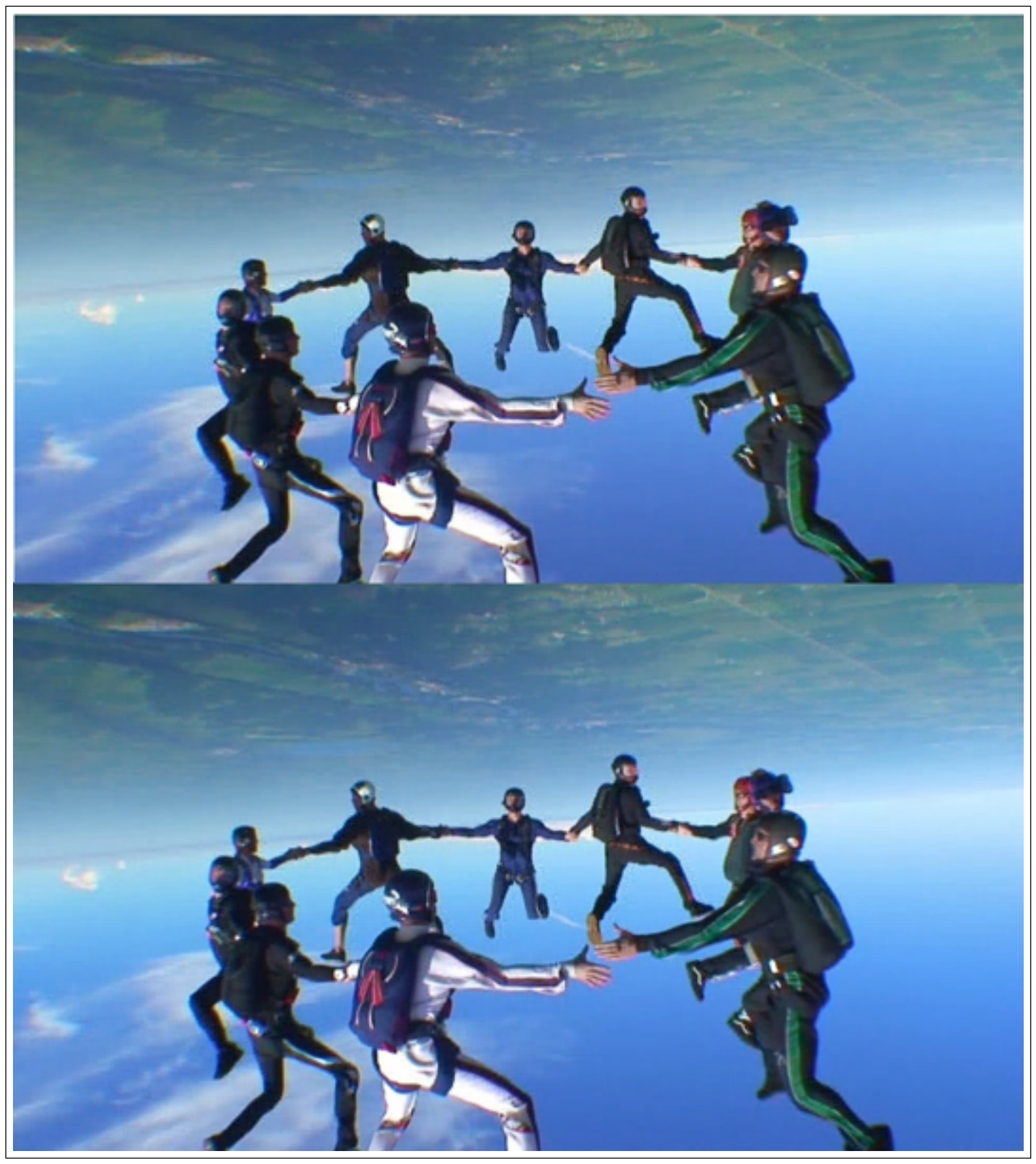

Fonte: Elaborada pelo autor. 
Figura 51 - Par estéreo recuperado utilizando limiar 4

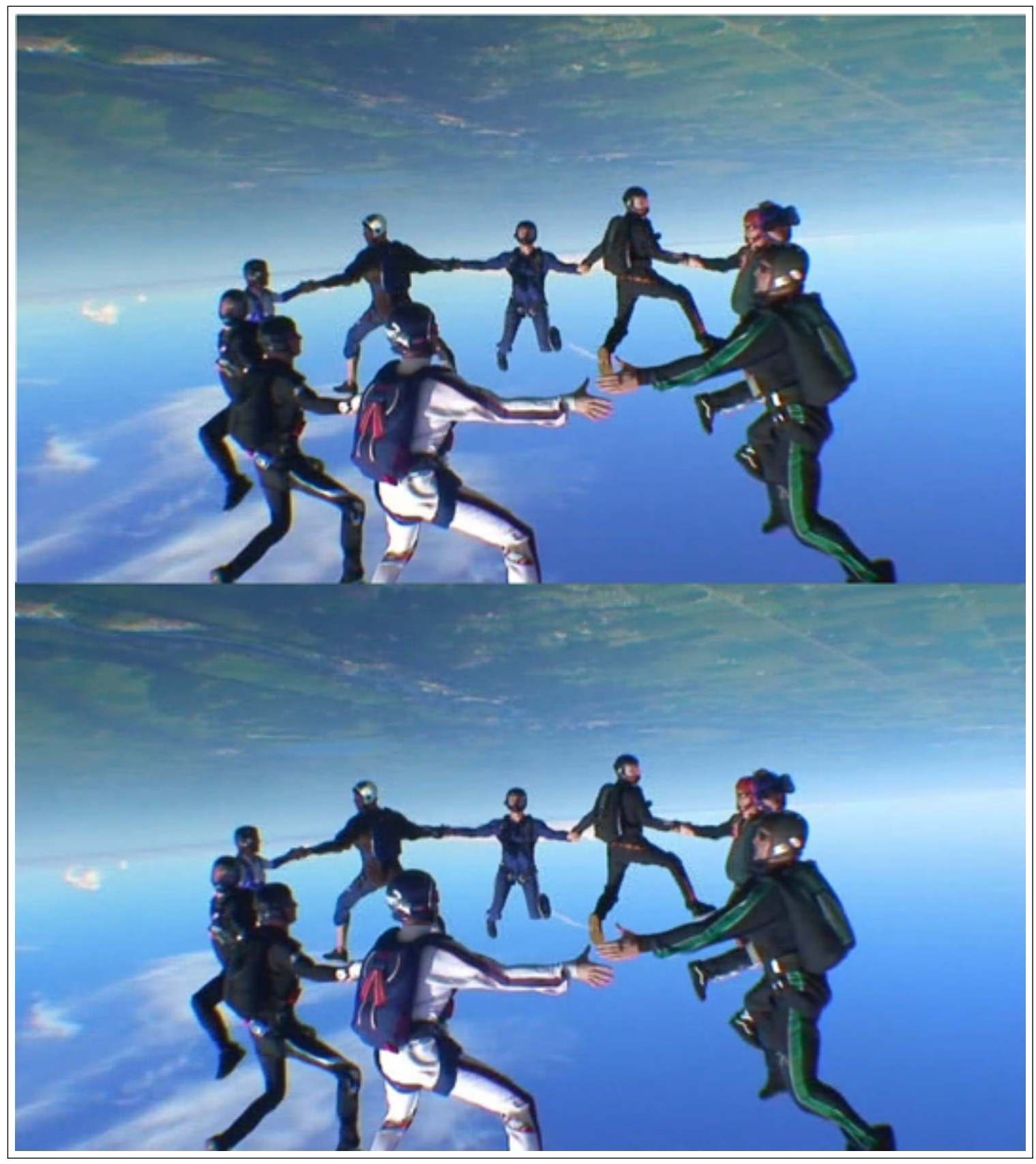

Fonte: Elaborada pelo autor. 
Figura 52 - Par estéreo recuperado utilizando limiar 5

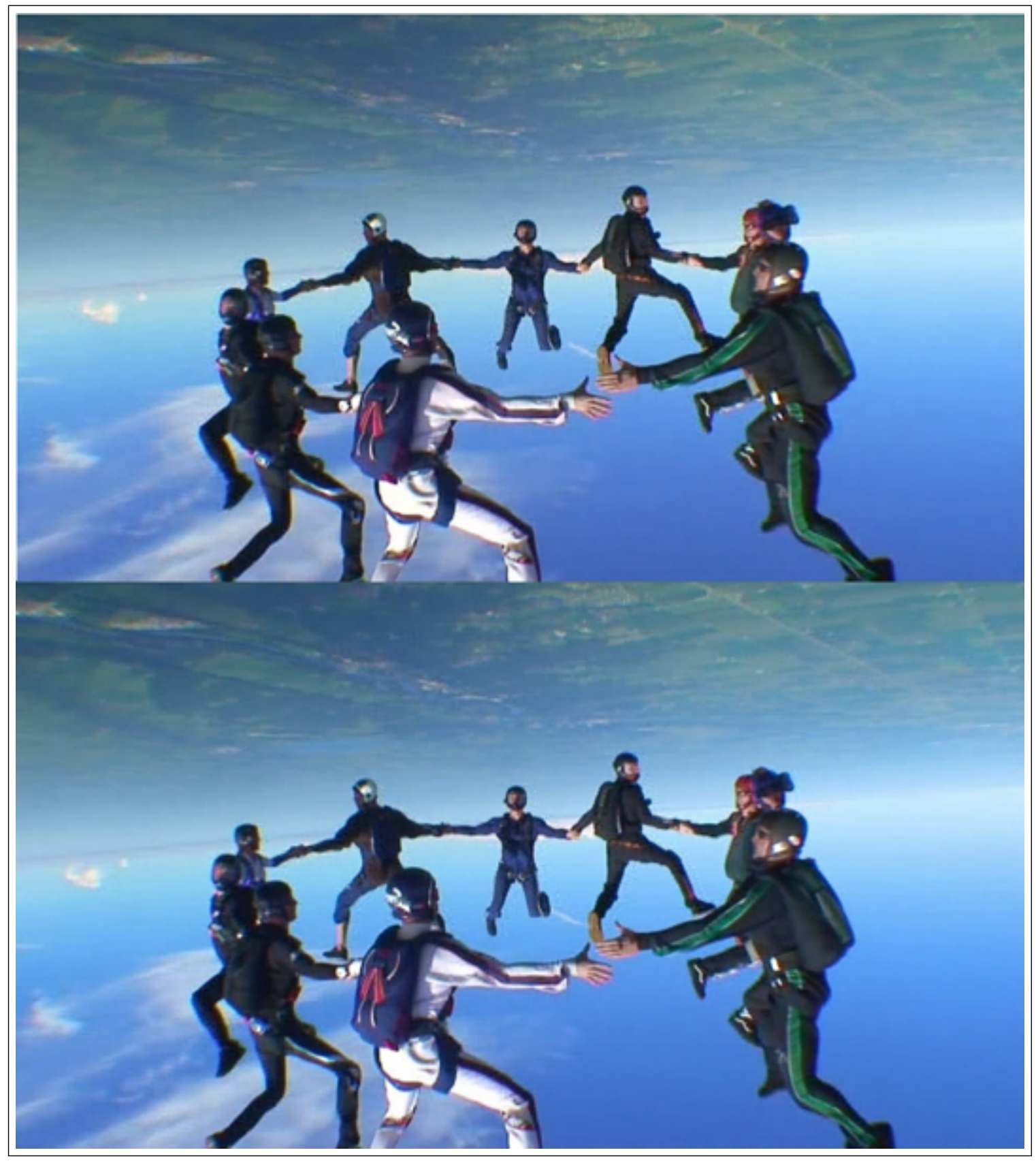

Fonte: Elaborada pelo autor.

A cada incremento no limiar, aumenta a adição de ruídos na imagem, porém, a diferença entre as imagens original e processada é desprezível. Mesmo com a ampliação em $200 \%$ de uma região do par estéreo recuperado, a perda de qualidade da imagem é quase imperceptível. Como um exemplo, para que a degradação da imagem possa ser percebida, a imagem ilustrada na Figura 53 (C) foi gerada utilizando-se limiar 30.

A diferença no valor PSNR obtida utilizando-se o limiar 0 e o limiar 5 é de $0,44 \mathrm{~dB}$, sendo tais diferenças visuais entre estes limiares impercepitíveis. Apesar da diferença de PSNR ser mínima, a taxa de compressão na utilização do limiar 5 é superior em 4,52\%, tornando o 
Figura 53 - (A) Imagem original; (B) Imagem recuperada com limiar 5; (C) Imagem recuperada com limiar 30

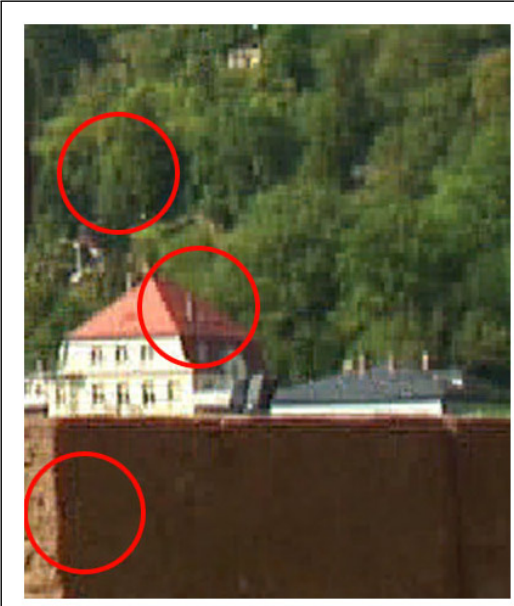

(A)

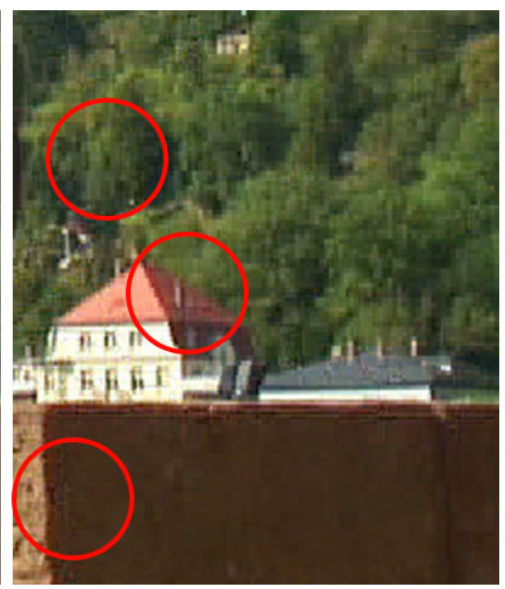

(B)

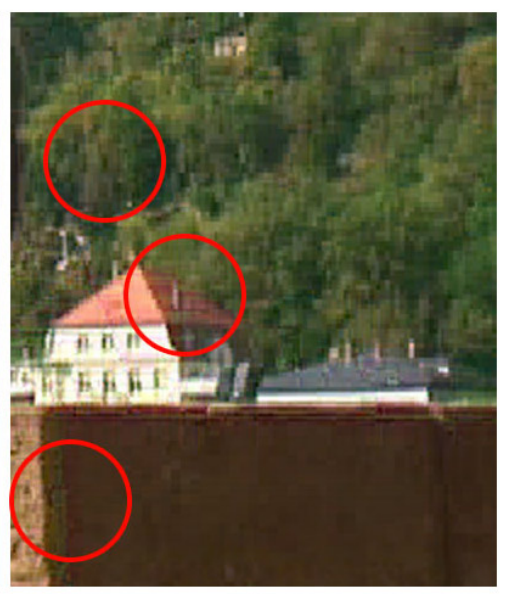

(C)

Fonte: Elaborada pelo autor.

limiar 5 a melhor opção em relação a PSNR e taxa de compressão.

Uma última análise foi realizada a fim de verificar a necessidade da utilização da etapa de codificação diferencial. Uma abordagem alternativa seria simplesmente enviar todas as componentes (incluindo $\mathrm{Y}_{2}$ ) do anáglifo complementar para a transformação DWT e posterior quantização. Exatamente como se faz com as componentes do anáglifo principal. Isso tornaria o processo mais simétrico. Como ambas abordagens diferem apenas no modo como as perdas ocorrem no componente $\mathrm{Y}_{2}$, cabe verificar qual delas oferece melhores taxa de compressão e qualidade objetiva de imagem. Assim, esta análise baseia-se em modificar o processo de armazenamento e recuperação do componente $\mathrm{Y}_{2}$. Como ilustrado na Figura 54, a codificação diferencial (etapa 4 da Figura 39) é eliminada e submete-se o componente $\mathrm{Y}_{2}$ integralmente à DWT com posterior quantização.

Figura 54 - Codificação HaaRGlyph eliminando a codificação diferencial

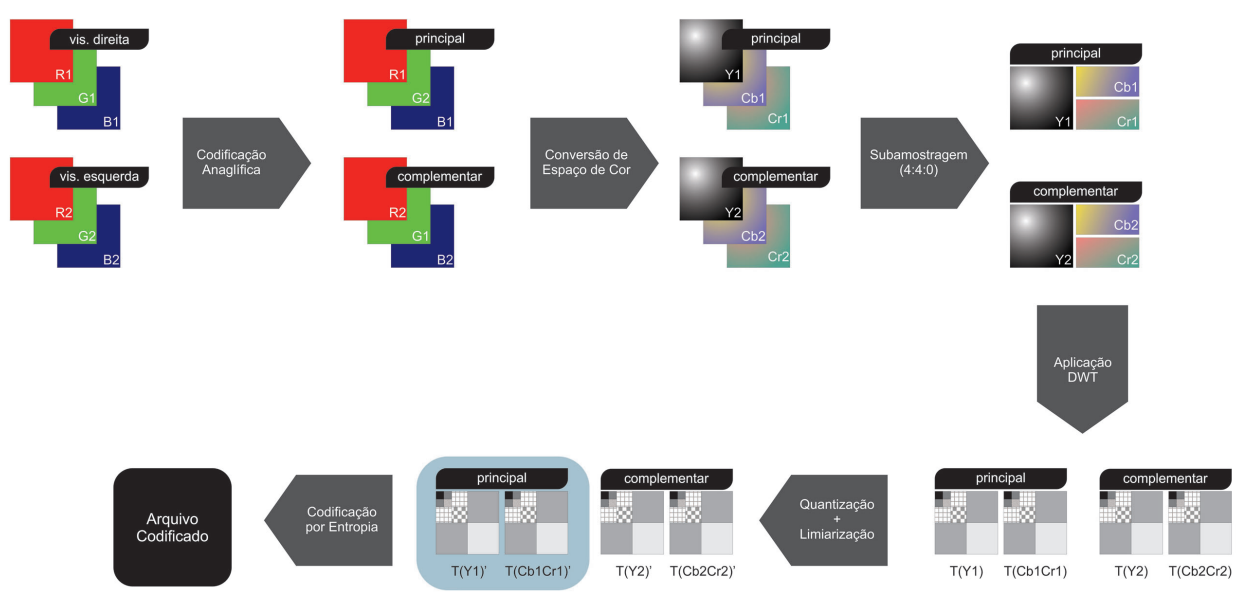

Fonte: Elaborada pelo autor. 
A análise utilizou macroblocos com dimensões de 32 × 32, 64 × 64 e 128 x 128 pixels, sendo a cada macrobloco aplicado 1, 2, 3 e o nível máximo de níveis da DWT, totalizando 12 testes. Uma bases de imagens estereoscópicas compostas por 32 imagens estereoscópicas foi utilizada na realização dos testes (ANDRADE; CORDEBELLO; GOULARTE, 2010). Após a aplicação de cada teste, a média aritmética de cada componente ( $\mathrm{Y}, \mathrm{Cb}$ e $\mathrm{Cr}$ ) das 32 imagens é calculada, sendo por fim realizada a média aritmética entre a média entre as três componentes.

Os cinco melhores resultados em ordem decrescente levando-se em consideração a taxa de compressão, são apresentados na Tabela 7, enquanto a tabela Tabela 8 apresenta os cinco melhores resultados em ordem decrescente, levando-se em consideração o valor PSNR.

Tabela 7 - Melhores resultados de compressão da HaaRGlyph utilizando o componente $\mathrm{Y}_{1}$

\begin{tabular}{l|c|c|c}
\hline Macrobloco (pixel) & Níveis DWT & PSNR (dB) & Compressão (\%) \\
\hline 64 x 64 & Máxima & 38,67 & 91,23 \\
32 x 32 & Máxima & 38,68 & 91,09 \\
64 x 64 & 3 & 38,55 & 90,96 \\
32 x 32 & 3 & 38,59 & 90,78 \\
64 x 64 & 2 & 38,76 & 90,78 \\
\hline
\end{tabular}

Fonte: Dados da pesquisa.

Tabela 8 - Melhores resultados de PSNR da HaaRGlyph utilizando o componente $\mathrm{Y}_{1}$

\begin{tabular}{l|c|c|c}
\hline Macrobloco (pixel) & Níveis DWT & PSNR (dB) & Compressão (\%) \\
\hline 128 x 128 & 3 & 38,93 & 89,16 \\
64 x 64 & 2 & 38,76 & 90,78 \\
32 x 32 & Máxima & 38,68 & 91,09 \\
64 x 64 & Máxima & 38,67 & 91,23 \\
128 x 128 & 2 & 38,67 & 89,03 \\
\hline
\end{tabular}

Fonte: Dados da pesquisa.

Os dados mostram que as diferenças entre a taxa de compressão e PSNR são muito pequenas, porém, em relação a taxa de compressão e PSNR, a melhor opção entre os resultados aprensentados é alcançado por macroblocos de dimensão 64 x 64 pixels com a aplicação da quantidade máxima de iterações da DWT. Além de ser o melhor resultado em termos de compressão, sua diferença PSNR é de apenas $0,26 \mathrm{~dB}$ em relação ao melhor resultado PSNR obtido pelas análises, obtendo um ganho de $2,07 \%$ de compressão.

A Tabela 9, apresenta o melhor resultado de taxa de compressão alcançado utilizando a componente $\mathrm{Y}_{2}$ e utilizando a estrutura Diferença de Luminância $\left(\mathrm{Y}_{\mathrm{d}}\right.$ - conforme apresentado Tabela 5).

Os resultados apresentados na Tabela 9 mostram que as diferenças são mínimas: 0,35\% de compressão e 0,25dB de PSNR em favor da Diferença de Luminância. Apesar de, neste trabalho, não ser possível afirmar que estatisticamente não há diferenças, computacionalmente elas são desprezíveis. Assim, adotando-se a abordagem alternativa tem-se os seguintes ganhos: 
Tabela 9 - Comparação da HaaRGlyph utilizando a componente $\mathrm{Y}_{2}$ e a estrutura Diferença de Luminância $\left(\mathrm{Y}_{\mathrm{d}}\right)$

\begin{tabular}{l|c|c|c|c|c}
\hline Componente & Macrobloco(pixel) & Níveis DWT & Limiar & PSNR (dB) & Compressão (\%) \\
\hline $\mathrm{Y}_{1}$ & $64 \times 64$ & Máxima & - & 38,67 & 91,23 \\
$\mathrm{Y}_{\mathrm{d}}$ & $64 \times 64$ & Máxima & 5 & 38,92 & 91,57 \\
\hline
\end{tabular}

Fonte: Dados da pesquisa.

- o processo torna-se simétrico, uma vez que a mesmo procedimento é adotado para os anáglifos principal e complementar;

- o processo torna-se mais genérico, uma vez que DWTs são mais estáveis a diferenças nos dados do que limiares - o limiar 5 pode não oferecer sempre o melhor resultado, dependendo do conjunto de dados.

\subsection{Comparação entre HaaRGlyph e RevGlyph}

$\mathrm{Na}$ análise realizada por Zingarelli (2013), a utilização da técnica RevGlyph (descrita na subseção 3.4.2) com diferentes limiares para a compressão da Diferença de Luminâncias apontam o limiar 2 como sendo o melhor compromisso entre qualidade e compressão. Para o teste utilizou-se a base de vídeos construída por Andrade, Cordebello e Goularte (2010) contendo 32 pares de vídeos estereoscópicos no formato lado-a-lado. Um quadro foi extraído de cada vídeo da base, formando-se assim a base de testes formada por 32 imagens estereoscópicas. $\mathrm{O}$ valor PSNR é composto pela média aritmética entre cada uma das componentes ( $\mathrm{Y}, \mathrm{Cb}$ e $\mathrm{Cr}$ ) da base de imagens.

A Tabela 10 mostra os resultados da HaaRGlyph ( macroblocos de dimensão $64 \mathrm{x}$ 64, aplicando-se a quantidade máxima de níveis da DWT - Tabela 5) em comparação com a RevGlyph. Ambas técnicas utilizam limiar 2 para Diferença de Luminância. A última linha mostra a diferença entre os valores da HaaRGlyph e da RevGlyph.

Tabela 10 - Comparação entre HaaRGlyph e a RevGlyph

\begin{tabular}{l|c|c}
\hline Método & PSNR(dB) & Taxa de Compressão (\%) \\
\hline HaaRGlyph & 39,26 & 90,01 \\
RevGlyph & 38,97 & 76,02 \\
Diferença & 0,29 & 13,99 \\
\hline
\end{tabular}

Fonte: Dados da pesquisa.

Como pode ser observado, a HaaRGlyph superou a RevGlyph, tanto em relação ao valor PSNR quanto em relação a taxa de compressão. Apesar da HaaRGlyph submeter as componentes (incluindo as subamostradas) à DWT e quantização, resultando na perda de dados, enquanto nenhum método de perda de dados (além da subamostragem de crominância e da codificação diferencial) ser aplicado na RevGlyph, a HaaRGlyph leva uma ínfima vantagem em termos de 
PSNR ( $0,29 \mathrm{~dB})$ em comparação a RevGlyph. A perda de dados ocasionados por este processo, explica também o porquê a HaaRGlyph alcança 13,99\% mais compressão do que o método proposto por Zingarelli (2013).

\subsection{Avaliação subjetiva}

A DWT apontada nos testes objetivos como a melhor em relação a PSNR e compressão (macroblocos com dimensões 64 x 64 pixels, com número máximo de níveis DWT possível e valor limiar 5 para o agrupamento dos valores na estrutura Diferença de Luminâncias), foi utilizada para a geração de imagens que foram submetidas a testes subjetivos com o método DSCQS (subseção 3.6.2). Como descrito na subseção 3.6.3, as 32 amostras foram exibidas a um grupo de 30 pessoas, de ambos sexos com idade variando entre 17 e 55 anos, todos sem prévia experiência com processamento de imagens e vídeos digitais, nos quais utilizaram o cardboard, citado na subseção 2.2.4, para que cada imagem do par estéreo fosse direcionado ao olho correspondente. $\mathrm{O}$ tempo médio de cada um dos testes subjetivos foi de 27 minutos.

A Tabela 11, apresenta os valores médios de MOS (subseção 3.6.2) obtidos na análise subjetiva para cada uma das 32 imagens que compõem a base. As colunas da tabela representam o nome da imagem, o valor MOS do par estéreo original, o valor MOS do par estéreo recuperado e por fim a diferença entre o MOS obtido pelo par estéreo original e par estéreo recuperado. Adicionalmente, última linha apresenta a média aritmética de cada uma das colunas.

Analisando as diferença entre valores médios MOS obtidos pelo par estéreo original e o recuperado, nota-se que a maior diferença é dada pela imagem dos05 com valor 0,69. Em contrapartida, o par estéreo recuperado da imagem trave01 obteve a média MOS superior em 0,27 em comparação ao MOS obtido pelo par estéreo original.

Após análises subjetivas com vídeos estereoscópicos realizados, Andrade (2012) informa o valor 3,5 como sendo o valor crítico de MOS apontado pelos testes. Assim, segundo Andrade (2012) os vídeos analisados que atingiram valores de MOS inferiores a este, apresentaram perda de qualidade que prejudicam a percepção da profundidade. A Figura 55 mostra a divisão dos resultados MOS obtidos pelo par estéreo original e par estéreo recuperado.

Entre as 32 imagens estereoscópicas da bases utilizada, 26 imagens originais obteram valor superior ou igual a 3,5, enquanto a mesma condição foi atingida por 22 imagens recuperadas. Entre as faixas de valor 3 e 3,5, encontram-se 5 imagens originais e 8 imagens recuperadas. Adicionalmente apenas 1 imagem original e 2 imagens recuperadas obtiveram a média MOS abaixo de 3. Vale ressaltar que nenhuma imagem original obteve média máxima MOS e que as diferenças entre as médias MOS das imagens originais e recuperadas são pequenas, não afetando significativamente a percepção de profundidade das imagens. 
Figura 55 - Resultados MOS.

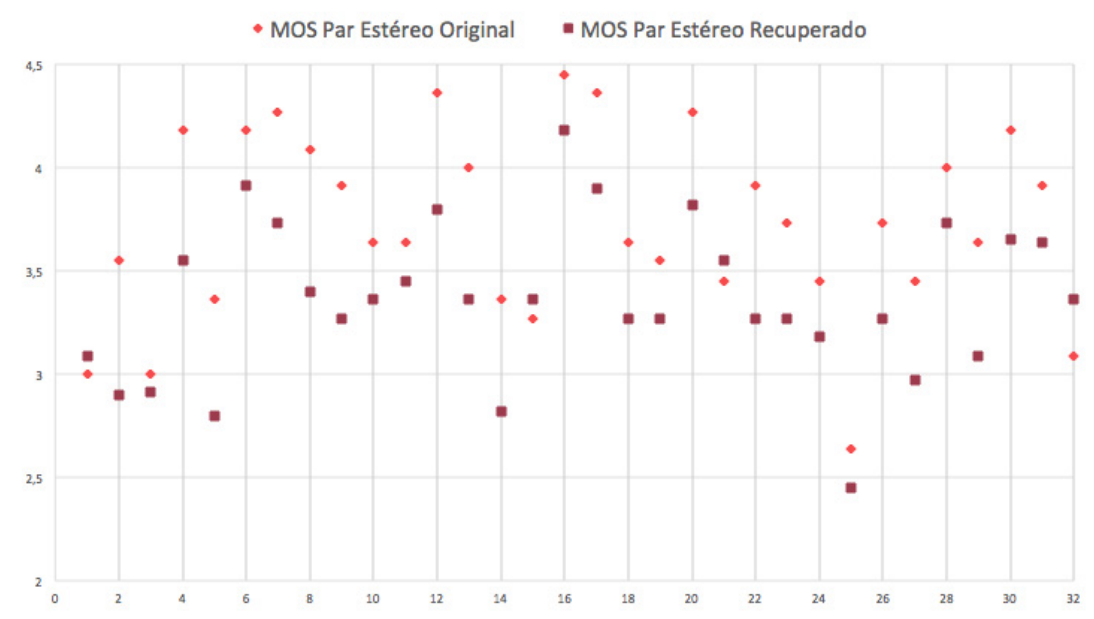

Fonte: Elaborada pelo autor.

\subsection{Considerações finais}

As análises realizadas comprovam que é possível aplicar métodos mais aprimoradas de codificação de vídeo à RevGlyph (ZINGARELLI, 2013), a fim de obter maior taxa de compressão sem que ocorram perdas que prejudiquem a correta percepção de profundidade da imagem. Este cenário constata a viabilidade da HaaRGlyph no processo de reversão anaglífica, que contribui em direção a um processo alternativo de codificação de vídeos estereoscópicos capaz de ser utilizada por qualquer método de visualização estereoscópica.

Assim, com base nos resultados discutidos neste capítulo, propõe-se que as etapas de codificação ilustradas na Figura 39 utilizem as configurações resumidas a seguir:

- Etapa 1: codificação anaglífica verde/magenta;

- Etapa 2: conversão do espaço de cor $\mathrm{RGB} \Rightarrow \mathrm{YCbCr}$;

- Etapa 3: subamostragem de crominância 4:4:0;

- Etapa 4: codificação diferencial entre $\mathrm{Y}_{1}$ e $\mathrm{Y}_{2}$ utilizando-se o limiar 5 para o agrupamento dos valores sequenciais;

- Etapa 5: aplicação da quantidade máxima de iterações DWT Haar utilizando macroblocos com dimensões 64 x 64 pixels;

- Etapa 6: quantização dos coeficientes DWT utilizando a matriz de quantização desenvolvida por Andrade (2012);

- Etapa 7: aplicação de um método de codificação sem perdas baseado no algoritmo LZ77. 
Tabela 11 - Análise MOS

\begin{tabular}{|c|c|c|c|}
\hline Imagem (.bmp) & MOS par original & MOS par recuperado & Diferença \\
\hline $\operatorname{arv01}$ & 3 & 3,09 & $-0,09$ \\
\hline corr01 & 3,8 & 3,15 & 0,65 \\
\hline cruz01 & 3 & 2,91 & 0,09 \\
\hline do01 & 4,78 & 4,15 & 0,63 \\
\hline do02 & 4,14 & 3,58 & 0,56 \\
\hline do03 & 4,18 & 3,91 & 0,27 \\
\hline do04 & 4,71 & 4,17 & 0,54 \\
\hline do05 & 4,63 & 3,94 & 0,69 \\
\hline $\mathrm{dz} 01$ & 4,36 & 3,72 & 0,64 \\
\hline $\mathrm{dz0}$ & 4,14 & 3,86 & 0,28 \\
\hline $\mathrm{dz03}$ & 3,64 & 3,45 & 0,19 \\
\hline $\mathrm{dz04}$ & 4,64 & 4,08 & 0,56 \\
\hline fw01 & 4,5 & 3,86 & 0,64 \\
\hline fw02 & 3,72 & 3,18 & 0,54 \\
\hline hei01 & 3,57 & 3,66 & $-0,09$ \\
\hline hei02 & 4,45 & 4,18 & 0,27 \\
\hline hei03 & 4,36 & 3,9 & 0,46 \\
\hline hei04 & 3,95 & 3,58 & 0,37 \\
\hline mp01 & 3,82 & 3,54 & 0,28 \\
\hline old01 & 4,27 & 3,82 & 0,45 \\
\hline old02 & 3,45 & 3,55 & $-0,1$ \\
\hline old03 & 4,41 & 3,77 & 0,64 \\
\hline old04 & 3,73 & 3,27 & 0,46 \\
\hline rv01 & 3,45 & 3,18 & 0,27 \\
\hline rv02 & 2,64 & 2,45 & 0,19 \\
\hline rv03 & 4,03 & 3,57 & 0,46 \\
\hline rv04 & 3,67 & 3,19 & 0,48 \\
\hline rv05 & 4 & 3,73 & 0,27 \\
\hline rv06 & 4,11 & 3,56 & 0,55 \\
\hline sky01 & 4,18 & 3,65 & 0,53 \\
\hline sky02 & 3,91 & 3,64 & 0,27 \\
\hline trave 01 & 3,09 & 3,36 & $-0,27$ \\
\hline Média & 3,95 & 3,58 & 0,37 \\
\hline
\end{tabular}

Fonte: Dados da pesquisa.

Vale lembrar que as etapas são interdependentes e a alteração de qualquer parâmetro influi no resultado final. Desse modo, seguindo-se as configurações propostas, garante-se atingir melhores taxas de compressão, sem perda significativa de percepção de profundidade, em relação à técnica de reversão anaglífica relacionada (subseção 3.4.2). 
Este trabalho apresentou um método de codificação para vídeos estereoscópicos. O objetivo do método é investigar se é possível reduzir uma lacuna de pesquisa identificada: não foram encontradas técnicas para codificação de vídeo 3D que forneçam altas taxas de compressão sem perda significativa de qualidade na percepção de profundidade e que, ao mesmo tempo, possibilitem que o conteúdo seja facilmente visualizado independentemente do modo de visualização escolhido.

O método proposto, denominado HaaRGlyph, utiliza conceitos de dois métodos relacionados explorando codificação anaglífica, a qual permite o armazenamento de apenas metade dos dados presentes no par estéreo. Adicionalmente, compressão com perdas baseada em Transformadas Wavelets e Quantização é aplicada de modo criterioso, atingindo boas taxas de compressão sem comprometer a percepção de profundidade.

O método de compressão foi integrado a uma técnica de reversão anaglífica. Tais técnicas possibilitam que um vídeo estereoscópico anaglífico seja decodificado de modo a obter uma aproximação do par estéreo original, sendo independentes de métodos de visualização. Como resultado, o método proposto possibilita reversão anaglífica com melhores taxas de compressão do que trabalhos relacionados.

O método HaaRGlyph foi avaliado segundo técnicas objetivas e subjetivas e comparado aos métodos relacionados. Os resultados indicam a vantagem na qualidade objetiva e na taxa de compressão da HaaRGlyph (PSNR 39,26 dB e taxa de compressão 90,01\%) em comparação ao método RevGlyph (PSNR 38,97 dB e taxa de compressão 76,02\%). A análise subjetiva do par estéreo recuperado obteve o valor 3,53 como média dos valores de MOS, enquanto o par estéreo original alçancou o valor 3,89, mostrando que a diferença entre as médias MOS obtidas são próximas $(0,37)$ e não prejudicam a qualidade visual da imagem recuperada. 


\subsection{Principais contribuições}

A principal contribuição deste trabalho é o método de codificação HaaRGlyph. A ferramenta desenvolvida como implementação do método também é uma contribuição, ao passo que possibilita que novos módulos sejam facilmente acoplados, facilitando futuras análises.

Uma terceira contribuição, é a atualização dos conhecimentos do grupo de pesquisa no tópico. Os resultados obtidos pela HaaRGlyph foram organizados em um artigo a ser submetido a um evento da área, tal como o Simpósio Brasileiro em Sistemas Multimídia e Web (WebMedia). A formação de recursos humanos qualificados, em nível de mestrado e de iniciação científica, também pode ser citada como uma das contribuições deste trabalho.

\subsection{Trabalhos futuros}

A utilização da HaaRGlyph para a compressão espacial desenvolvida neste trabalho, demonstra-se um passo significativo para a conceber um método de compressão de vídeos estereoscópicos utilizando DWT que seja genérico. Além disto, como citado na seção 6.1 a técnica é passível de alterações e propicia de forma simples a investigação de posteriores pesquisas. Entre as possíveis investigações, encontra-se a análise objetiva/subjetiva na utilização de outras famílias de wavelets, bem como outros métodos de quantização pós processamento DWT.

Para novas implementações a serem vinculadas a HaaRGlyph, sugere-se fazer o uso de técnicas para a organização e representação dos dados wavelet. Entre os algoritmos existentes para a representação das informações wavelets, pode-se citar: Embedded Zerotree Wavelet Coder (EZW) proposto por Shapiro (1993), Morphological Representation of Wavelet Data (MRWD) proposto por Servetto, Ramchandran e Orchard (1995), Set Partitioning in Hierarchical Trees (SPIHT) proposto por Said e Pearlman (1996) e Significance-Linked Connected Component Analysis (SLCCA) proposto por Bing-Bing, Vass e Zhuang (1999). Todas as técnicas citadas visam explorar propriedades estatísticas das transformadas wavets, nos quais destacam-se: a localização espaço frequência, a compactação de energia, a clusterização de coeficientes significativos em uma subbanda, a similaridade entre subbandas em diferentes escalas e o decaimento da magnitude de coeficientes wavelets entre subbandas à medida que se refina a escala de resolução. Assim, espera-se favorecer a compressão do arquivo codificado.

Outro trabalho que apresenta melhoria na técnica desenvolvida, é a possibilidade de utilizar-se a compressão temporal e/ou compressão por disparidade encontrada em codificações múltipla visões. Aconselha-se que nas futuras etapas deste desenvolvimento, sejam realizados testes subjetivos para garantir que a qualidade visual dos vídeos seja mantida. Em razão da complexidade das etapas envolvidas no processos de compressão temporal e por disparidade, este trabalho configura-se como uma possibilidade de pesquisa de um doutorado. 
A HaaRGlyph não soluciona definitivamente o problema da reversão anaglífica. Um dos principais problemas existentes, é a necessidade de se alterar o processo de conversão anaglífica, de modo a disponibilizar um cabeçalho com dados adicionais para que a reversão seja possível. Além de gerar overhead, imagens que já encontram-se no formato anaglífico não se beneficiam da reversão, pois não é possível obter as informações necessárias para a recriação do par estéreo. Para este fim, como última sugestão, pode-se investigar a reversão de um vídeo anaglífico a seu correspondente par estéreo, baseando-se apenas nas informações intracodificadas nas imagens anaglíficas. 



\section{REFERÊNCIAS}

ANDRADE, L. A.; GOULARTE, R. Uma Análise da Influência da Subamostragem de Crominância em Vídeos Estereoscópicos Anaglíficos. 2010. Disponível em: <http://www.lbd. dcc.ufmg.br/colecoes/webmedia/2010/23_webmi_c.pdf>. Acesso em: 01/03/2016. Citado 3 vezes nas páginas 25,42 e 61 .

ANDRADE, L. A.; ZINGARELLI, M. R.; SILVA, R. R.; GOULARTE, R. A new approach to spatial compression of stereoscopic videos. Multimedia Tools Appl., Kluwer Academic Publishers, Hingham, MA, USA, v. 71, n. 3, p. 1673-1697, ago. 2014. ISSN 1380-7501. Disponível em: <http://dx.doi.org/10.1007/s11042-012-1300-0>. Citado na página 72.

ANDRADE, L. A. de. Compressão espacial de vídeos estereoscópicos: uma abordagem baseada em codificação anaglífica. Tese (Doutorado) — Instituto de Ciências Matemáticas e de Computação, Universidade de São Paulo, São Carlos, 2012. Citado 16 vezes nas páginas 25, $48,50,52,55,61,62,63,64,73,74,75,82,87,98$ e 99.

ANDRADE, L. A. de; CORDEBELlo, P. D.; GOULARTE, R. Construção de uma Base de Vídeos Digitais Estereoscópicos. 2010. Disponível em: <http://www.icmc.usp.br/CMS/ Arquivos/arquivos_enviados/BIBLIOTECA_113_RT_351.pdf>. Acesso em: 01/03/2016. Citado 6 vezes nas páginas 62, 71, 82, 87, 96 e 97.

ANDRADE, L. A. de; GOULARTE, R. Anaglyphic stereoscopic perception on lossy compressed digital videos. In: Proceedings of the XV Brazilian Symposium on Multimedia and the Web. New York, NY, USA: ACM, 2009. (WebMedia '09), p. 29:1-29:8. ISBN 978-1-60558-880-3. Disponível em: <http://doi.acm.org/10.1145/1858477.1858506>. Citado na página 24.

AZEVEDO, E.; CONCI, A. Computação gráfica: teoria e prática. [S.1.]: Campus, 2003. Citado na página 42.

BARBOSA, A. Entenda os tipos de 3D. 2014. Disponível em: <http://www.3volts.gimpacto. com.br/entenda-os-tipos-de-3d/>. Acesso em: 01/03/2016. Citado 4 vezes nas páginas 33, 35, 36 e 38 .

BING-BING, C.; VASS, J.; ZHUANG, X. Significance-linked connected component analysis for wavelet image coding. IEEE Transactions on Image Processing, v. 8, n. 6, p. 774-784, Jun 1999. ISSN 1057-7149. Citado na página 102.

CANON. EOS Movie Compression Options: All-I and IPB. 2010. Disponível em: <http://www.canon.com.hk/cpx/en/technical/va_EOS_Movie_Compression_Options_All_ I_and_IPB.html>. Acesso em: 01/03/2016. Citado na página 59.

CHAPMAN, N.; CHAPMAN, J. Digital Multimedia, 3rd ed. [S.1.]: Wiley, 2004. Citado na página 58.

COSTA, P.; FERNANDES, H.; MARTINS, P.; BARROSO, J.; HADJILEONTIADIS, L. J. Obstacle detection using stereo imaging to assist the navigation of visually impaired people. 
Procedia Computer Science, v. 14, p. 83 - 93, 2012. ISSN 1877-0509. Proceedings of the 4th International Conference on Software Development for Enhancing Accessibility and Fighting Info-exclusion (DSAI 2012). Disponível em: <http://www.sciencedirect.com/science/article/pii/ S1877050912007727>. Citado na página 39.

DARIBO, I.; TILLIER, C.; PESQUET-POPESCU, B. Adaptive wavelet coding of the depth map for stereoscopic view synthesis. In: Multimedia Signal Processing, 2008 IEEE 10th Workshop on. [S.1.: s.n.], 2008. p. 413-417. Citado na página 60.

DAUBECHIES, I. Ten Lectures on Wavelets. Society for Industrial and Applied Mathematics, 1992. 357 p. Disponível em: <http://epubs.siam.org/doi/abs/10.1137/1.9781611970104>. Citado na página 48.

EBRAHIMI, F.; CHAMIK, M.; WINKLER, S. JPEG vs. JPEG 2000: an objective comparison of image encoding quality. 2004. 300-308 p. Disponível em: <http://dx.doi.org/10.1117/ 12.564835>. Citado na página 46.

FEHN, C.; BARRE, R. de la; PASTOOR, S. Interactive 3-dtv-concepts and key technologies. Proceedings of the IEEE, v. 94, n. 3, p. 524-538, March 2006. ISSN 0018-9219. Citado na página 24.

FEHN, C.; KAUFF, P.; BEECK, M. O. D.; ERNST, F.; IJSSELSTEIJN, W.; POLLEFEYS, M.; GOOL, L. V.; OFEK, E.; SEXTON, I. An evolutionary and optimised approach on 3d-tv. In: In Proceedings of International Broadcast Conference. [S.1.: s.n.], 2002. p. 357-365. Citado 2 vezes nas páginas 23 e 54 .

FEITOSA-SANTANA, C.; OIWA, N. N.; COSTA, M. F. d.; TIEDEMANN, K. B.; SILVEIRA, L. C. d. L.; VENTURA, D. F. Espaço de cores. Psicologia USP, scielo, v. 17, p. 35 - 62, 00 2006. ISSN 0103-6564. Disponível em: <http://www.scielo.br/scielo.php?script=sci_arttext\& pid=S0103-65642006000400003\&nrm=iso >. Citado na página 42.

FUGIVARA, S.; MORAES, A. de O.; ALMEIDA, J. C. J. de. Aplicação da transformada de wavelets para compressão de dados de telemetria. 2008. Citado na página 48.

GOLDSTEIN, E. B. Sensation and Perception. [S.1.]: Linda Schreiber, 2010. Citado 6 vezes nas páginas 23, 24, 27, 28, 29 e 30.

GONO, T.; SYUTO, T.; YAMAGATA, T.; FUJISAWA, N. Time-resolved scanning stereo piv measurement of three-dimensional velocity field of highly buoyant jet. Journal of Visualization, v. 15, n. 3, p. 231-240, 2012. ISSN 1875-8975. Disponível em: <http://dx.doi.org/10.1007/ s12650-012-0129-y>. Citado na página 39.

GONZALEZ, R. C.; WOODS, R. E. Digital Image Processing. 3rd ed. [S.1.]: Upper Saddle River: Prentice-Hall, 2008. Citado 4 vezes nas páginas 41, 50, 58 e 62.

GOOGLE. Google CardBoard. 2012. Disponível em: <https://www.google.com/get/cardboard/ >. Acesso em: 01/03/2016. Citado na página 37.

GåSVIK, K. J. Optical Metrology. [S.1.]: Wiley, 2002. Citado na página 34.

HALSALL, F. Multimedia Communications: Applications, Networks, Protocols And Standards. [S.1.]: Addison-Wesley, 2000. Citado 3 vezes nas páginas 42, 46 e 52. 
ITU-R. ITU-R BT.709-5: Parameter values for the HDTV standards for production and international programme exchange. [S.1.], 2002. Citado na página 43.

Methodology for the subjective assessment of the quality of television pictures. [S.1.], 2002. Citado 2 vezes nas páginas 25 e 70.

ITU-T. Recommendation J.247: Objective perceptual multimedia video quality measurement in the presence of a full reference. [S.1.], 2008. Citado na página 71.

JAYANT, N. S. Waveform Quantization and Coding. [S.1.]: IEEE Press, 1976. Citado na página 50.

KERR, D. A. Chrominance Subsampling in Digital Images. 2012. Disponível em: <http: //dougkerr.net/Pumpkin/articles/Subsampling.pdf>. Acesso em: 01/03/2016. Citado 2 vezes nas páginas 44 e 45.

LIPTON, L. Foundations of the Stereoscopic Cinema: a study in depth. New York: Van Nostrand Reinhold:, 1982. Citado 2 vezes nas páginas 27 e 39.

Stereo-vision formats for video and computer graphics. 1997. 239-244 p. Disponível em: <http://dx.doi.org/10.1117/12.274462>. Citado 2 vezes nas páginas 24 e 54.

MAITRE, M.; DO, M. N. Depth and depth-color coding using shape-adaptive wavelets. J. Vis. Comun. Image Represent., Academic Press, Inc., Orlando, FL, USA, v. 21, n. 5-6, p. 513-522, jul. 2010. ISSN 1047-3203. Disponível em: <http://dx.doi.org/10.1016/j.jvcir.2010.03.005>. Citado na página 60.

MANDAL, M. K. Multimedia Signals and Systems. [S.1.]: Kluwer Academic Publishers, 2003. ISBN 1-4020-7270-8. Citado na página 63.

MENDIBURU, B. 3D Movie Making: Stereoscopic Digital Cinema from Script to Screen. [S.1.]: Focal Press, 2009. Citado 3 vezes nas páginas 24, 33 e 35.

MULLER, K.; MERKLE, P.; WIEGAND, T. 3-d video representation using depth maps. Proceedings of the IEEE, v. 99, n. 4, p. 643-656, April 2011. ISSN 0018-9219. Citado 2 vezes nas páginas 24 e 56.

NAYAN, M. Y.; EDIRISINGHE, E. A.; BEZ, H. E. Baseline jpeg-like dwt codec for disparity compensated residual coding of stereo images. In: Proceedings of the 20th UK Conference on Eurographics. Washington, DC, USA: IEEE Computer Society, 2002. (EGUK '02), p. 67. ISBN 0-7695-1518-5. Disponível em: <http://dl.acm.org/citation.cfm?id=787261.787766>. Citado 5 vezes nas páginas 51, 52, 62, 63 e 75 .

NGUYEN, T. N.; MICHAELIS, B.; AL-HAMADI, A.; TORNOW, M.; MEINECKE, M. M. Stereo-camera-based urban environment perception using occupancy grid and object tracking. IEEE Transactions on Intelligent Transportation Systems, v. 13, n. 1, p. 154-165, March 2012. ISSN 1524-9050. Citado na página 39.

NIMBLEVR. Nimble VR. 2012. Citado na página 36.

OLSSON, P.; NYSJÖ, F.; HIRSCH, J.-M.; CARLBOM, I. B. A haptics-assisted craniomaxillofacial surgery planning system for restoring skeletal anatomy in complex trauma cases. International Journal of Computer Assisted Radiology and Surgery, v. 8, n. 6, p. 887-894, 2013. ISSN 1861-6429. Disponível em: <http://dx.doi.org/10.1007/s11548-013-0827-5>. Citado na página 39. 
REDERT, A.; BEECK, M. O. de; FEHN, C.; IJSSELSTEIJN, W.; POLLEFEYS, M.; GOOL, L. V.; OFEK, E.; SEXTON, I.; SURMAN, P. Advanced three-dimensional television system technologies. In: 3D Data Processing Visualization and Transmission, 2002. Proceedings. First International Symposium on. [S.1.: s.n.], 2002. p. 313-319. Citado na página 56.

RIBEIRO, N.; TORRES, J. Tecnologias de Compressão Multimédia. $3^{\text {a }}$ Edição. [S.1.]: FCA, 2007. Citado na página 53.

RICHARDSON, I. E. H.264 and MPEG-4 Video Compression: Video Coding for Nextgeneration Multimedia. Londres: Wiley, 2003. ISBN 0-470-84837-5. Citado 3 vezes nas páginas 42, 43 e 46.

SAID, A.; PEARLMAN, W. A. A new, fast, and efficient image codec based on set partitioning in hierarchical trees. IEEE Transactions on Circuits and Systems for Video Technology, v. 6, n. 3, p. 243-250, Jun 1996. ISSN 1051-8215. Citado na página 102.

SALOMON, D. A Concise Introduction to Data Compression. pub-SV:adr: pub-SV, 2008. xiii +310 p. ISBN 1-84800-071-5. Citado na página 44 .

SEALES, W. B.; YUAN, C. J.; BROWN, M. Efficient content extraction in compressed images. In: Content-Based Access of Image and Video Libraries, 1997. Proceedings. IEEE Workshop on. [S.1.: s.n.], 1997. p. 52-58. Citado na página 50.

SERVETTO, S. D.; RAMCHANDRAN, K.; ORCHARD, M. T. Wavelet based image coding via morphological prediction of significance. In: Image Processing, 1995. Proceedings., International Conference on. [S.l.: s.n.], 1995. v. 1, p. 530-533 vol.1. Citado na página 102.

SHAPIRO, J. M. Embedded image coding using zerotrees of wavelet coefficients. IEEE Transactions on Signal Processing, v. 41, n. 12, p. 3445-3462, Dec 1993. ISSN 1053-587X. Citado 2 vezes nas páginas 48 e 102 .

SIEGEL, M.; GUNATILAKE, P.; SETHURAMAN, S.; JORDAN, A. G. Compression of stereo image pairs and streams. 1994. 258-268 p. Disponível em: <http://dx.doi.org/10.1117/12. 173899>. Citado na página 24.

SINGH, S. K.; CHAUHAN, D. S.; VATSA, M.; SINGH, R. A Robust Skin Color Based Face Detection Algorithm. 2012. Disponível em: <http://www2.tku.edu.tw/ tkjse/6-4/6-4-6.pdf>. Acesso em: 01/03/2016. Citado na página 43.

SISCOUTTO, R. A.; SZENBERG, F.; TORI, R.; RAPOSO, A. B.; CELES, W.; GATTASS, M. Realidade virtual conceitos e tendências. Mania Livro, p. 179 - 201, 2004. ISSN 2316333X. Disponível em: <http://webserver2.tecgraf.puc-rio.br/ abraposo/pubs/livro_pre_svr2004/ CAP11_stereo.pdf>. Citado 3 vezes nas páginas 28, 29 e 32.

SMOLIC, A.; MUELlER, K.; MERKLE, P.; KAUFF, P.; WIEGAND, T. An overview of available and emerging $3 \mathrm{~d}$ video formats and depth enhanced stereo as efficient generic solution. In: Picture Coding Symposium, 2009. PCS 2009. [S.1.: s.n.], 2009. p. 1-4. Citado 3 vezes nas páginas 24,54 e 57.

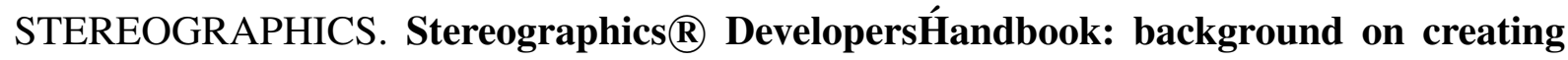

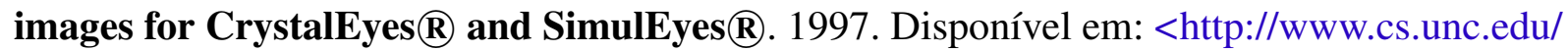
$\sim$ stc/FAQs/Stereo/stereo-handbook.pdf>. Acesso em: 01/03/2016. Citado 4 vezes nas páginas $24,28,30$ e 31. 
STRATER, L.; KENNEDY, R. A.; SCERBO, M. W.; PAPELIS, Y.; CROLL, M.; GARCIA, H.; GRIFFITH, T.; FLYNN, J. R.; PROAPS, A. B.; SHAH, S. J.; PROCCI, K.; BOWERS, C. Me and my ve, part 3. Proceedings of the Human Factors and Ergonomics Society Annual Meeting, v. 58, n. 1, p. 2397-2401, 2014. Disponível em: <http://pro.sagepub.com/content/58/1/ 2397.abstract>. Citado na página 39.

SUPPIA, A. d. O. Monstro brasileiro revive em 3D. CiÃe Cultura, scielocec, v. 59, p. 57 - 59, 06 2007. ISSN 0009-6725. Disponível em: <http://cienciaecultura.bvs.br/scielo.php?script=sci_ arttext\&pid=S0009-67252007000200024\&nrm=iso $>$. Citado na página 24.

SYMES, P. Digital Video Compression. [S.1.]: McGraw-Hill, 2003. ISBN 978-0071424875. Citado na página 46.

TAM, W. J.; ZHANG, L. 3d-tv content generation: 2d-to-3d conversion. In: Multimedia and Expo, 2006 IEEE International Conference on. [S.1.: s.n.], 2006. p. 1869-1872. Citado na página 23.

TAMBOLI, S.; UDUPI, V. Image compression using haar wavelet transform. International Journal of Advanced Research in Computer and Communication Engineering, v. 2, 2013. Citado na página 50.

THANAPIROM, S.; FERNANDO, W. A. C.; EDIRISINGHE, E. A. Zerotree-based stereoscopic video codec. Optical Engineering, v. 44, n. 7, p. 077004-077004-10, 2005. Disponível em: <http://dx.doi.org/10.1117/1.1951768>. Citado 2 vezes nas páginas 51 e 63.

TOMKOWIAK, M. T.; LYSEL, M. S. V.; SPEIDEL, M. A. Monoplane stereoscopic imaging method for inverse geometry x-ray fluoroscopy. 2013. 86692W-86692W-10 p. Disponível em: <http://dx.doi.org/10.1117/12.2006238>. Citado na página 39.

VETRO, A.; WIEGAND, T.; SULLIVAN, G. J. Overview of the stereo and multiview video coding extensions of the h.264/mpeg-4 avc standard. Proceedings of the IEEE, v. 99, n. 4, p. 626-642, April 2011. ISSN 0018-9219. Citado 3 vezes nas páginas 54, 59 e 60.

VILLASENOR, J.; BELZER, B.; LIAO, J. Wavelet filter evaluation for image compression. IEEE Transactions on Image Processing, v. 4, n. 8, p. 1053-1060, Aug 1995. ISSN 1057-7149. Citado na página 47.

WANDELL, B. A. Foundations of Vision. [S.1.]: Sinauer Associates, 1995. ISBN 9780878938537. Citado na página 71.

WANG, J.; LI, J.; WIEDERHOLD, G. Simplicity: semantics-sensitive integrated matching for picture libraries. IEEE Transactions on Pattern Analysis and Machine Intelligence, v. 23, n. 9, p. 947-963, Sep 2001. ISSN 0162-8828. Citado na página 82.

WANG, Z.; BOVIK, A. C.; SHEIKH, H. R.; SIMONCELLI, E. P. Image quality assessment: from error visibility to structural similarity. IEEE Transactions on Image Processing, v. 13, n. 4, p. 600-612, April 2004. ISSN 1057-7149. Citado na página 70.

WOODS, A. J.; YUEN, K. L.; KARVINEN, K. S. Characterizing crosstalk in anaglyphic stereoscopic images on lcd monitors and plasma displays. Journal of the Society for Information Display, Blackwell Publishing Ltd, v. 15, n. 11, p. 889-898, 2007. ISSN 1938-3657. Disponível em: <http://dx.doi.org/10.1889/1.2812989>. Citado na página 42. 
ZHAN-WEI, L.; PING, A.; SU-XING, L.; ZHAO-YANG, Z. Arbitrary view generation based on dibr. In: Intelligent Signal Processing and Communication Systems, 2007. ISPACS 2007. International Symposium on. [S.1.: s.n.], 2007. p. 168-171. Citado na página 56.

ZINGARELLI, M. R. U. RevGlyph - codificação e reversão estereoscópica anaglífica. Dissertação (Mestrado) - Instituto de Ciências Matemáticas e de Computação, Universidade de São Paulo, São Carlos, 2013. Citado 14 vezes nas páginas 25, 33, 64, 65, 66, 67, 68, 73, 74, 81, 87, 97, 98 e 99.

ZIV, J.; LEMPEL, A. A universal algorithm for sequential data compression. IEEE Transactions on Information Theory, v. 23, n. 3, p. 337-343, May 1977. ISSN 0018-9448. Citado na página 75 . 